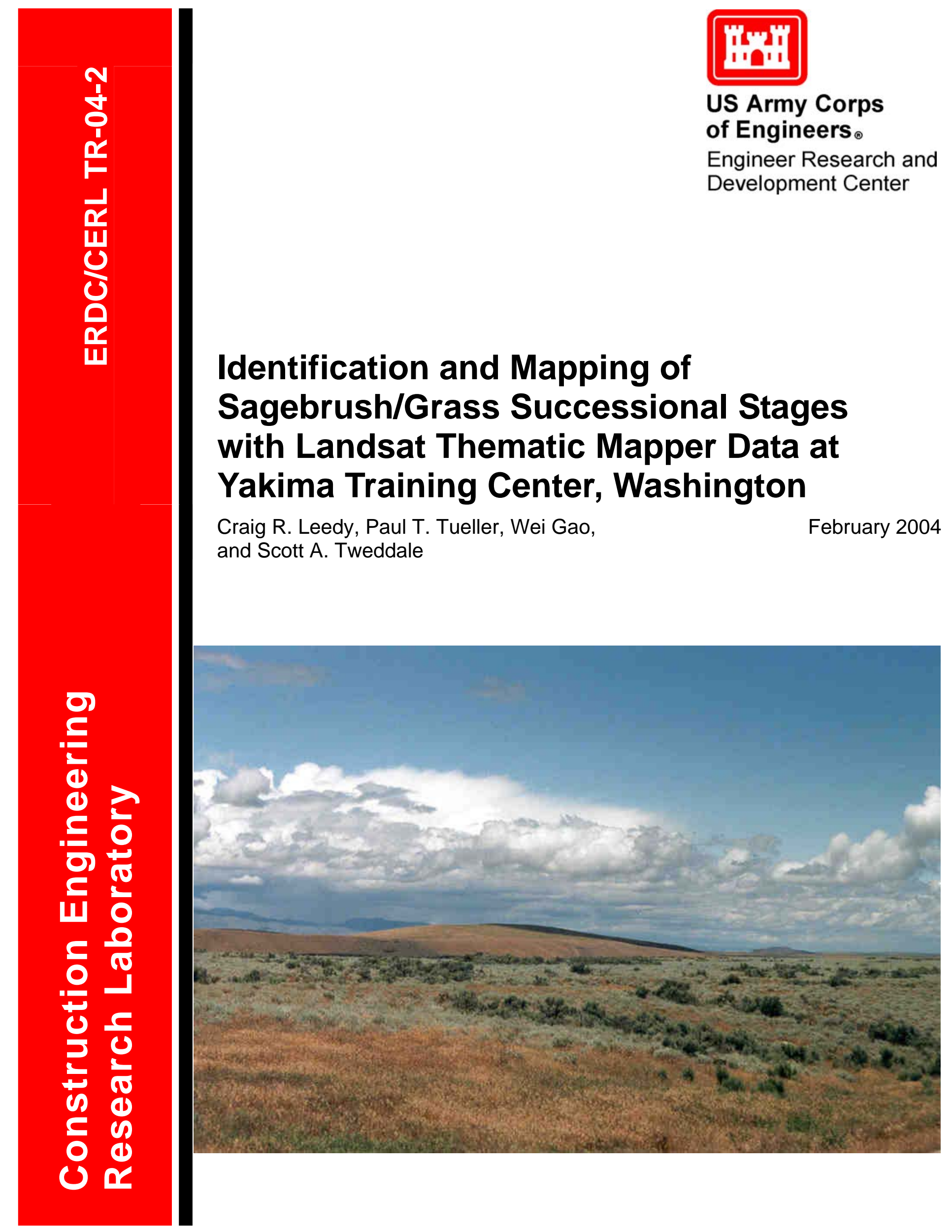





\section{Identification and Mapping of Sagebrush/Grass Successional Stages with Landsat Thematic Mapper Data at Yakima Training Center, Washington}

Craig R. Leedy, Paul T. Tueller, and Wei Gao

Department of Environmental and Resource Sciences

University of Nevada-Reno

1000 Valley Road

Reno, Nevada, 89512-0013

Scott A. Tweddale

Construction Engineering Research Laboratory

PO Box 9005

Champaign, IL 61826-9005

Final Report

Approved for public release; distribution is unlimited.

Prepared for

U.S. Army Corps of Engineers

Washington, DC 20310-0600

Under

EN-TS5 
ABSTRACT: In the future, remote sensing technologies will become an increasingly important and valuable tool for military land managers in semiarid regions. These technologies, when combined with field samples, have the potential to accurately monitor rangeland trends from year to year with smaller monetary investments compared to field sampling exclusively. This research attempted to identify and map successional changes on semiarid rangelands at Yakima Training Center, WA, using remote sensing techniques by developing a model derived from analysis of dependent and independent variables chosen from field surveys of vegetation and geomorphic data, along with the interpretation of Landsat TM data.

Preliminary results based on small data sets separated by elevation and slope direction showed both low and some reasonable $\mathrm{R}^{2}$ values, including some $\mathrm{R}^{2}$ near 0.70 . The removal of elevation and slope direction and consideration of multicollinearity and outliers and influentials provided generally significant relationships among dependent and independent variables. Significant relationships between multiple dependent and independent variables were also identified using canonical correlation analysis. Variability among the releves, collection of field vegetation and soil data over the entire summer including many phenophases, and the correction of the raster radiance values for topography were assumed to be factors that may have reduced the predictive capabilities of the techniques investigated.

DISCLAIMER: The contents of this report are not to be used for advertising, publication, or promotional purposes.

Citation of trade names does not constitute an official endorsement or approval of the use of such commercial products.

All product names and trademarks cited are the property of their respective owners. The findings of this report are not to be construed as an official Department of the Army position unless so designated by other authorized documents.

DESTROY THIS REPORT WHEN IT IS NO LONGER NEEDED. DO NOT RETURN IT TO THE ORIGINATOR. 


\section{Contents}

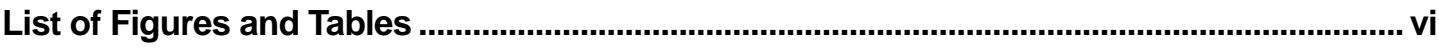

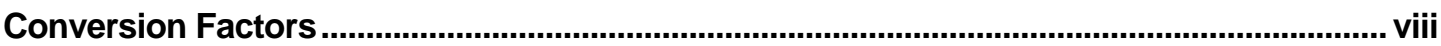

Preface

1 Introduction

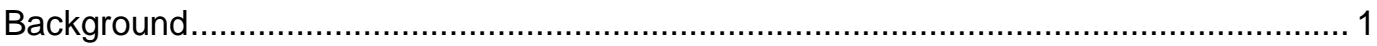

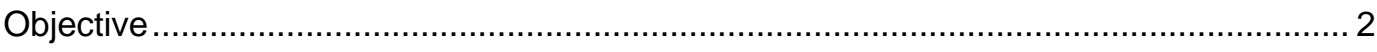

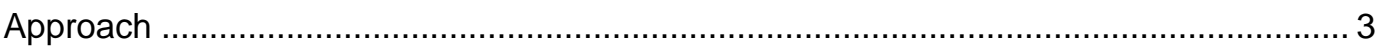

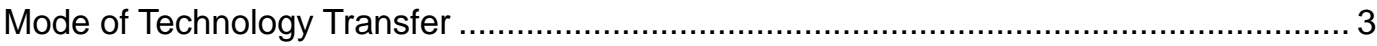

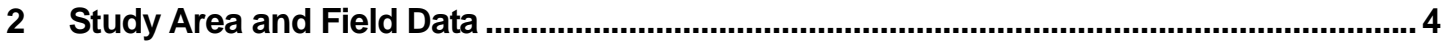

Study Area

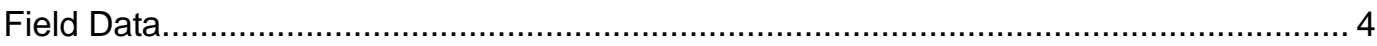

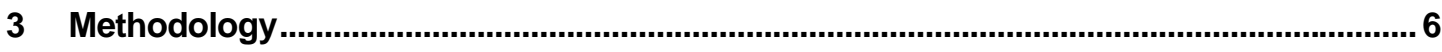

Definition of Seral Arrays on Sagebrush/grass Rangelands .......................................... 6

Quantification of Vegetation and Soil Parameters with Thematic Mapper Data................. 8

Landsat Thematic Mapper for Identification of Seral Stages of

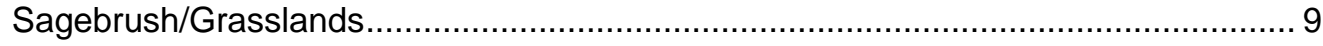

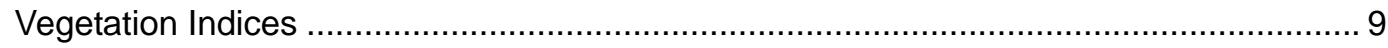

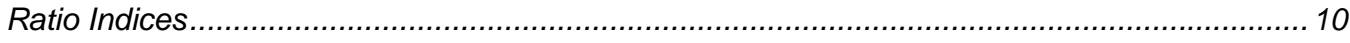

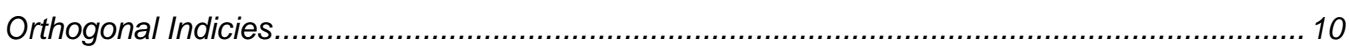

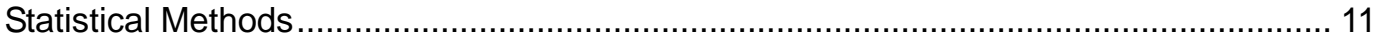

Outliers and Model Specification .......................................................................... 12

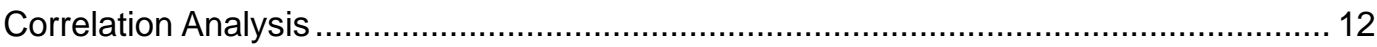

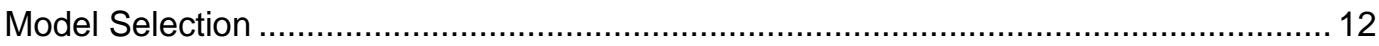

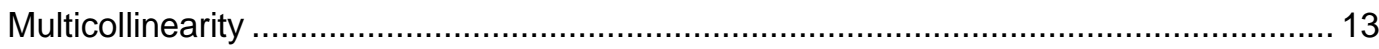

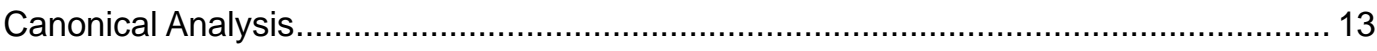

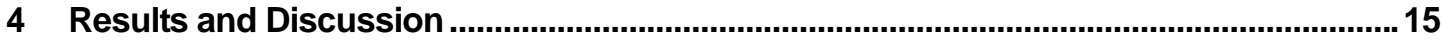

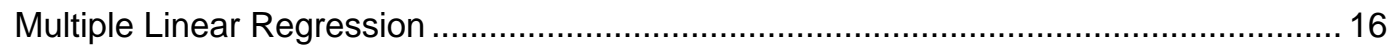

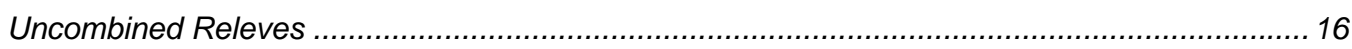

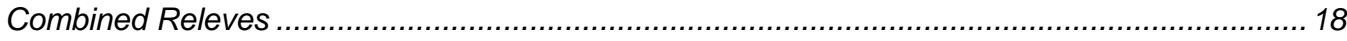

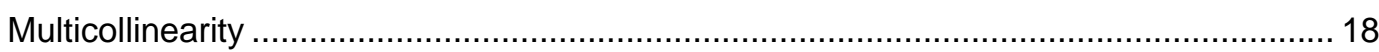

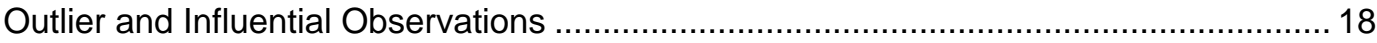




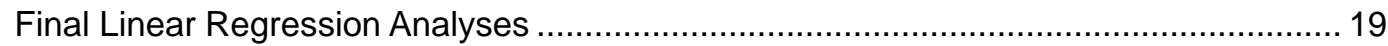

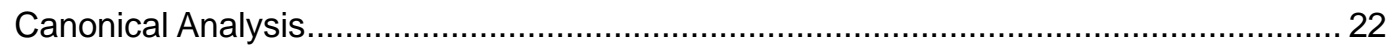

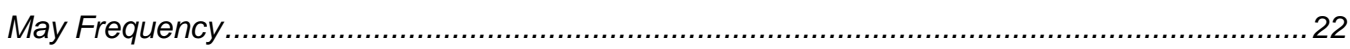

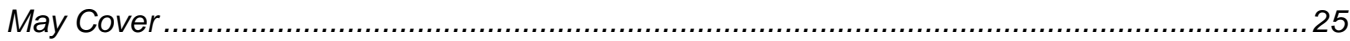

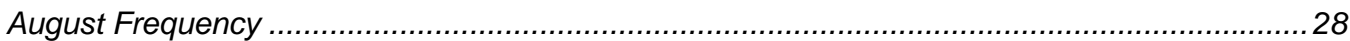

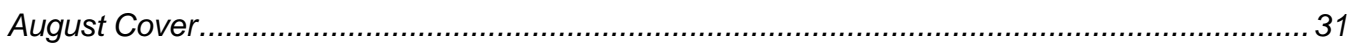

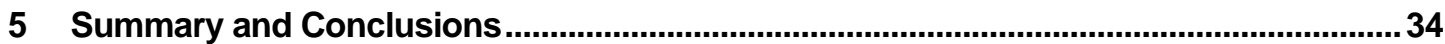

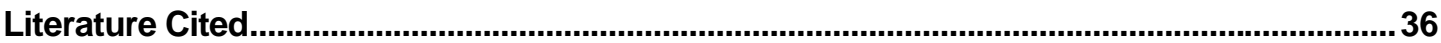

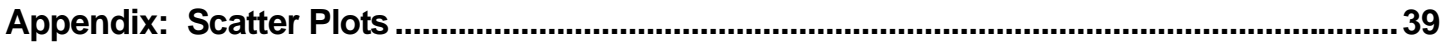

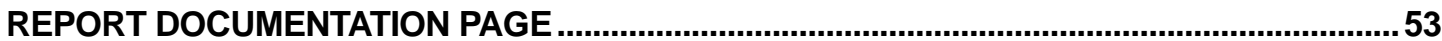




\section{List of Figures and Tables}

\section{Figures}

1. The relationships of percent cover AGSP, ARTR, BRTE, and POSA when AGSP

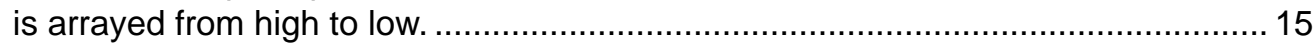

2. A scatter plot showing the actual and predicted ARTR cover for the 37 releves........ 17

3. A scatter plot showing the actual and predicted ORGMATT cover for the 37 releves.

4. A scatter plot showing all 91 releves of the actual verses predicted ARTR values from the August frequency data matrix.

5. A scatter plot of 91 releves showing the actual verses predicted ORGMATT values form the August frequency data matrix.

6. The position of releves according to ORGMATT content in the surface soil for field 1 vs index 1.

7. The position of releves according to the cover of AGSP for field 2 vs. index $2 \ldots \ldots \ldots . . .28$

8. Releves according to ORGMATT in the surface soil for field 1 vs. index 1 ................ 31

9. Releve position according to its amount of ORGMATT for field 1 vs. index 1 ............ 33

\section{Tables}

1 How the key plant species help predict seral stages............................................. 7

2 Mathematical abbreviations and definitions of ratio based indicies. .......................... 10

3 An example of the original data analysis for 37 releves using the north slope

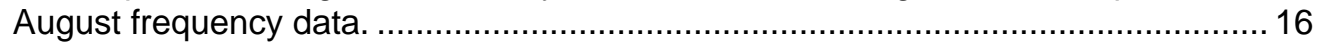

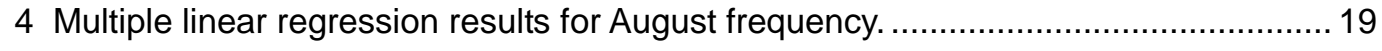

5 Multiple linear regression results for August cover. ................................................ 20

6 Multiple linear regression results for May frequency. ................................................ 20

7 Multiple linear regression results for May cover. ....................................................... 21

8 Results of canonical analysis showing the significance of the first three pair of the canonical variates for May frequency.......................................................... 23

9 The canonical coefficients of the first, second, and third pair of linear composites of the dependent and independent variables for May frequency. ........................... 24

10 Results of canonical analysis showing the significance of the first and second pair of the canonical variates for May cover.

11 The canonical coefficients of the first and second pair of linear composites of the dependent and independent variables for May cover. 
12 Results of canonical analysis showing the significance of the first pair of the canonical variates for August frequency.

13 The canonical coefficients of the first and second pair of linear composites of the dependent and independent variables for August frequency.

14 Results of canonical analysis showing the significance of the first pair of the canonical variates for August cover.

15 The canonical coefficients of the first and second pair of linear composites of the dependent and independent variables for August cover...... 


\section{Conversion Factors}

Non-SI* units of measurement used in this report can be converted to SI units as follows:

\begin{tabular}{|c|c|c|}
\hline Multiply & By & To Obtain \\
\hline acres & $4,046.873$ & square meters \\
\hline cubic feet & 0.02831685 & cubic meters \\
\hline cubic inches & 0.00001638706 & cubic meters \\
\hline degrees (angle) & 0.01745329 & radians \\
\hline degrees Fahrenheit & $(5 / 9) \times\left({ }^{\circ} \mathrm{F}-32\right)$ & degrees Celsius \\
\hline degrees Fahrenheit & $(5 / 9) \times\left({ }^{\circ} \mathrm{F}-32\right)+273.15$ & kelvins \\
\hline feet & 0.3048 & meters \\
\hline gallons (U.S. liquid) & 0.003785412 & cubic meters \\
\hline horsepower (550 ft-lb force per second) & 745.6999 & watts \\
\hline inches & 0.0254 & meters \\
\hline kips per square foot & 47.88026 & kilopascals \\
\hline kips per square inch & 6.894757 & megapascals \\
\hline miles (U.S. statute) & 1.609347 & kilometers \\
\hline pounds (force) & 4.448222 & newtons \\
\hline pounds (force) per square inch & 0.006894757 & megapascals \\
\hline pounds (mass) & 0.4535924 & kilograms \\
\hline square feet & 0.09290304 & square meters \\
\hline square miles & $2,589,998$ & square meters \\
\hline tons (force) & $8,896.443$ & newtons \\
\hline tons ( 2,000 pounds, mass) & 907.1847 & kilograms \\
\hline yards & 0.9144 & meters \\
\hline
\end{tabular}

\footnotetext{
*Système International d'Unités (“International System of Measurement”), commonly known as the "metric system."
} 


\section{Preface}

This study was conducted for the Directorate of Environmental Programs under project 4A1620A896," Environmental Quality Technology; Work Unit EN-TS5, "Comparative Data Acquisition Alternatives for Training Area Management." The technical monitor was Dr. Victor E. Diersing, DAIM-ED-N.

The work was performed by the Department of Environmental and Resource Sciences, University of Nevada-Reno and the Ecological Processes Branch (CN$\mathrm{N})$ of the Installations Division $(\mathrm{CN})$, Construction Engineering Research Laboratory (CERL). The CERL Principal Investigator was Scott A. Tweddale. From the Department of Environmental and Resource Sciences, University of NevadaReno, Craig R. Leedy is a graduate research assistant, Dr. Paul T. Tueller is a Professor of Range Ecology, and Wei Gao is a graduate research assistant. The Yakima Training Center Environmental and Natural Resources Directorate provided data. The technical editor was Gloria J. Wienke, Information Technology Laboratory. Steve Hodapp is Chief, CEERD-CN-N, and Dr. John T. Bandy is Chief, CEERD-CN. The associated Technical Director was Dr. William D. Severinghaus, CEERD-CV-T. The Director of CERL is Dr. Alan W. Moore.

CERL is an element of the U.S. Army Engineer Research and Development Center (ERDC), U.S. Army Corps of Engineers. The Commander and Executive Director of ERDC is COL James R. Rowan and the Director of ERDC is Dr. James R. Houston. 


\section{Introduction}

\section{Background}

Land managers at U.S. Army training and testing installations require accurate and timely resource characterization and assessment of training and testing land condition to make informed land management decisions. Because of the significant costs required to properly collect necessary data, land managers are often forced to base decisions on less than adequate information that might not accurately represent current trends in the installation land condition. Therefore, remote sensing technologies, when combined with traditional field surveys, provide a valuable source of information to installation land managers.

Remotely sensed imagery provides synoptic views of the landscape at potentially high temporal frequency, and therefore provides an ideal supplement to field surveys when attempting to characterize and monitor changes in land condition at different scales and levels of detail. Erosion status and species composition have been identified as two of the most critical metrics to assess current land condition. Therefore, erosional and depositional models, and plant community dynamic simulation models are currently under development to evaluate and predict erosion and secondary succession.

Succession is defined as a cumulative change in the species composition of vegetation at one location over the course of 1 to 500 years (Barbour et al. 1987). The ability to identify successional stages is valuable because it can help land managers identify and map range condition classes and thus describe range trend. Range trend can be defined as the direction of successional change toward which a plant community assumes/exhibits as it reacts to climatic changes and/or human uses. Range trend is important to a manager because it provides evidence that a site is moving toward or away from any desired range condition.

Range condition is defined by Heady and Child (1994) as an inseparable complex of location, present vegetation, and potential vegetation. Presently, range condition is determined by abiotic factors (i.e., soil, climate, slope, and aspect) and biotic factors (i.e., plant vigor, ground litter, seed germination, and species composition). Maintenance of a high standard of plant vigor and an appropriate species composition, along with reasonable multiple uses of the range land would 
be a desirable range condition. Obviously, the most important attribute of military training and testing range condition is its ability to support the primary training and testing mission on a sustainable basis.

While there are a number of remotely sensed data sources that potentially could be useful for this study, Landsat Thematic Mapper (TM) data was selected for analysis, primarily because it is readily available to installation resource managers. Both Landsat TM radiance data (the spectral response of individual bands) and vegetation indices derived from the radiance data offer an approach to relate vegetation/soil parameters to Landsat TM data.

Previous studies have shown significant relationships using this approach. For example, Tueller and Yuan (1992) were successful using pixel modeling with Landsat TM data for measuring vegetation changes of dominant shrubs on arid landscapes. Tueller (1992) had good results identifying annual vegetation patterns using Landsat Multispectral Scanner (MSS) images. Basavaraju (1994) found a significant relationship for predicting east side Sierra Nevada chaparral fire types using a combination of Ratio Vegetation Index (RVI), Modified Normalized Difference Vegetation Index (MNDVI), Soil Brightness Index (SBI), and TM5. Keller-Hatzel (1992) was able to characterize the variability within Pinyon/Juniper woodlands in western Nevada.

The ability to accurately assess and predict both erosion status and changes in species composition (community dynamics) relative to training load will significantly improve the ability to predict changes in land condition based on proposed training and testing loads. This study was designed to develop a model that could identify and facilitate the mapping of successional stages of semiarid plant communities using remotely sensed imagery and field survey.

\section{Objective}

The objective of this study was to develop statistical models that would be able to identify the difference between high, low and intermediate seral stages on semiarid sagebrush dominated rangelands at Yakima Training Center, Washington, using both field information alone, and field data combined with remotely sensed imagery. Specifically, three null hypotheses were formulated and tested:

$\mathrm{H}_{0} 1$ : The development of association tables with relevant Land Condition Trend Analysis data cannot define seral arrays on sagebrush/grass rangelands. 
$\mathrm{H}_{\mathrm{o}} 2$ : Various vegetation and surface soil parameters cannot be successfully quantified using Landsat Thematic Mapper spectral data.

$\mathrm{H}_{\mathrm{o}} 3$ : Individual bands or vegetation indices based on Landsat Thematic Mapper spectral data cannot be used to distinguish among seral stages of sagebrush/grasslands.

\section{Approach}

Field measurements within plant communities which were dominated by $A r$ temisia tridentata were derived from Land Condition Trend Analysis (LCTA) transect data and soil surveys completed by the Natural Resources Conservation Service (NRCS). A successional array was used to describe the placement of different seral stages of $A$. tridentata dominated communities upon a gradient in an ascending order starting from low seral moving up through high seral (presently referred to by many rangeland scientists as a potential natural community).

Several statistical procedures were used to investigate relationships between remotely sensed imagery and field measurements, including multiple linear regression analysis and canonical analysis. Specifically, statistical procedures were used to investigate the utility of remotely sensed imagery for estimating vegetation and soil parameters and for distinguishing between seral stages of sagebrush/grassland communities.

\section{Mode of Technology Transfer}

The results of this research will be provided directly to Yakima Training Center, Washington.

This report will be made accessible through the World Wide Web (WWW) at URL:

http://www.cecer.army.mil 


\section{Study Area and Field Data}

\section{Study Area}

The study area is Yakima Training Center (YTC), which is located in southcentral Washington. YTC is approximately 330,000 acres or 106,704 hectares. The training center resides on subordinate east-west anticline ridges extending east from the Cascade Mountains (Fenneman 1931). Elevations range from 121 $\mathrm{m}$ to $1280 \mathrm{~m}$. The prevalent vegetation is dominated by sagebrush/grassland communities. The training center's eastern border is the Columbia River and its western border is Interstate Highway 82. The installation is located within the rain shadow of the Cascade Mountains. The mean annual precipitation ranges from 8 to 16 inches and the mean annual pan evaporation from 48 to 64 inches per year (USGS 1970). Furthermore, the vegetation composition of this area is similar to millions of acres of semiarid rangelands of the western United States, including several other arid and semiarid training and testing installations.

\section{Field Data}

All ground data were obtained using the U.S. Army Land Condition Trend Analysis (LCTA) Plot Inventory Field Methods program. The LCTA program was designed to assist in evaluating the capability of land resources to support multiple-use demands on a sustained basis and monitor changes over time (Tazik et al. 1992). The LCTA program is a natural resource inventory and monitoring program consisting of permanent plots or releves that are measured annually. LCTA uses standard methods of vegetation measurement such as canopy cover (the amount of ground covered by a species for a given area), density (the number of plants of a given species for a given area), and frequency (the number of occurrences of a species per number of quadrants). The most important information in the database for the purpose of this study was species frequency and soil characteristics. Tueller and Platou's (1991) previous research has suggested that frequency and soil characteristics (e.g., the amount of cryptogamic crust and organic matter present) are useful for defining successional gradients in sagebrush/grass ecosystems. LCTA field data at YTC has been collected yearly since 1989 . 
General soils information was provided from a soil survey completed on the YTC by the NRCS. More in-depth soil analyses were performed by the National Soil Survey Laboratory in Lincoln, Nebraska, on soil samples collected by the Corps for each releve (Tazik et al. 1992). These analyses include quantification of the organic matter for surface horizons. 


\section{Methodology}

\section{Definition of Seral Arrays on Sagebrush/grass Rangelands}

Researchers have established 202 permanent LCTA plots (releves) at YTC. These plots were randomly installed to capture the variety among the plant communities on the firing center (Mueller-Dombois and Ellenberg 1974). LCTA site data were grouped according to species dominance, general species composition, soil characteristics, elevation, and aspect (direction). In addition, a number of sites were visited in the field to provide background information for placing the various sites into seral categories. Several procedures were used to define seral arrays of sagebrush/grass rangelands.

Three major sagebrush/grass types are present on the YTC. They are dominated by Artemisia tridentata, Artemisia tripartita, and Artemisia ridgida. This study emphasized plant communities that had $A$. tridentata as the dominate shrub. All releves within plant communities that had significant amounts of $A$. tripartita or A. ridgida were excluded. The key plant species that were used to define these arrays in addition to big sagebrush (A. tridentate, ARTR), were bluebunch wheatgrass (Agropyron spicatum, AGSP), Sandberg's bluegrass (Poa sandbergii, POSA), bottlebrush squirreltail (Sitanion hystrix, SIHY) and cheatgrass (Bromus tectorum, BRTE; Table 1). Plant communities with a significant amount of bluebunch wheatgrass were associated with the high seral end of the array. Bluebunch wheatgrass is considered a major component of the make-up of climax vegetation on sagebrush/grass sites (Daubenmire 1970) of the study area. Plant communities that had large quantities of Sandberg's bluegrass and or bottlebrush squirreltail were associated with mid-seral sites because these species are good indicators for areas that have not reached a potential natural community or near climax vegetation. Cheatgrass is an invader species that is routinely associated with sites that have been disturbed (Warg 1983). Young (1992) states that cheatgrass has the ability to truncate natural succession because perennial bunchgrass seedlings have limited access to soil moisture. Although cheatgrass commonly forms stable monocultures by truncating natural succession, it has been documented to precede sagebrush restablishment (Leonard et al. 1988, Tueller 1973). Therefore, communities that have a high composition of cheatgrass were associated with a low seral stage. On YTC, Army maneuvers 
and range fires are the primary disturbances that allow cheatgrass to dominate low-seral sites.

Table 1. How the key plant species help predict seral stages.

\begin{tabular}{|l|l|l|l|l|l|}
\hline Stage & \multicolumn{5}{|c|}{ Percent of Plant Species on Site } \\
\hline High & AGSP $(+)$ & POSE $(=)$ & SYHI $(=)$ & BRTE $(-)$ & ARTR $(=)$ \\
\hline Med & AGSP $(-)$ & POSE $(+)$ & SYHI $(+)$ & BRTE $(+)$ & ARTR $(+)$ \\
\hline Low & AGSP $(-)$ & POSE $(-)$ & SYHI $(-)$ & BRTE $(++)$ & ARTR $(+)$ \\
\hline $\begin{array}{l}\text { AGSP = Agropyron spicatum POSE }=\text { Poa secunda SYHI = Sitanion hystrix BRTE = Bromus } \\
\text { tectorum ARTR }=\text { Artemisia tridentate }(+) \text { increasing }(-) \text { decreasing }(=) \text { stable or not changing }\end{array}$ \\
\hline
\end{tabular}

After exclusion of releves that were not dominated by $A$. tridentata, aspect and elevation differences among the selected releves were recorded. These are important distinctions due to the differences in climate between elevations and aspects. To account for elevation differences, approximately 20 plots were initially selected from a higher elevation and 20 plots from a lower elevation. Each represented an array from high seral to low seral. An arbitrary cutoff elevation was used to separate the releves into two sets, placing half the plots on a particular direction of slope above that point and half below.

To help examine and separate the sets of releves, aspect was initially separated into categories. Transects that had an aspect between 315 and 45 degrees were interpreted as being located on north facing slopes, and transects located between 45 and 135 degrees were considered as east facing. This pattern was continued until all 360 degrees of aspect were assigned into four categories.

Various soil parameters were also used in this analysis, including depth, color, thickness of the A and B horizons, texture, and presence of clay in the A and B horizons (data collected by the NRCS). Soil characteristics were considered essential for defining the successional relationships because of the importance of the physical (e.g., texture and parent material) and chemical characteristics that influence the plant community. Leonard et al. (1988) have shown that vegetation soil relationships on semiarid rangelands region strongly influence the seral status of the plant community. For example, a plant's ability to withstand moisture stress will have an effect on its ability to survive on a arid soil; Wyoming big sagebrush (A. tridentata var. Wyomingensis) can survive on the drier hillsides, whereas basin big sagebrush (A. tridentata var. tridentata) is restricted more to drainages and valley floors that have deeper soils capable of holding more moisture. 
Selected sites were visited during the growing season to obtain a visual impression of the plant species composition and the associated soil characteristics. Photographs and detailed field notes were taken to aid in the interpretation of the LCTA data. To test the first hypothesis, results of matching field notes and photos, along with LCTA and soil survey results were examined and compared for any indication of significant seral arrays.

\section{Quantification of Vegetation and Soil Parameters with Thematic Mapper Data}

The association tables used to test the first hypothesis were adjusted to create four data matrices (May frequency, May cover, August frequency, and August cover) by adding radiance and vegetation index values from the May and August Landsat TM data. The ground data was the same for all four matrices and only the Landsat-derived data differed for each matrix. Each matrix was then divided into two elevation and three aspect directions. To test $\mathrm{H}_{0} 2$, statistical analysis was performed on independent and dependent variables associated with the LCTA data and TM data included in the four data matrices. Vegetation characteristics (canopy cover, density, frequency, total plant cover, the percent cover of individual species, amount of bare ground, etc.), geomorphic characteristics (soil depth and texture, thickness of the A and B horizons, and the presence of clay in the A and B horizon) and soil organic matter content were considered the dependent variables. The independent variables for the analysis are the individual radiance values from Landsat TM bands plus vegetation and soil indices derived from the satellite data.

TNT-MIPS (Totally New Technology Map and Image Processing System) and Geographical Resources Analysis Support System (GRASS 4.1) software were used to extract spectral information from TM data that corresponded to the geographic location of LCTA releves on the ground. Twenty picture elements (pixels) were selected from homogeneous areas (polygons) associated with each selected releve. For ease of data manipulation and also to adequately represent releve variability, Crippen (1987) suggests using 20 pixels for deriving a mean value. Jensen (1986) defines a pixel as having both spatial and spectral properties. The spatial variable defines the apparent size of the resolution cell and the spectral properties define the intensity of the spectral response for that cell in a particular band. Each TM pixel represents a $30 \mathrm{~m} \times 30 \mathrm{~m}$ area on the ground. These homogeneous areas or mixed pixels were selected to represent specific seral plant communities from the vegetation. A pixel or group of pixels can be placed into a category of known vegetation components by the brightness value 
(Tueller 1989). For example, pixel values from a sagebrush dominated site will have different spectral responses than pixels from a grass dominated site. From these homogeneous sites, the mean pixel radiance values from six (bands 1, 2, 3, 4,5 , and 7) of the seven bands were calculated and included in the statistical matrices.

Topographically corrected images were utilized for reducing the variability among pixels due to topography. These corrected images were used because of the rugged terrain and the effects of shadowing on the east-west running ridges. Civco (1989) and Kawata et al. (1988) describe the applications and effects that topographic corrections can have on Landsat data.

\section{Landsat Thematic Mapper for Identification of Seral Stages of Sagebrush/Grasslands}

It is difficult to define seral stages using satellite imagery alone. However, multiple linear regression analysis can be used to determine if the relationships between satellite and ground derived parameters are sufficient to show that the satellite data can be used to identify different seral stages. To test the third hypothesis, individual TM bands or vegetation indices were included for defining the seral arrays. These data were the same as used in testing the previous hypothesis. Linear regression models were used to relate the LCTA ground data to the spectral data associated with the sites in the arrays defined above.

\section{Vegetation Indices}

Vegetation indices are mathematical combinations of red and near infrared reflectance that have been developed to reduce multispectral scanner data observed by satellites to a single number or index, for the purpose of qualitatively and quantitatively assessing vegetation conditions. On arid and semiarid rangelands, soil background conditions and shadow effects influence the signals from the multispectral scanner. These influences complicate the use of indices for evaluating vegetation (Tueller 1987). According to Jackson et al. (1983), the ideal vegetation index would be one that was sensitive to vegetation and insensitive to soil backgrounds. In addition, vegetation indices can be influenced by atmospheric conditions such as clouds and haze and should be adjusted to represent true values (Kauth and Thomas 1976). There are two categories of vegetation indices: ratio-based indices and orthogonal indices. 


\section{Ratio Indices}

Ratio indices are derived by dividing one spectral band by another to get a ratio [e.g., RVI (TM4/TM3)] or by subtracting one band from another. One of the most commonly applied ratio vegetation indexes is the Normalized Difference Vegetation Index [e.g., NDVI (TM4-TM3/TM4+TM3)]. The ratio based indices of importance are: ratio vegetation index (RVI, Pearson and Miller 1972), the difference vegetation index (DVI, Richardson and Wiegand 1977), the normalized difference vegetation index (NDVI, Rouse et al. 1974), the transformed normalized difference index (TNDVI, Rouse et al. 1974), the weighted difference vegetation index (WDVI, Clevers 1986 and 1989), the soil adjusted vegetation index (SAVI, Huete 1988) and the transformed soil adjusted vegetation index (TSAVI, Baret et al. 1989). Table 2 shows the ratio formulas used to derive these indices.

Table 2. Mathematical abbreviations and definitions of ratio based indicies.

\begin{tabular}{|c|c|c|}
\hline Name & Abbreviation & Mathmatical Formula \\
\hline Ratio Vegetation Index & $\mathrm{RVI}$ & NIR / RED \\
\hline Difference Vegetation Index & DVI & NIR - RED \\
\hline $\begin{array}{l}\text { Normalized Difference Vegetation } \\
\text { Index }\end{array}$ & NDVI & (NIR - RED) / (NIR + RED) \\
\hline $\begin{array}{l}\text { Transformed Normalized Difference } \\
\text { Vegetation Index }\end{array}$ & TNDVI & SQRT[(NIR - RED) / (RED + NIR) +.5] \\
\hline Weighted Vegetation Index & WDVI & {$[N I R-(N I R / R E D) *$ RED } \\
\hline Soil Adjusted Vegetation Index & SAVI & $(\mathrm{NIR}-\mathrm{RED}) /(\mathrm{RED}+\mathrm{NIR}+0.5) *(1.5)$ \\
\hline $\begin{array}{l}\text { Transform Soil Adjustment } \\
\text { Vegetation Index }\end{array}$ & TSAVI & $\begin{array}{l}a 1 \text { * (NIR - a1 * RED - b1) / } \\
{\left[a 1 \text { * NIR + RED - a1 *b1 * }\left(a 1^{2}+1\right)\right]}\end{array}$ \\
\hline
\end{tabular}

\section{Orthogonal Indicies}

Orthogonal indices are multidimensional values obtained from a calculated soil line. The calculated soil line is a linear relationship derived by plotting the brightest and darkest unvegetated pixel values from a TM data scene. The orthogonal indices that were investigated are the two-dimensional perpendicular vegetation index (PVI, Richardson and Wiegand 1977), the green vegetation index (GVI, Kaulth and Thomas 1976), the yellow vegetation index (YVI, Kauth and Thomas 1976), the nonsuch vegetation index (NVI, Kauth and Thomas 1976), the soil brightness index (SBI, Jackson 1983), and the n-dimensional total absorption index (TAI, Ustin et al. 1986). 
The resulting ratio and orthognal index values were added to the four matricies used in multilinear regression analysis to evaluate the potential for predicting ground parameters associated with the seral stages.

\section{Statistical Methods}

Multiple linear regression analysis and canonical analysis were used to evaluate the relationship between plant community characteristics and Landsat TM data. The association table used to test the first hypothesis was modified and transformed into four data matrices (May frequency, May cover, August frequency, and August cover) to test the second and third hypotheses.

Multiple linear regression analysis is a technique to express the idea that a dependent variable varies with one or a set of independent variables. It is a mostly univariate method because it involves accounting for variation in only one dependent variable (Freund and Littell 1992, Manly 1986). To use the linear regression analysis appropriately, the assumption that the error term (the differences between the observed values of the dependent variable and those expected from the model) of a model represents natural variation in the data cannot be violated, otherwise, the resulting analysis may provide results of questionable validity. Outliers and specification error can violate the assumption. Outliers are unusual observations that do not fit the model. Because they can bias parameter estimates and mislead results, it is important to detect and fix or remove outliers before doing any analysis. Specification errors occur when the model is incorrectly specified (does not contain all of the necessary terms, such as quadratic and cross product terms) and may also result in biased estimates of parameters.

Another statistical approach tested was canonical analysis. Canonical correlation analysis is a generalization of multiple regression in which several dependent variables are simultaneously related to several independent variables (Manly 1986). It is very useful for identifying relationships between sets of multiple dependent and multiple independent variables (Hair et al 1992). The point of a multivariate analysis is to consider several related random variables simultaneously, each one considered equally important at the start of the analysis. This analysis maximizes the correlations between these linear combinations. In some sets of multivariate data, the variables divide naturally into two groups (dependent variables and independent variables). Canonical analysis can be used to investigate the relationships between the two groups of variables. 


\section{Outliers and Model Specification}

Residuals (including Cook's D) and influence statistics from $\mathrm{SAS}^{1}$ software were analyzed to detect the significant outliers. The partial residual plots (partial option in model statement) and rsreg procedure from SAS program were used to test specification errors of specified models. A curved pattern in the residual plot suggests that a quadratic term in one or more variables should be included in the model. The rsreg procedure builds and evaluates a quadratic response surface model. The need for linear, quadratic, and cross-product terms is determined from the output.

\section{Correlation Analysis}

Because all the independent variables are either Landsat TM data or their mathematical derivations, it is necessary to determine if they are correlated. Pearsons all-possible correlation analysis was used to examine the correlation among independent variables. Results indicated that many independent variables were highly correlated. When variables were highly correlated, one of the variables was subjectively removed from the analysis. Such variables were removed because they did not increase the predictive capability of the model. This method was repeated until all autocorrelation was accounted for among the various data matrices. This procedure reduced the overall number of independent variables from 22 down to 14 .

\section{Model Selection}

Since not all independent variables in a regression model contribute significantly to the predictive power of the model, it is desirable to identify a suitable subset of important variables. For a given number of variables, a best subset model is one that produces the minimum error sum of squares, or the maximum $\mathrm{R}^{2}$. The $R$-square selection method, $C(P)$ statistic, and Forward option in SAS were used to select useful models. Best subset regressions were then used to define the most appropriate use of various combinations of independent and dependent

\footnotetext{
${ }^{1}$ Citing trade names and companies does not constitute endorsement by the U.S. Army or the Corps of Engineers. Contact information: SAS Institute Inc., SAS Campus Drive, Cary, NC 27513.
} 
variables. The objective was to identify the most promising independent and dependent variables for the models.

\section{Multicollinearity}

Multicollinearity is defined as a high degree of correlation among several independent variables. In addition to using Pearson's all-possible correlation procedure to delete some highly correlated variables, two methods (described below) were used to define and remove any remaining multicollinearity.

Although the existence of multicollinearity is not a violation of the assumptions underlying the use of regression analysis, it tends to inflate the variances of predicted values and the variances of parameter estimates. Because the use and interpretation of regression coefficients are very important for many regression analyses, it is important to detect and remove the effects of multicollinearity. The highly correlated independent variables (correlation coefficients larger than 0.9) were adjusted using Pearson's all-possible correlation analysis as previously discussed. Then variance inflation factors and analysis of structure methods (vif and collinoint options in procedures from the SAS program) were applied to detect and remove the multicollinearity. The number of independent variables was reduced from 14 or 15 down to either 5 or 6 , depending on the respective data set (May cover, May frequency, August cover, and August frequency). To include the direction of slope effect in the analysis, two dummy independent variables were created for each data set. These were called north (NOR) and south (SOU).

\section{Canonical Analysis}

Given two sets of variables, the cancorr procedure from SAS program was used to find a linear combination from each set, called a canonical variable, such that the correlation between the two canonical variables was maximized. The process of constructing canonical correlation continued until the number of pairs of canonical variables equaled the number of variables in the smaller group.

In the four data sets, the number of dependent variables was smaller than the number of independent variables, thus determining seven pairs of canonical variables. The second pair of canonical variables is not related to and is independent of the first pair (this is true for all seven pairs) and produces the second highest correlation between coefficients. The cancorr procedure provides multiple regression analysis options to aid in interpreting the canonical analysis. Af- 
ter deciding which canonical variables are significant, these variables can be interpreted in terms of the original variables with large canonical coefficients.

Since a certain degree of correlation exists among dependent variables, it may be more desirable to examine the relationship between sets of both multiple dependent and independent variables. Also, because TM pixel radiance values are related to ground characteristics, each dependent variable makes a contribution to the measurements, thus providing another reason to consider the dependent variables equally important and relate them simultaneously to independent variables. In this situation, multivariate analysis methods are appropriate techniques to be employed.

Multiple linear regression and canonical correlation analyses were performed on the four different data sets previously described. The linear combinations of dependent and independent variables were established (canonical variable) so that the correlation between the canonical variables was maximized. 


\section{Results and Discussion}

To test the first hypothesis, plots were sorted by key species (e.g., AGSP) in a descending order within hand-drawn association tables. The associated species values or measurements in the table were then examined for any ascending or descending pattern to determine which species and soil surface parameters could be used as predictors of seral stage. It was hypothesized that if there was a decrease in AGSP, then there may be a corresponding increase in BRTE or other low successional species. To test this hypothesis, these species were plotted against each other and fitted with a best fit line. The line showed a very slight increase in BRTE when AGSP decreased, but no concrete assumptions could be made (Figure 1). BRTE, ARTR, and POSA all had higher values than AGSP at the low end of the array, which was expected. This same procedure was preformed on all other mixtures of important species and vegetation measurements available in the association tables. There were no statistical procedures performed on the data from the association tables.

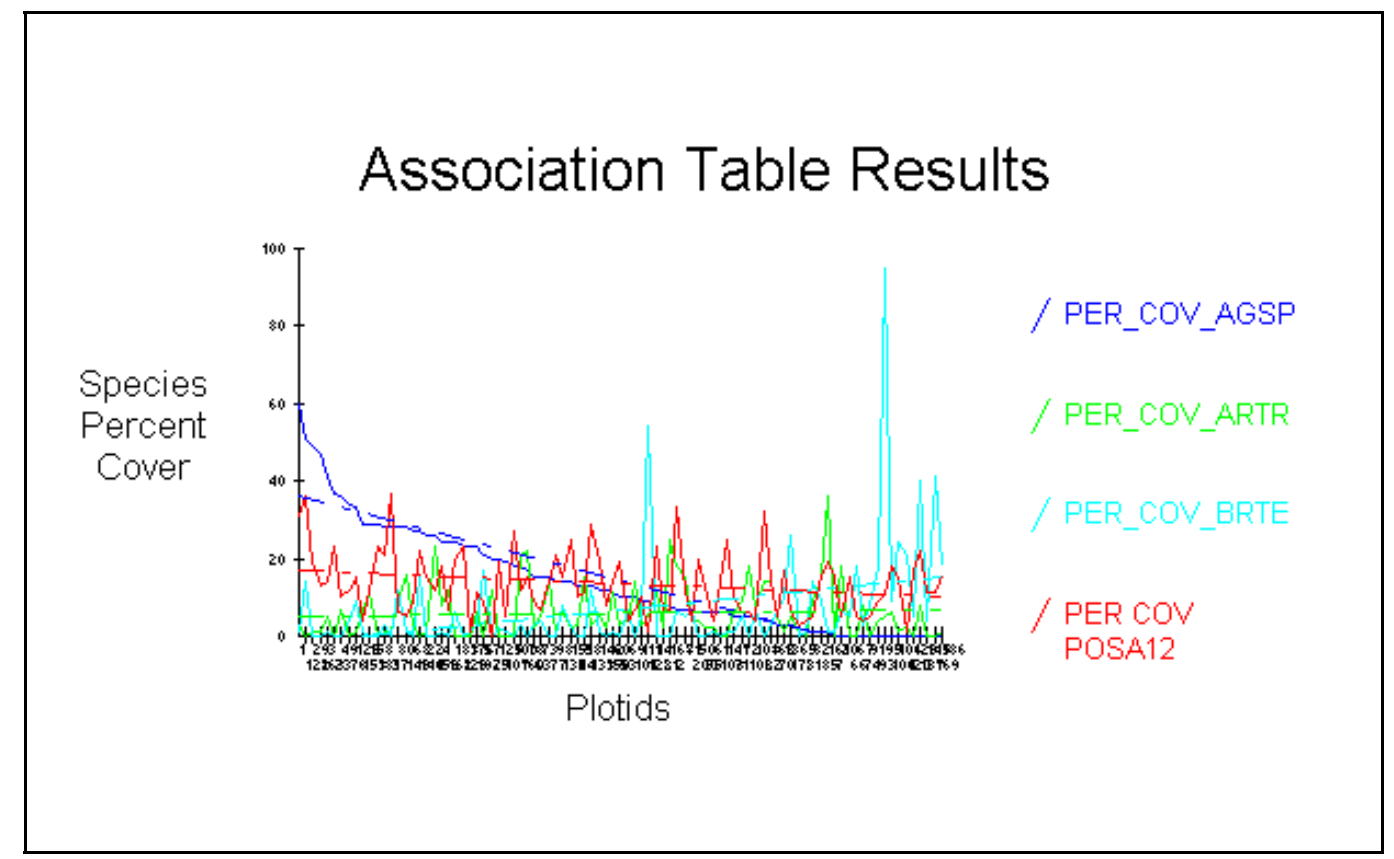

Figure 1. The relationships of percent cover AGSP, ARTR, BRTE, and POSA when AGSP is arrayed from high to low. 


\section{Multiple Linear Regression}

\section{Uncombined Releves}

Original analysis included multiple linear regression analysis of several arrays from the different elevations and different slope or drainage directions. This constituted a statistical test of the second hypothesis. While many of these results generally had low $\mathrm{R}^{2}$ values, some appeared reasonable; however, problems with multicollinearity persisted. An example of the original data is summarized in Table 3. Figures 2 and 3 are scatter diagrams showing two of the significant relationships from this data set. Even though the $\mathrm{R}^{2}$ values were low and preclude predictability, the scatter diagrams appear to show relationship that are significant.

All analyses were based on the original methodological approach. Releves were originally categorized by elevation (greater and less than 700 meters) and drainage direction in order to group the plots into one of six natural categories or releve arrays. The categories were level, south, and north facing slopes. All releves found on near level slopes (from 0 to 5 percent) were placed in the level category. All releves that positioned on slopes (greater than 5 percent) that drained toward the southwest, southeast, south, and east were placed in the south facing category. All releves that were positioned on slopes (greater than 5 percent) that drained toward the northwest, northeast, north, and west were placed in the north facing category. The aspect direction of the releves did not provide a good natural separation.

Table 3. An example of the original data analysis for 37 releves using the north slope August frequency data.

\begin{tabular}{|l|l|l|l|}
\hline $\begin{array}{l}\text { Dependent } \\
\text { Variables }\end{array}$ & Independent Variables & R-square & P-value \\
\hline AGSP & $\begin{array}{l}\text { NVI, TM2, TM7, RVI, DVI, } \\
\text { TNDVI, TM5, NDVI }\end{array}$ & 0.57 & 0.2015 \\
\hline ARTR & $\begin{array}{l}\text { GVI, NVI, MNDVI,TSAVI, } \\
\text { TNDVI, TM5, TM7, TM3 }\end{array}$ & 0.62 & 0.0039 \\
\hline BRTE & WDVI, TM7 & 0.45 & 0.0004 \\
\hline GCLITTER & GVI, TSAVI & 0.14 & 0.2321 \\
\hline GCBARE & GVI, TM7, TSAVI & 0.15 & 0.4339 \\
\hline TOTPER & SAVI, TSAVI, NVI & 0.09 & 0.4616 \\
\hline ORGMATT & GVI, TM5, MNDVI, NDVI & 0.52 & 0.0481 \\
\hline
\end{tabular}


The lack of significant regressions and the problem of multicollinearity dictated an alternate approach for evaluating elevation effects. It was later concluded that sample sizes between 10 and 37 releves were perhaps too small, or that the data variance was too great. For these reasons, all 91 releves with big sagebrush as the dominant shrub were used in the analysis.

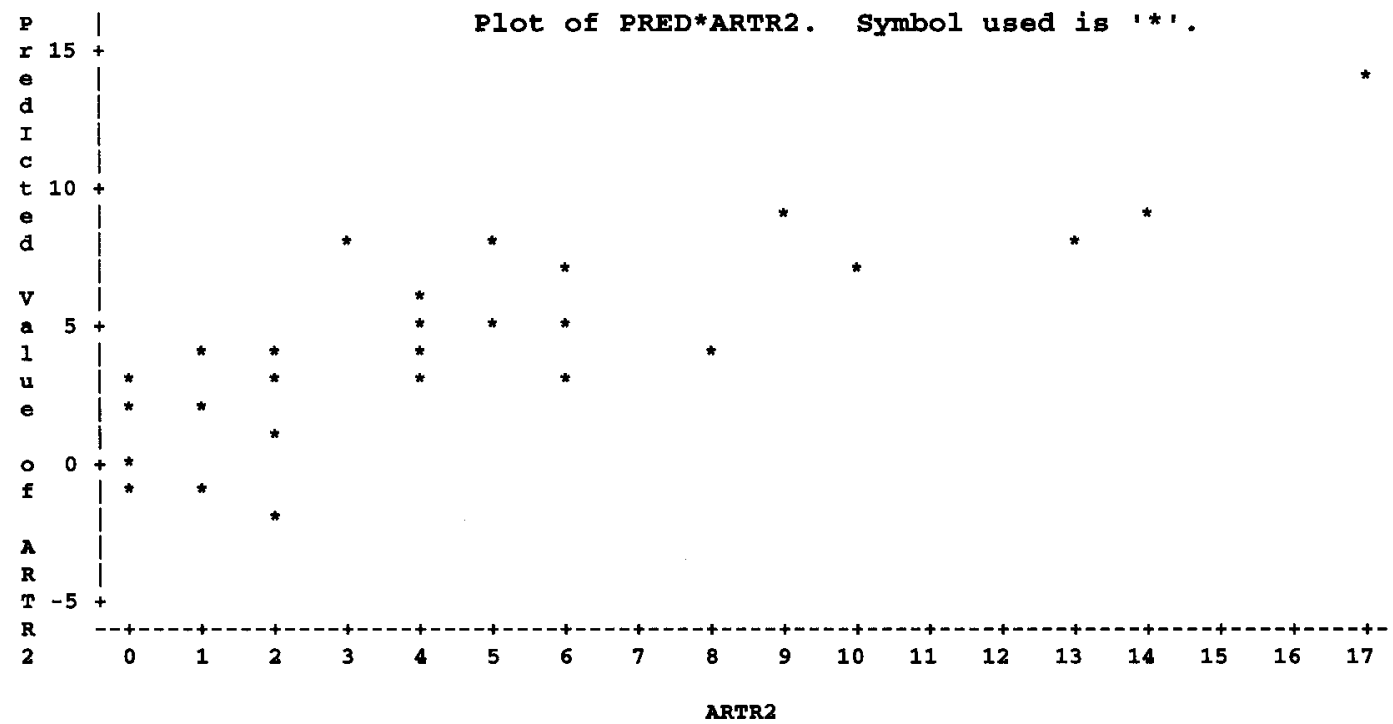

NOTE: 10 obs hidden.

Figure 2. A scatter plot showing the actual and predicted ARTR cover for the 37 releves.

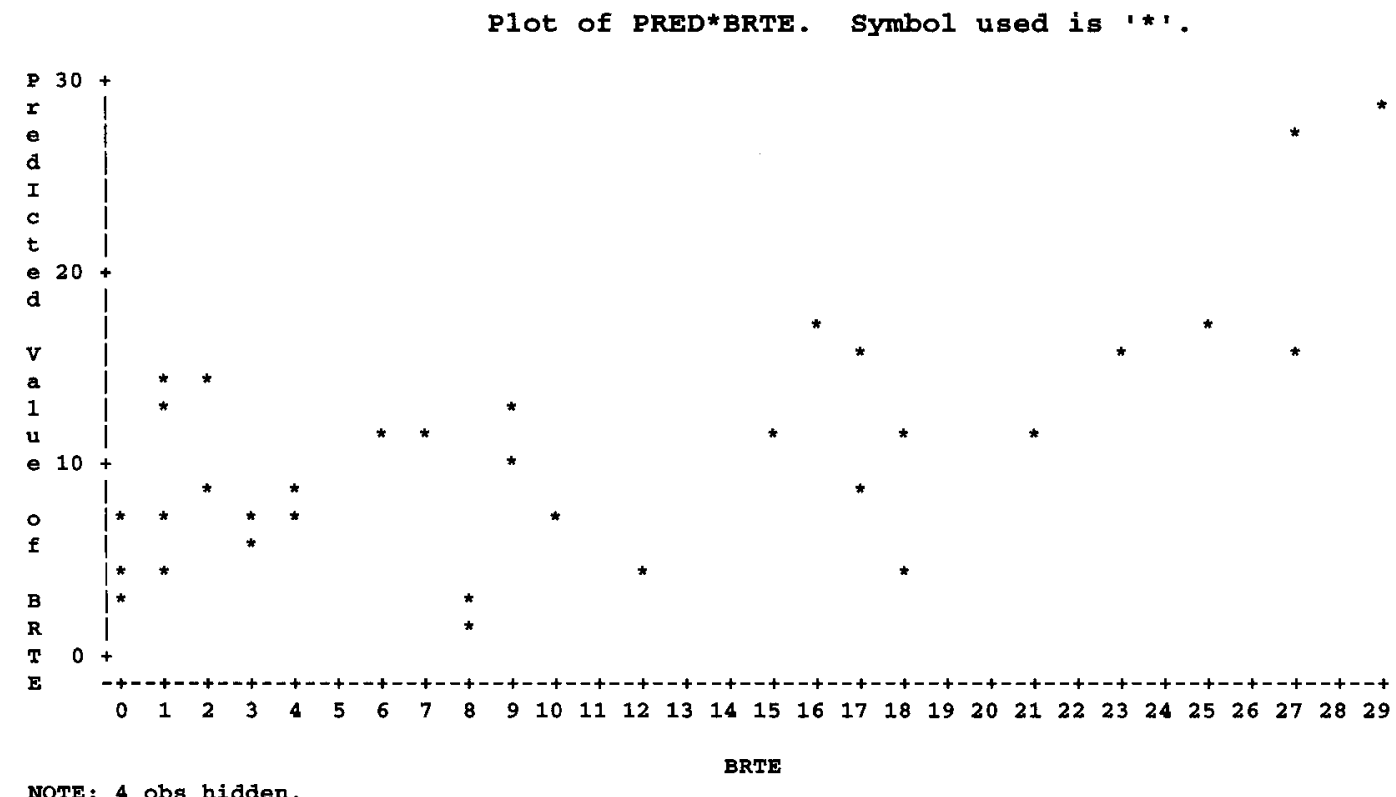

Figure 3. A scatter plot showing the actual and predicted ORGMATT cover for the 37 releves. 
When the three drainage direction categories were separated by elevation, the sample size was too small and did not adequately characterize the variability within the proposed successional arrays. Therefore, the drainage direction categories were removed from the regression analysis. However, the influence of these natural separation categories was again inserted into the analysis as independent variables during multivariate regression and canonical analysis.

\section{Combined Releves}

Analysis of all 91 big sagebrush releves was conducted to initiate a more rigorous approach to the analyses. The following discussion describes the steps taken to develop best subsets (using SAS best subset regression) of independent variables, to test for multicollinearity, and to identify statistical outliers and influential observations among the releves.

\section{Multicollinearity}

All independent variables showed some multicollinearity. Many of the correlations were 0.95 and higher. This problem was attributed to the fact that all vegetation indices were derived from the same six TM bands that are also included as independent variables. To address this problem, the proc corr procedure within SAS was used to identify and examine independent variables with high correlations as explained previously.

The vif(variance inflation factor) and collinoint options in the proc reg statement from SAS were used to further combat the multicollinearity problem. The vif option creates values that can be interpreted for multicollinearity. vif values greater than $1 /\left(1-R^{2}\right)$ show multicollinearity and were removed (SAS 1988). The collinoint option uses the square root of the ratio between the largest and smallest eigen values. This ratio is referred to as a condition number. Myers (1990) recommends that the square of the condition number greater than 1,000 indicates serious multicollinearity. Hence, variables with condition numbers greater than 1000 in this study were removed. The independent variables were reduced via this procedure from 22 to about 6 , depending on the data matrix.

\section{Outlier and Influential Observations}

Four of the 91 observations were identified as either statistical outliers or influential observations. Outliers were removed primarily for statistical reasons. There was no thread of similarity or outstanding factors associated with those 
releves removed. These releves were then removed to improve the strength and stability of the model. This left from 7 to 9 independent variables (Tables 4, 5, 6, and 7) for each matrix. In each case, the same seven dependent variables were included in the analysis (Tables 4, 5, 6, and 7).

\section{Final Linear Regression Analyses}

After the exclusion of outliers and influential observations, the data matrices included 87 to 89 releves that contained ARTR and AGSP. From this, each of the seven dependent variables for May cover and frequency and August cover and frequency were analyzed using the 7 to 9 independent variables depending on the matrix (Tables 4, 5, 6, and 7). Results from these regressions still showed quite low $\mathrm{R}^{2}$ values, although many were highly significant. The dependent variable organic matter throughout this analysis consistently had higher $\mathrm{R}^{2}$ values that ranged from 0.20 to 0.38 (Tables $4,5,6$, and 7). This suggests that the variation inherent in the natural vegetation precludes the possibility of obtaining high $\mathrm{R}^{2}$ values with this data set.

Table 4. Multiple linear regression results for August frequency.

\begin{tabular}{|l|l|l|l|l|}
\hline $\begin{array}{l}\text { Dependent } \\
\text { Variable }\end{array}$ & $\begin{array}{l}\text { Significant Independent } \\
\text { Variables }\end{array}$ & $\begin{array}{l}\text { Mean Square } \\
\text { Error }\end{array}$ & R-square & P-value \\
\hline AGSP & $\begin{array}{l}\text { TM1, NDVI, YVI, NVI, TSAVI, } \\
\text { WDVI, SAVI, NOR, SOU }\end{array}$ & 66.41 & 0.16 & 0.1051 \\
\hline ARTR2 & $\begin{array}{l}\text { TM1, NDVI, YVI, NVI, TSAVI, } \\
\text { WDVI, SAVI, NOR, SOU }\end{array}$ & 25.66 & 0.26 & 0.0040 \\
\hline BRTE & $\begin{array}{l}\text { TM1, NDVI, YVI, NVI, TSAVI, } \\
\text { WDVI, SAVI, NOR, SOU }\end{array}$ & 99.12 & 0.15 & 0.1354 \\
\hline TOTPER & $\begin{array}{l}\text { TM1, NDVI, YVI, NVI, TSAVI, } \\
\text { WDVI, SAVI, NOR, SOU }\end{array}$ & 179.13 & 0.27 & 0.0020 \\
\hline GCBARE & $\begin{array}{l}\text { TM1, NDVI, YVI, NVI, TSAVI, } \\
\text { WDVI, SAVI, NOR, SOU }\end{array}$ & 190.82 & 0.26 & 0.0029 \\
\hline ORGMATT & $\begin{array}{l}\text { TM1, NDVI, YVI, NVI, TSAVI, } \\
\text { WDVI, SAVI, NOR, SOU }\end{array}$ & 236.28 & 0.26 & 0.0038 \\
\hline
\end{tabular}


Table 5. Multiple linear regression results for August cover.

\begin{tabular}{|l|l|l|l|l|}
\hline $\begin{array}{l}\text { Dependent } \\
\text { Variable }\end{array}$ & $\begin{array}{l}\text { Significant Independent } \\
\text { Variables }\end{array}$ & $\begin{array}{l}\text { Mean Square } \\
\text { Error }\end{array}$ & R-square & P-value \\
\hline AGSP & $\begin{array}{l}\text { TM1, NDVI, YVI, NVI, TSAVI, } \\
\text { WDVI, SAVI, NOR, SOU }\end{array}$ & 142.98 & 0.13 & 0.2080 \\
\hline ARTR2 & $\begin{array}{l}\text { TM1, NDVI, YVI, NVI, TSAVI, } \\
\text { WDVI, SAVI, NOR, SOU }\end{array}$ & 43.85 & 0.22 & 0.0152 \\
\hline BRTE & $\begin{array}{l}\text { TM1, NDVI, YVI, NVI, TSAVI, } \\
\text { WDVI, SAVI, NOR, SOU }\end{array}$ & 111.82 & 0.14 & 0.1537 \\
\hline TOTPER & $\begin{array}{l}\text { TM1, NDVI, YVI, NVI, TSAVI, } \\
\text { WDVI, SAVI, NOR, SOU }\end{array}$ & 176.93 & 0.26 & 0.0029 \\
\hline GCBARE & $\begin{array}{l}\text { TM1, NDVI, YVI, NVI, TSAVI, } \\
\text { WDVI, SAVI, NOR, SOU }\end{array}$ & 187.29 & 0.26 & 0.0025 \\
\hline GCLITTER & $\begin{array}{l}\text { TM1, NDVI, YVI, NVI, TSAVI, } \\
\text { WDVI, SAVI, NOR, SOU }\end{array}$ & 230.55 & 0.26 & 0.0030 \\
\hline ORGMATT & $\begin{array}{l}\text { TM1, NDVI, YVI, NVI, TSAVI, } \\
\text { WDVI, SAVI, NOR, SOU }\end{array}$ & 0.35 & 0.36 & 0.0001 \\
\hline
\end{tabular}

Table 6. Multiple linear regression results for May frequency.

\begin{tabular}{|l|l|l|l|l|}
\hline $\begin{array}{l}\text { Dependent } \\
\text { Variable }\end{array}$ & $\begin{array}{l}\text { Significant Independent } \\
\text { Variables }\end{array}$ & $\begin{array}{l}\text { Mean Square } \\
\text { Error }\end{array}$ & R-square & P-value \\
\hline AGSP & $\begin{array}{l}\text { TM2, NDVI, PVI, WDVI, SAVI, } \\
\text { NOR, SOU }\end{array}$ & 105.76 & 0.23 & 0.0026 \\
\hline ARTR2 & $\begin{array}{l}\text { TM2, NDVI, PVI, WDVI, SAVI, } \\
\text { NOR, SOU }\end{array}$ & 27.33 & 0.22 & 0.0048 \\
\hline BRTE & $\begin{array}{l}\text { TM2, NDVI, PVI, WDVI, SAVI, } \\
\text { NOR, SOU }\end{array}$ & 152.59 & 0.19 & 0.0158 \\
\hline TOTPER & $\begin{array}{l}\text { TM2, NDVI, PVI, WDVI, SAVI, } \\
\text { NOR, SOU }\end{array}$ & 169.08 & 0.30 & 0.0001 \\
\hline GCBARE & $\begin{array}{l}\text { TM2, NDVI, PVI, WDVI, SAVI, } \\
\text { NOR, SOU }\end{array}$ & 189.78 & 0.23 & 0.0025 \\
\hline GCLITTER & $\begin{array}{l}\text { TM2, NDVI, PVI, WDVI, SAVI, } \\
\text { NOR, SOU }\end{array}$ & 227.01 & 0.25 & 0.0011 \\
\hline ORGMATT & $\begin{array}{l}\text { TM2, NDVI, PVI, WDVI, SAVI, } \\
\text { NOR, SOU }\end{array}$ & 0.35 & 0.37 & 0.0001 \\
\hline
\end{tabular}


Table 7. Multiple linear regression results for May cover.

\begin{tabular}{|l|l|l|l|l|}
\hline $\begin{array}{l}\text { Dependent } \\
\text { Variable }\end{array}$ & $\begin{array}{l}\text { Significant Independent } \\
\text { Variables }\end{array}$ & $\begin{array}{l}\text { Mean Square } \\
\text { error }\end{array}$ & R-square & P-value \\
\hline AGSP & $\begin{array}{l}\text { TM1, PVI, GVI, TAI, TSAVI, } \\
\text { NOR, SOU }\end{array}$ & 198.13 & 0.13 & 0.1107 \\
\hline ARTR2 & $\begin{array}{l}\text { TM1, PVI, GVI, TAI, TSAVI, } \\
\text { NOR, SOU }\end{array}$ & 45.54 & 0.16 & 0.0416 \\
\hline BRTE & $\begin{array}{l}\text { TM1, PVI, GVI, TAI, TSAVI, } \\
\text { NOR, SOU }\end{array}$ & 179.87 & 0.08 & 0.4102 \\
\hline GCBARE & $\begin{array}{l}\text { TM1, PVI, GVI, TAI, TSAVI, } \\
\text { NOR, SOU }\end{array}$ & 180.87 & 0.25 & 0.0011 \\
\hline TOR, PVI, GVI, TAI, TSAVI, & 200.98 & 0.17 & 0.0208 \\
\hline ORGMATT & $\begin{array}{l}\text { TM1, PVI, GVI, TAI, TSAVI, } \\
\text { NOR, SOU }\end{array}$ & 234.96 & 0.21 & 0.0055 \\
\hline
\end{tabular}

Predicted versus actual scatter plots were generated for all seven dependent variables for each data matrix. These plots suggest the significance of the relationships and also show the variation of the data sets precluding high $\mathrm{R}^{2}$ values. The scatter plots that visually appear the best are for organic matter (Figure 4) and ARTR (Figure 5) for May frequency. Total percent cover, litter, and bare ground also showed significant relationships. All other scatter diagrams from these analyses are shown in the Appendix as Figures A-1 through A-26.

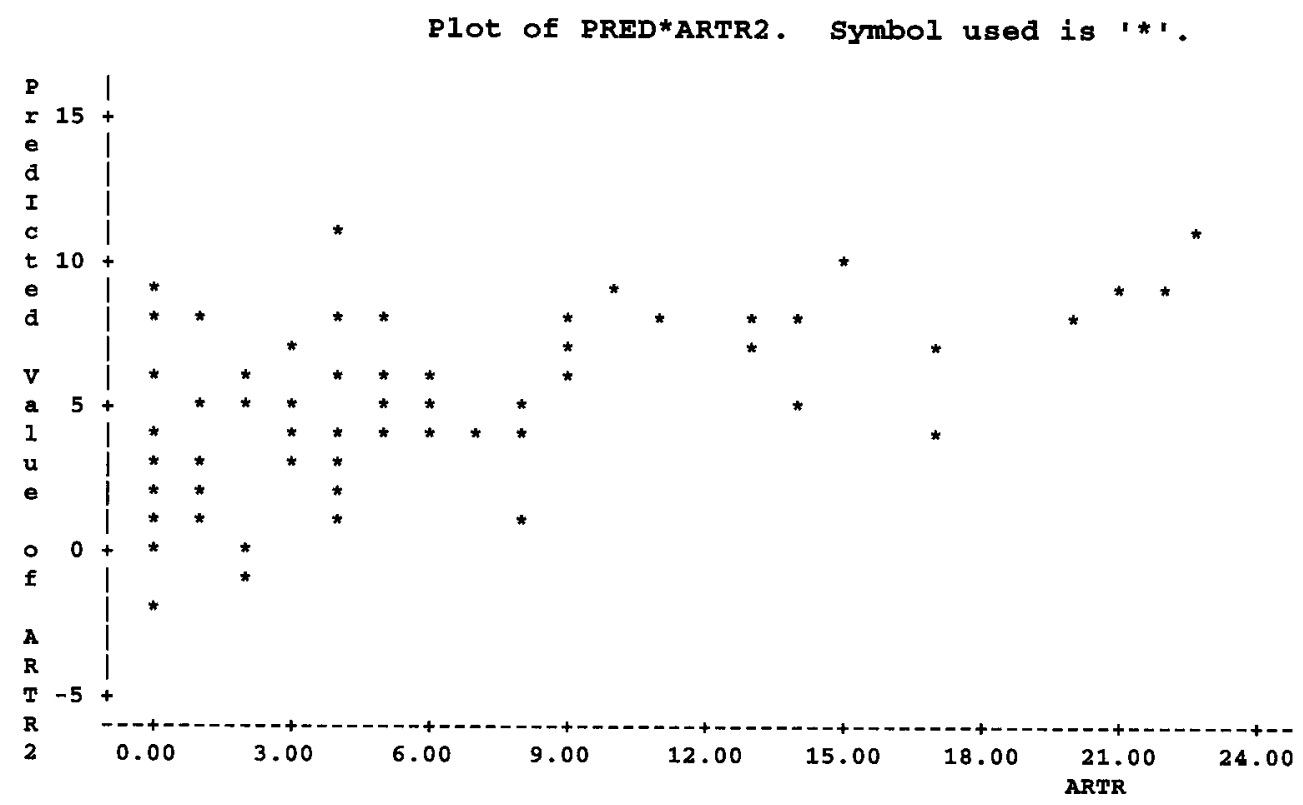

Figure 4. A scatter plot showing all 91 releves of the actual verses predicted ARTR values from the August frequency data matrix. 
Plot of PRED*ORGMATT. Symbol used is $1 *$ '.

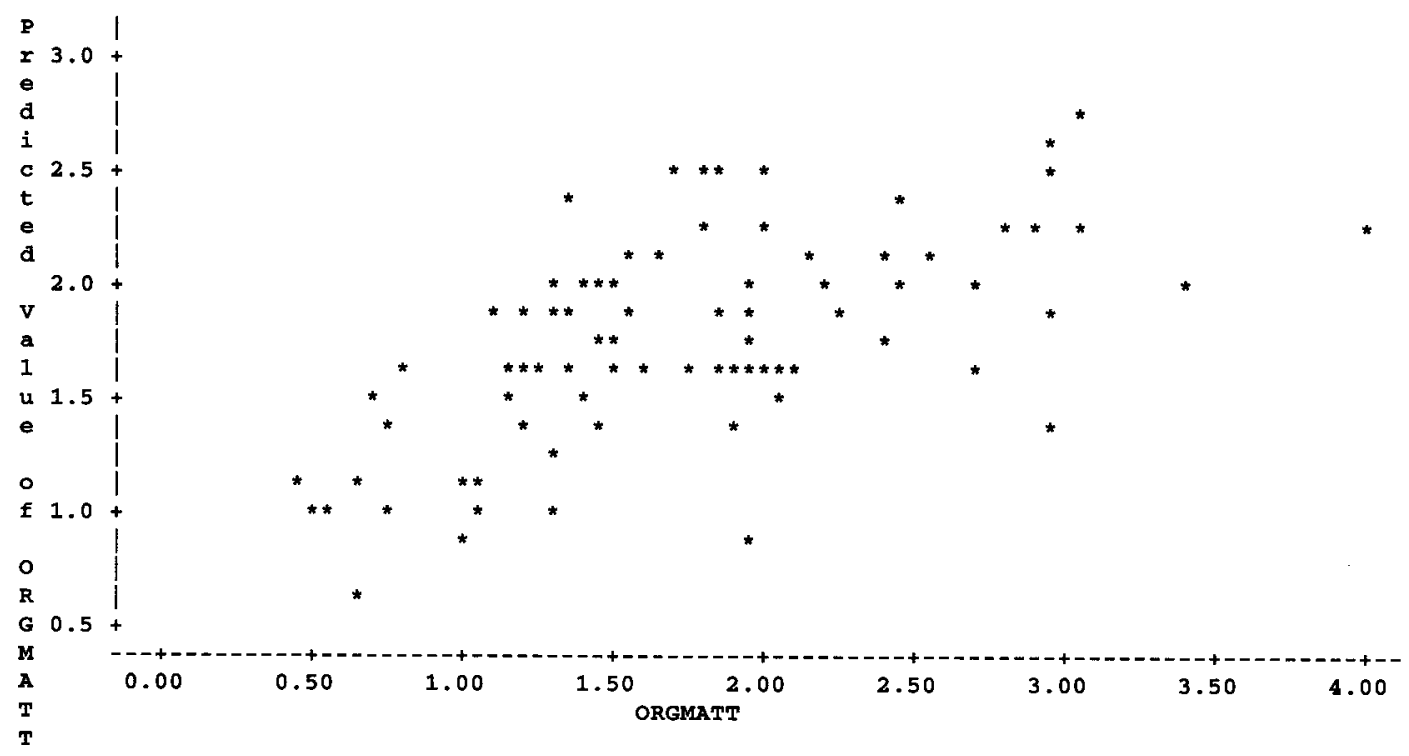

Figure 5. A scatter plot of 91 releves showing the actual verses predicted ORGMATT values form the August frequency data matrix.

\section{Canonical Analysis}

This analysis maximized the correlations among the several identified linear combinations. The higher the canonical coefficients, the more influence they have on the canonical variates. Only the independent variables used in the linear regression analysis were used in the canonical analysis. These variables were used because of the absence of any multi-multicollinearity problems.

\section{May Frequency}

The canonical analysis for the May frequency data matrix shows that 38 percent of the total variance is shared by the linear composites of the first pair of dependent and independent variables (Table 8). The second and third pair of canonical variables account for 65 percent and 85 percent of the cumulative variation (Table 8). All three canonical coefficient pairs are highly significant at $\mathrm{p}=0.0001$ for the first pair, $\mathrm{p}=0.0001$ for the second pair, and $\mathrm{p}=0.0007$ for the third pair. Again, each canonical variable is independent from the others. In this case, the first three canonical variables are able to reveal the intercorrelations between the dependent and independent variables and account for 85 percent of the variance on the ground (Table 8). 
Table 8. Results of canonical analysis showing the significance of the first three pair of the canonical variates for May frequency.

Bold indicates statistical significance.

\begin{tabular}{|l|l|l|l|l|l|}
\hline $\begin{array}{l}\text { Canonical } \\
\text { Correlation }\end{array}$ & $\begin{array}{l}\text { Adjusted } \\
\text { Canonical } \\
\text { Correlation }\end{array}$ & $\begin{array}{l}\text { Squared } \\
\text { Canonical } \\
\text { Correlation }\end{array}$ & Eigenvalue & Cumulative & P-value \\
\hline 0.6844 & 0.5976 & 0.4684 & 0.8814 & $\mathbf{0 . 3 8 5}$ & $\mathbf{0 . 0 0 0 1}$ \\
\hline 0.6167 & 0.5440 & 0.3804 & 0.6140 & $\mathbf{0 . 6 5 3 2}$ & $\mathbf{0 . 0 0 0 1}$ \\
\hline 0.5610 & & 0.3147 & 0.4594 & $\mathbf{0 . 8 5 3 9}$ & $\mathbf{0 . 0 0 0 7}$ \\
\hline 0.4176 & 0.3706 & 0.1744 & 0.2113 & 0.9462 & 0.0806 \\
\hline 0.2610 & 0.1515 & 0.0681 & 0.0732 & 0.9782 & 0.4023 \\
\hline 0.2059 & & 0.0424 & 0.0443 & 0.9975 & 0.4272 \\
\hline 0.0752 & & 0.0056 & 0.0057 & 1.0 & 0.5044 \\
\hline
\end{tabular}

The canonical correlation coefficients for the May frequency data matrix based on the groupings of the dependent and independent variables are described as follows:

The linear combination equations for the first pair of canonical variable using the coefficients for the dependent and independent variables are:

$$
\begin{aligned}
\text { Field } 1 & =\left(-.06^{*} \text { AGSP }\right)+\left(.13^{*} \text { ARTR }\right)+\left(-.39^{*} \text { BRTE }\right)+\left(.16^{*} \text { GCLITTER }\right)+ \\
& (6 * \text { GCBARE })+\left(.35^{*} \text { TOTPER }\right)+(.60 * \text { ORGMATT }) \\
\text { Index } 1 & =\left(.81^{*} \text { TM } 2\right)+\left(1.26^{*} \text { NDVI }\right)+\left(-.46^{*} \text { PVI }\right)+\left(-.18^{*} \text { WDVI }\right)+\left(.44^{*} \text { SAVI }\right) \\
& +\left(.29^{*} \text { NOR }\right)+\left(.39^{*} \text { SOU }\right)
\end{aligned}
$$

For the first field, organic matter was the only influential coefficient and for the first index TM2 and NDVI had the most influence (Table 9).

The coefficients for the second pair of dependent variables are:

$$
\begin{aligned}
\text { Field } 2 & =\left(-.69^{*} \text { AGSP }\right)+\left(-.58^{*} \text { ARTR } 2\right)+\left(.04^{*} \text { BRTE }\right)+\left(1.13^{*} \text { GCLITTER }\right)+ \\
& \left(1.3^{*} \text { GCBARE }\right)+\left(.36^{*} \text { TOTPER }\right)+\left(.23^{*} \text { ORGMATT }\right) \\
\text { Index } 2= & \left(1.1^{*} \text { TM } 2\right)+\left(-.41^{*} \text { NDVI }\right)+\left(1.2^{*} \text { PVI }\right)+\left(.87^{*} \text { WDVI }\right)+\left(-.58^{*} \text { SAVI }\right)+ \\
& \left(.57^{*} \text { NOR }\right)+\left(-.78^{*} \text { SOU }\right)
\end{aligned}
$$

In the second field, AGSP, ARTR2, GCLITTER, and GCBARE are identified as having influential canonical coefficients. The influential coefficients for index 2 are TM2, PVI, WDVI, SAVI, NOR, and SOU (Table 9). 
The coefficients for the third pair are:

$$
\begin{aligned}
\text { Field } 3 & =(.68 * \text { AGSP })+(-.58 * \text { ARTR })+(.56 * \text { BRTE })+(.36 * \text { GCLITTER })+ \\
& \left(-18^{*} \text { GCBARE }\right)+(-.76 * \text { TOTPER })+\left(.41^{*} \text { ORGMATT }\right) \\
\text { Index } 3 & =(-.80 * \text { TM } 2)+(.03 * \text { NDVI })+(.40 * \text { PVI })+(-1.58 * \text { WDVI })+(-.33 * \text { SAVI }) \\
+ & (.53 * \text { NOR })+(2.15 * \text { SOU })
\end{aligned}
$$

For the third pair, the influential coefficients for field 3 are AGSP, ARTR, BRTE, and TOTPER. For index 3, the coefficients are TM2, WDVI, NOR, and SOU. Data in Table 9 show the coefficients used in the canonical regression equations shown above.

Table 9. The canonical coefficients of the first, second, and third pair of linear composites of the dependent and independent variables for May frequency.

Bold indicates statistical significance.

\begin{tabular}{|l|c|c|c|}
\hline Variables & $\begin{array}{l}\text { Coefficients of } \\
\text { the first pair }\end{array}$ & $\begin{array}{l}\text { Coefficients of } \\
\text { the second pair }\end{array}$ & $\begin{array}{l}\text { Coefficients of } \\
\text { the third pair }\end{array}$ \\
\hline AGSP & -0.0688 & $-\mathbf{0 . 6 9 5 6}$ & $\mathbf{0 . 6 8 4 4}$ \\
\hline ARTR2 & 0.1319 & $-\mathbf{0 . 5 8 0 6}$ & $-\mathbf{0 . 5 8 5}$ \\
\hline BRTE & -0.3953 & 0.0403 & $\mathbf{0 . 5 6 6 5}$ \\
\hline GCLITTER & 0.1622 & $\mathbf{1 . 1 3 1 3}$ & 0.3624 \\
\hline GCBARE & 0.0604 & $\mathbf{1 . 3 0 8 1}$ & 0.1807 \\
\hline TOTPER & 0.3586 & 0.3687 & $\mathbf{0 . 7 6 5 7}$ \\
\hline ORGMATT & $\mathbf{0 . 6 0 2}$ & 0.2373 & 0.4115 \\
\hline TM2 & $\mathbf{0 . 8 1 1 9}$ & $\mathbf{- 1 . 1 0 9 5}$ & $-\mathbf{0 . 8 0 1 9}$ \\
\hline NDVI & $\mathbf{1 . 2 6 8 2}$ & -0.4154 & 0.039 \\
\hline PVI & -0.4697 & $\mathbf{1 . 2 3 2 9}$ & 0.4093 \\
\hline WDVI & -0.1847 & $\mathbf{0 . 8 7 9 7}$ & $\mathbf{- 1 . 5 8 1 1}$ \\
\hline SAVI & 0.4457 & $\mathbf{- 0 . 5 8 4 3}$ & -0.3348 \\
\hline NOR & 0.2946 & $\mathbf{0 . 5 7 1 2}$ & $\mathbf{0 . 5 3 6}$ \\
\hline SOU & 0.3998 & $\mathbf{- 0 . 7 8 6 1}$ & $\mathbf{2 . 1 5 7 1}$ \\
\hline
\end{tabular}

There is a direct linear relationship between the amount of organic matter and NDVI. Higher NDVI values indicate higher organic matter content (Table 9). Another example of this linear relationship is illustrated in Figure 6, where the amount of organic matter that a releve contains will determine its position on the graph.

For field 2 vs. index 2 , there is a linear trend in the location of the releves based on the amount of litter, bare ground, AGSP, and ARTR. The frequency of AGSP or ARTR located on a releve has a positive or negative relationship with the highlighted independent variables in Table 9. For example, with a decrease in AGSP frequency, the TM2 value will also decrease. 
For field 3 vs. index 3 the linear trend is defined by the amount of AGSP, BRTE, ARTR, and total percent cover. Here again, the highlighted dependent variables will have a positive or negative relationship with the highlighted independent variables. For example, the more AGSP frequency on a releve, the smaller the TM2 value will be. These relationships were all highly significant, but the nature of the canonical analysis tends to preclude biological explanation.

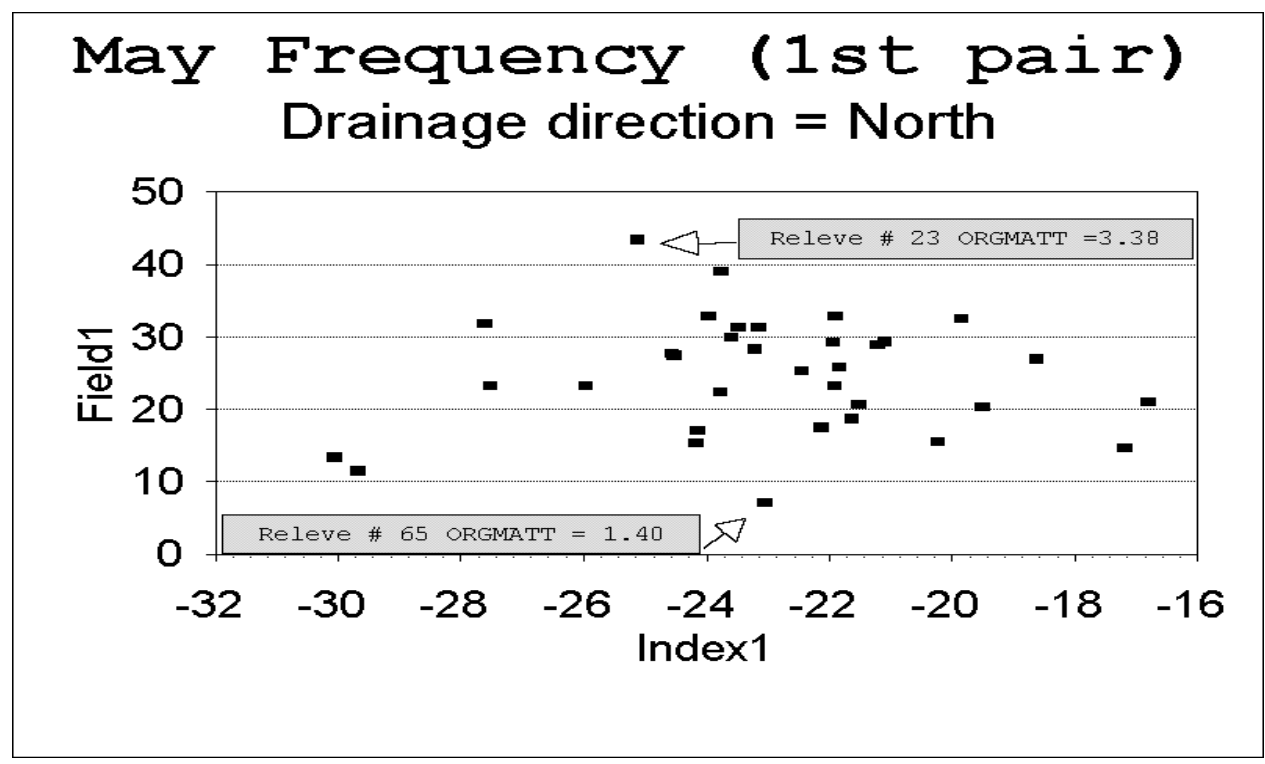

Figure 6. The position of releves according to ORGMATT content in the surface soil for field 1 vs index 1.

The releves pointed to are examples of specific releves and their organic matter content.

\section{May Cover}

The canonical analysis for the May cover data matrix shows that 45 percent of the total variance is shared by the linear composites of the first pair of dependent and independent variables. The first and second pair account for 74 percent of the cumulative variation. Both canonical coefficient pairs are significant at $p=0.0002$ for the first pair and $p=0.0408$ for the second pair. In this case, the first two canonical variables are able to reveal the intercorrelations that account for 74 percent of the variance on the ground (Table 10). 
Table 10. Results of canonical analysis showing the significance of the first and second pair of the canonical variates for May cover.

Bold indicates statistical significance.

\begin{tabular}{|l|l|l|l|l|l|}
\hline $\begin{array}{l}\text { Canonical } \\
\text { Correlation }\end{array}$ & $\begin{array}{l}\text { Adjusted } \\
\text { Canonical } \\
\text { Correlation }\end{array}$ & $\begin{array}{l}\text { Squared } \\
\text { Canonical } \\
\text { Correlation }\end{array}$ & Eigenvalue & Cumulative & P-value \\
\hline 0.6230 & 0.5339 & 0.3882 & 0.6346 & $\mathbf{0 . 4 4 6}$ & $\mathbf{0 . 0 0 0 2}$ \\
\hline 0.5219 & 0.4403 & 0.2724 & 0.3744 & $\mathbf{0 . 7 4 1 0}$ & $\mathbf{0 . 0 4 0 8}$ \\
\hline 0.4158 & 0.3447 & 0.1729 & 0.2091 & 0.8946 & 0.3827 \\
\hline 0.2634 & & 0.0693 & 0.0746 & 0.9494 & 0.7971 \\
\hline 0.2345 & & 0.0550 & 0.0582 & 0.9922 & 0.797 \\
\hline 0.1016 & & 0.0103 & 0.0104 & 0.9998 & 0.9308 \\
\hline 0.0158 & & 0.0002 & 0.0002 & 1.0000 & 0.8872 \\
\hline
\end{tabular}

The canonical correlation coefficients for the May cover data matrix based on the groupings of the dependent and independent variables are described as follows:

The linear combination equations for the first pair of canonical variable using the coefficients for the dependent and independent variables are:

$$
\begin{gathered}
\text { Field } 1=(-0.33 * \text { AGSP })+(-0.61 * \text { ARTR })+(0.09 * \text { BRTE })+(1.23 * \text { GCLITTER })+ \\
\left(1.11^{*} \text { GCBARE }\right)+(.51 * \text { TOTPER })(0.34 * \text { ORGMATT }) \\
\text { Index } 1=(0.009 * \text { TM } 2)+(1.77 * \text { PVI })+(1.36 * \text { GVI })+(-1.95 * \text { TAI })+ \\
(-0.03 * \text { TSAVI })+(0.51 * \text { NOR })+(0.17 * \text { SOU })
\end{gathered}
$$

For the first field ARTR, GCLITTER, GCBARE, and TOTPER were the most influential and for the first index PVI, GVI, TAI, and NOR were the most influence canonical coefficients (Table 11).

The linear combination equations for the second pair of canonical variables using the coefficients for the dependent and independent variables are:

$$
\begin{gathered}
\text { Field } 2=(.61 * \text { AGSP })+(0.39 * \text { ARTR })+(0.10 * \text { BRTE })+(-0.37 * \text { GCLITTER })+ \\
(-.65 * \text { GCBARE })+(-0.09 * \text { TOTPER })+(0.38 * \text { ORGMATT }) \\
\text { Index } 2=(0.3 .46 * \text { TM } 1)+(0.04 * \text { PVI })+(3.54 * \text { GVI })+(-4.68 * \text { TAI })+ \\
(-0.03 * \text { TSAVI })+(0.14 * \text { NOR })+(0.41 * \text { SOU })
\end{gathered}
$$

The influential coefficients for the second pair are AGSP and GCBARE for field 2 and TM1, GVI, and TAI for index 2 (Table 11).

There is a linear trend in the location of the releves based on the amount of litter, bare ground, total percent cover, and ARTR2 for field 1 versus index 1 . The percent cover of ARTR2 or the amount of bare ground located on a releve has a 
positive or negative relationship with the highlighted independent variables in Table 11. For example, with a decrease in ARTR2, the PVI value will increase.

For field 2 vs. index 2, the linear trend is defined by the amount of AGSP and bare ground. The percent cover of AGSP or the amount of bare ground located on a releve has a positive or negative relationship with the highlighted independent variables in Table 11. For example, with an increase in AGSP frequency, the TM1 value will also increase. Another example of this linear relationship is illustrated in Figure 7, where the amount of bare ground that a releve contains will determine its position on the graph.

Table 11. The canonical coefficients of the first and second pair of linear composites of the dependent and independent variables for May cover. Bold indicates statistical significance.

\begin{tabular}{|l|c|c|}
\hline Variables & $\begin{array}{l}\text { Coefficients of } \\
\text { the first pair }\end{array}$ & $\begin{array}{l}\text { Coefficients of } \\
\text { the second pair }\end{array}$ \\
\hline AGSP & -0.3396 & $\mathbf{0 . 6 1 2 2}$ \\
\hline ARTR2 & $\mathbf{- 0 . 6 1 2 4}$ & 0.3918 \\
\hline BRTE & 0.0992 & 0.1053 \\
\hline GCLITTER & $\mathbf{1 . 2 3 7}$ & -0.3744 \\
\hline GCBARE & $\mathbf{1 . 1 1 2 2}$ & $\mathbf{- 0 . 6 5 3}$ \\
\hline TOTPER & $\mathbf{0 . 5 3 0 2}$ & -0.0969 \\
\hline ORGMATT & 0.3469 & 0.3899 \\
\hline TM1 & 0.0092 & $\mathbf{3 . 4 6 0 9}$ \\
\hline PVI & $\mathbf{1 . 7 7 9 9}$ & 0.0484 \\
\hline GVI & $\mathbf{1 . 3 6 7 9}$ & $\mathbf{3 . 5 4 4 1}$ \\
\hline TAI & $\mathbf{- 1 . 9 5 3 5}$ & -4.6854 \\
\hline TSAVI & -0.0343 & -0.0348 \\
\hline NOR & $\mathbf{0 . 5 1 8 5}$ & 0.1494 \\
\hline SOU & 0.1766 & 0.41 \\
\hline
\end{tabular}




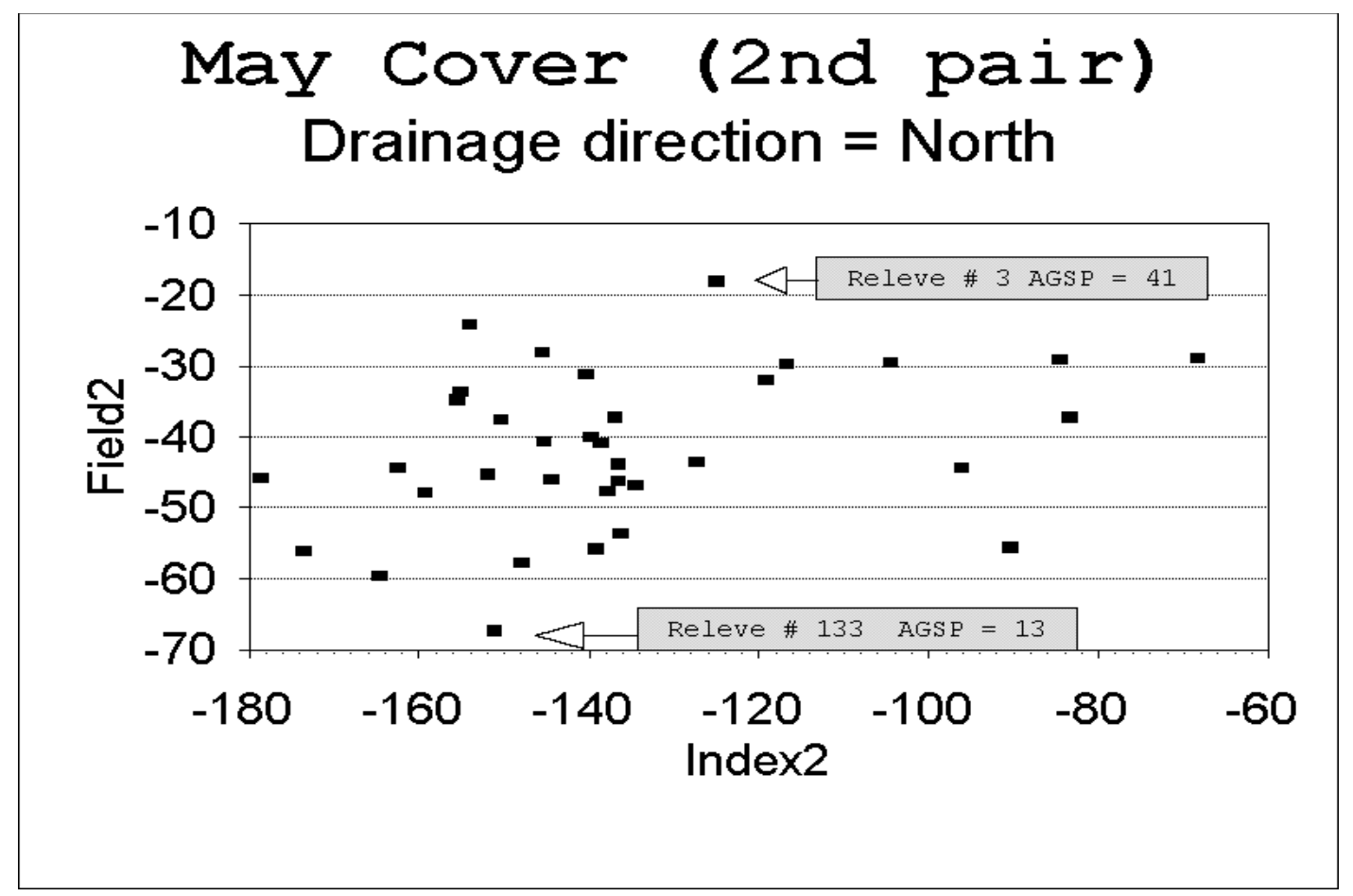

Figure 7. The position of releves according to the cover of AGSP for field 2 vs. index 2. The releves pointed to are examples of specific releves and their cover values.

\section{August Frequency}

The canonical analysis for the August frequency data matrix shows that 52 percent of the total variance is shared by the linear composites of the first pair of dependent and independent variables. The first and second pair account for 74 percent of the cumulative variation. Here, only the first pair off coefficients are significant $(p=0.0002)$ while the second pair is insignificant $(p=0.1206)$. In this case the second pair is used because a p-value of 0.1206 is reasonably significant in biological terms and its influence adds to the canonical regression. These first two canonical variables are able to reveal the intercorrelations that account for 74 percent of the variance on the ground (Table 12). 
Table 12. Results of canonical analysis showing the significance of the first pair of the canonical variates for August frequency.

Bold indicates statistical significance.

\begin{tabular}{|l|l|l|l|l|l|}
\hline $\begin{array}{l}\text { Canonical } \\
\text { Correlation }\end{array}$ & $\begin{array}{l}\text { Adjusted } \\
\text { Canonical } \\
\text { Correlation }\end{array}$ & $\begin{array}{l}\text { Squared } \\
\text { Canonical } \\
\text { Correlation }\end{array}$ & Eigenvalue & Cumulative & P-value \\
\hline 0.6970 & 0.6276 & 0.4859 & 0.9453 & $\mathbf{0 . 5 2 1 6}$ & $\mathbf{0 . 0 0 0 2}$ \\
\hline 0.5395 & 0.4346 & 0.2911 & 0.4107 & $\mathbf{0 . 7 4 8 2}$ & $\mathbf{0 . 1 2 0 6}$ \\
\hline 0.4088 & 0.2583 & 0.1671 & 0.2007 & 0.8590 & 0.5625 \\
\hline 0.3255 & & 0.1059 & 0.1185 & 0.9244 & 0.7576 \\
\hline 0.3039 & & 0.0923 & 0.1018 & 0.9805 & 0.8057 \\
\hline 0.1459 & & 0.0212 & 0.0218 & 0.9925 & 0.9511 \\
\hline 0.1157 & & 0.0133 & 0.0136 & 1.0000 & 0.7904 \\
\hline
\end{tabular}

The canonical correlation coefficients for the August Frequency data matrix based on the groupings of the dependent and independent variables are described as follow:

The linear combination equations for the first pair of canonical variable using the coefficients for the dependent and independent variables are:

$$
\text { Field } \begin{aligned}
1 & =(0.02 * \text { AGSP })+(0.23 * \text { ARTR })+(-0.21 * \text { BRTE })+ \\
& \left(-0.008^{*} \text { GCLITTER }\right)+(-0.22 * \text { GCBARE })+(0.31 * \text { TOTPER })+ \\
& (0.56 * \text { ORGMATT })
\end{aligned}
$$

$$
\begin{aligned}
\text { Index } 1 & =(-0.11 * \mathrm{TM} 1)+(0.19 * \mathrm{NDVI})+(-0.02 * \mathrm{YVI})+(0.03 * \mathrm{NVI})+ \\
& (0.09 * \mathrm{TSAVI})+(0.43 * \mathrm{WDVI})+(.91 * \mathrm{SAVI})+(0.36 * \mathrm{NOR})+ \\
& (0.17 * \mathrm{SOU})
\end{aligned}
$$

For the first field, organic matter was the only influential coefficient, and for the first index, SAVI had the most influence (Table 13).

The linear combination equations for the second pair of canonical variable using the coefficients for the dependent and independent variables are:

$$
\text { Field } \begin{aligned}
2 & =(0.19 * \text { AGSP })+(-0.85 * \text { ARTR })+(0.37 * \text { BRTE })+ \\
& (0.97 * \text { GCLITTER })+(1.03 * \text { GCBARE })+\left(0.22^{*} \text { TOTPER }\right)+ \\
& (0.33 * \text { ORGMATT })
\end{aligned}
$$

Index $2=(-0.85 * \mathrm{TM} 1)+\left(-0.53^{*} \mathrm{NDVI}\right)+\left(0.33^{*} \mathrm{YVI}\right)+\left(0.15^{*} \mathrm{NVI}\right)+$ $(-0.28 * \mathrm{TSAVI})+(1.04 * \mathrm{WDVI})+(0.003 * \mathrm{SAVI})+(0.98 * \mathrm{NOR})+$ $(0.75 * \mathrm{SOU})$ 
In the second field, ARTR, GCLITTER, and GCBARE are identified as having influential canonical coefficients. The influential coefficients for index 2 are TM1, NDVI, WDVI, NOR, and SOU (Table 13).

Table 13. The canonical coefficients of the first and second pair of linear composites of the dependent and independent variables for August frequency.

Bold indicates statistical significance.

\begin{tabular}{|l|c|c|}
\hline Variables & $\begin{array}{l}\text { Coefficients of } \\
\text { the first pair }\end{array}$ & $\begin{array}{l}\text { Coefficients of } \\
\text { the second pair }\end{array}$ \\
\hline AGSP & 0.0251 & 0.1968 \\
\hline ARTR2 & 0.2355 & -0.8539 \\
\hline BRTE & -0.2128 & 0.3798 \\
\hline TOTPER & 0.3119 & 0.2255 \\
\hline GCBARE & -0.2200 & $\mathbf{1 . 0 3 1 1}$ \\
\hline GCLITTER & -0.0081 & $\mathbf{0 . 9 7 4 3}$ \\
\hline ORGMATT & $\mathbf{0 . 5 2 6 5}$ & 0.3379 \\
\hline TM1 & -0.1111 & $-\mathbf{0 . 8 5 0 5}$ \\
\hline NDVI & 0.1915 & $\mathbf{- 0 . 5 3 2 3}$ \\
\hline YVI & -0.0215 & 0.3347 \\
\hline NVI & 0.0361 & 0.1564 \\
\hline TSAVI & 0.0932 & -0.2887 \\
\hline WDVI & 0.4374 & $\mathbf{1 . 0 4 1 5}$ \\
\hline SAVI & $\mathbf{0 . 9 1 2 3}$ & 0.0030 \\
\hline NOR & 0.3614 & $\mathbf{0 . 9 8 4 9}$ \\
\hline SOU & 0.1784 & $\mathbf{0 . 7 5 8 8}$ \\
\hline
\end{tabular}

For field 1 vs. index 1 , there is a linear trend in the location of the releves based only on the amount of organic matter. The amount of organic matter located on a releve has a positive or negative relationship with the highlighted independent variable SAVI (Table 13). In this case, with an increase in organic matter, the SAVI value will also increase. Another example of this linear relationship is illustrated in Figure 8, where the amount of organic matter that a releve contains will determine its position on the graph.

For field 2 vs. index 2 , the linear trend is defined by the amount of litter, bare ground, and ARTR. The percent cover of ARTR2 or the amount of bare ground located on a releve has a positive or negative relationship with the highlighted independent variables in Table 13. For example, with an increase in AGSP frequency, the TM1 value will decrease. 


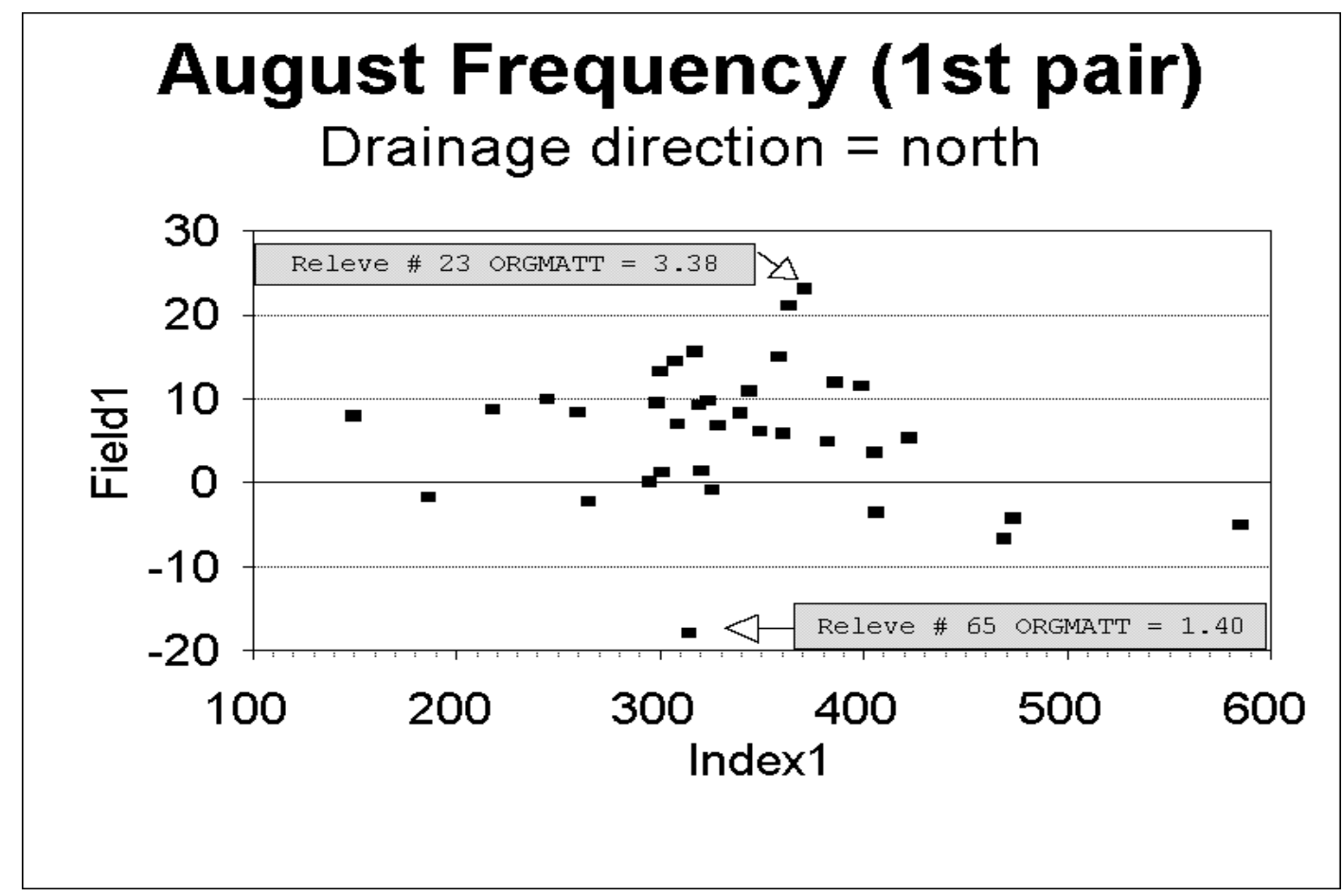

Figure 8. Releves according to ORGMATT in the surface soil for field 1 vs. index 1. The releves identified are examples of specific releves and their organic content.

\section{August Cover}

The canonical analysis for the August cover data matrix shows that 50 percent of the total variance is shared by the linear composites of the first pair of dependent and independent variables. Here, only the first pair off coefficients are significant at $p=0.0018$. In this case, only the first canonical variable is able to reveal the intercorrelations that account for 50 percent of the variance on the ground (Table 14).

Table 14. Results of canonical analysis showing the significance of the first pair of the canonical variates for August cover.

Bold indicates statistical significance.

\begin{tabular}{|l|l|l|l|l|l|}
\hline $\begin{array}{l}\text { Canonical } \\
\text { Correlation }\end{array}$ & $\begin{array}{l}\text { Adjusted } \\
\text { Canonical } \\
\text { Correlation }\end{array}$ & $\begin{array}{l}\text { Squared } \\
\text { Canonical } \\
\text { Correlation }\end{array}$ & Eigenvalue & Cumulative & P-value \\
\hline 0.6682 & 0.5873 & 0.4466 & 0.8071 & $\mathbf{0 . 5 0 9 3}$ & $\mathbf{0 . 0 0 1 8}$ \\
\hline 0.5650 & 0.4922 & 0.3192 & 0.4691 & 0.8053 & 0.2609 \\
\hline 0.3666 & 0.2103 & 0.1344 & 0.1553 & 0.9033 & 0.9345 \\
\hline 0.2686 & 0.0942 & 0.0721 & 0.0778 & 0.9524 & 0.9816 \\
\hline 0.2014 & & 0.0405 & 0.0423 & 0.9791 & 0.9815 \\
\hline 0.1592 & & 0.0253 & 0.0260 & 0.9956 & 0.9569 \\
\hline 0.0836 & & 0.0070 & 0.0071 & 1.0000 & 0.9058 \\
\hline
\end{tabular}


The canonical correlation coefficients for the August Cover data matrix based on the groupings of the dependent and independent variables are described as follows:

The linear combination equation for the canonical variable using the coefficients from the dependent and independent variables are:

$$
\begin{gathered}
\text { Field } 1=(0.05 * \text { AGSP })+(-0.01 * \text { ARTR })+(-0.04 * \text { BRTE })+(0.23 * \text { GCLITTER })+ \\
(0.05 * \text { GCBARE })+\left(0.33^{*} \text { TOTPER }\right)+(.66 * \text { ORGMATT }) \\
\text { Index } 1=(-0.26 * \text { TM } 1)+(0.08 * \text { NDVI })+(0.07 * \mathrm{NVI})+(0.009 * \text { TSAVI })+ \\
(.63 * \mathrm{WDVI})+(.86 * \mathrm{SAVI})+(.58 * \mathrm{NOR})+(0.38 * \mathrm{SOU})
\end{gathered}
$$

For the first field, organic matter was the only influential coefficient and for the first index WDVI, SAVI, and NOR had the most influence (Table 15).

For field 1 vs. index 1, there is a linear trend in the location of the releves based only on the amount of organic matter. The amount of organic matter located on a releve has a positive relationship with the highlighted independent variables found in Table 15. For example, with an increase in organic matter, the SAVI value will also increase. Another example of this linear relationship is illustrated in Figure 9, where the amount of organic matter that a releve contains will determine its position on the graph.

Table 15. The canonical coefficients of the first and second pair of linear composites of the dependent and independent variables for August cover.

Bold indicates statistical significance.

\begin{tabular}{|l|c|}
\hline Variables & $\begin{array}{l}\text { Coefficients of the } \\
\text { first pair }\end{array}$ \\
\hline AGSP & 0.051 \\
\hline ARTR2 & -0.0161 \\
\hline BRTE & -0.0463 \\
\hline GCLITTER & 0.2339 \\
\hline GCBARE & 0.0554 \\
\hline TOTPER & 0.3373 \\
\hline ORGMATT & $\mathbf{0 . 6 6 8 6}$ \\
\hline TM1 & -0.2608 \\
\hline NDVI & 0.0882 \\
\hline YVI & 0.0714 \\
\hline NVI & 0.0922 \\
\hline TSAVI & 0.0093 \\
\hline WDVI & $\mathbf{0 . 6 3 1 3}$ \\
\hline SAVI & $\mathbf{0 . 8 6 6 4}$ \\
\hline NOR & $\mathbf{0 . 5 8 2 2}$ \\
\hline SOU & 0.38 \\
\hline
\end{tabular}




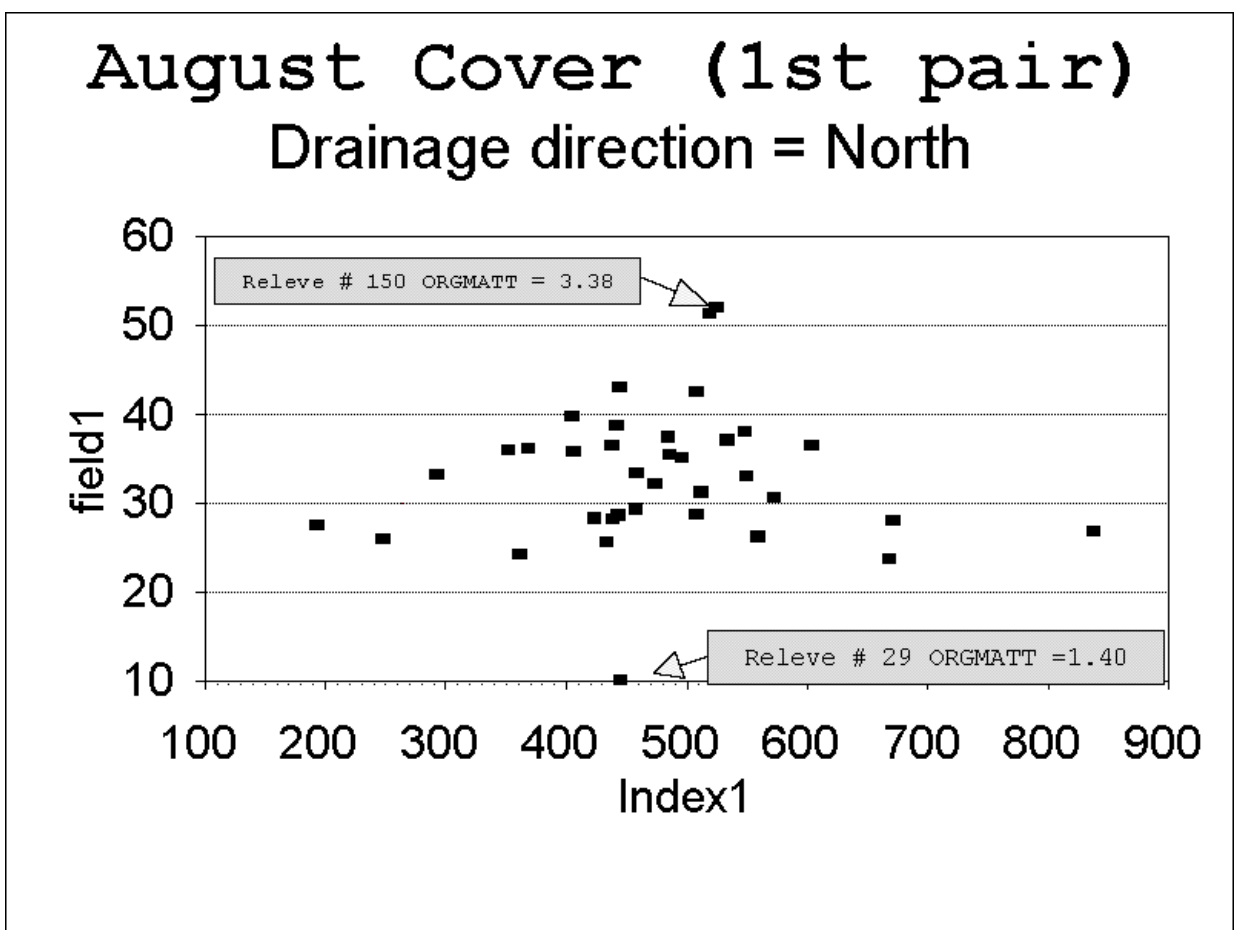

Figure 9. Releve position according to its amount of ORGMATT for field 1 vs. index 1. The releves identified are examples of specific releves and their organic matter content. 


\section{Summary and Conclusions}

Unlike previous work, where combined field observations and remotely sensed imagery provided some predictive capabilities in semiarid ecosystems (Tueller and Yuan 1992, Tueller 1992, Basavaraju 1994, Keller-Hatzell 1992, Senseman 1996), the results of this study were not conclusive. The data sets studied were, in most cases, of high statistical significance and seemed to describe relationships of interest. However, when increased rigor was applied to the analysis using both multiple linear regression and canonical regression models, the data sets that were analyzed turned out to lack the variation required to successfully describe the successional stages within the big sagebrush/grass ecosystems at the Yakima Training Center. Specifically, $\mathrm{H}_{0} 1$ was accepted because the association tables of pertinent LCTA data did not show thresholds indicating specific seral situations and were therefore not able to define successional arrays. These results were subjective and show that most of the anticipated relationships between various species in the successional arrays were not strong. Null hypothesis $\mathrm{H}_{0} 2$ was rejected. There were strong relationships between individual vegetation or soil parameters and TM spectral data. Null hypothesis $\mathrm{H}_{\mathrm{o}} 3$ was accepted. Again, individual bands or vegetation indices based on Landsat TM spectral data were not able to distinguish among seral stages of sagebrush/grasslands with the data set analyzed.

Several factors may have contributed to the inability to statistically identify successional stages within the big sagebrush/grass ecosystems at the Yakima Training Center using remote imagery and LCTA field surveys. The topographic corrections, which were applied to reduce shadowing effects, may have equalized the pixel radiance values so much that variance within the data set from the ARTR/AGSP releves was lost or reduced. Additional studies using more observations on north slopes and using all shrub dominated vegetation types might provide greater among-site variability and thus serve to improve the multiple linear regression models. It may also be that these particular ARTR/AGSP releves lacked the overall variation that were found in earlier studies (Tueller and Yuan 1992, Tueller 1992, Basavaraju 1994, Keller-Hatzel 1992, and Senseman 1996) and tended to reduce the $\mathrm{R}^{2}$ values and thus reduce the predictability. Another factor is that hypotheses testing was conducted using either May or August radiance data from satellite images, while LCTA field measurements of vegetation were collected throughout the summer months. Therefore, the field data in- 
cluded a potentially wide variety of phenological expressions that may have influenced the variance. In controlled experiments, field measurements are only collected in close proximity to image collection dates in order to reduce phenological noise. However, LCTA is an inventory and monitoring program that is subject to time and monetary constraints, and therefore, there will always be an asynchronous relationship between field survey dates, which typically span an entire growing season, and image acquisition dates.

However, some of the scatter diagrams suggest that there are relationships that might be useful for predictive purposes. For example, there is a general consistent relationship among the data sets with respect to organic matter. The amount of organic matter in the surface soil may be important in defining releves in different seral stages within semiarid ecoregions.

The statistical analyses performed in this research warrant further investigation with different data sets. As higher spatial and spectral resolution satellite imagery becomes more readily available to installation resource managers, it is likely that the strength of relationships between field data and imagery will improve. A high percentage of the public land in the United States, including land on Army training and testing installations, is located in sagebrush/grass or similar ecosystems. Improvement of remote sensing techniques for study and monitoring of these ecosystems can be useful for future management strategies, both as an independent source of information, and also as input into other spatial and temporal models that are under development to help predict future training land conditions. There is still potential to develop models that can predict and map successional stages with the use of remote sensing techniques. 


\section{Literature Cited}

Barbour M.G,, J.H. Burk, and W.D. Pitts. 1987. Terrestrial Plant Ecology Second ed. Benjamin/Cummings Publishing Company.

Baret, F., Guyot, G. and Major, D.J., 1989. "TSAVI: A vegetation index which minimizes soil brightness effects on LAI and APAR estimations." In: Quantitative Remote Sensing for the Nineties, Proc. IGARSS '89, Vancouver, Canada, Vol. 3 pp. 1355-1358.

Basavaraju, K. 1994. "The Spectral Characteristics of Eastside Sierra Nevada Chaparral Fire Types.” M.S. Thesis, University of Nevada, Reno.

Civco, D.L. 1989. "Topographic Normalization of Landsat Thematic Mapper Digital Imagery," Photogramm. Eng. Remote Sens., vol 59, no. 9, pp 1303-1309.

Clevers, J.G.P.W., 1989. "The application of a weighted infrared-red vegetation index for estimating Leaf Area Index by correcting for soil moisture.” Remote Sensing of Environment, 29, 25-37.

Clevers, J.G.P.W., 1986. “Application of remote sensing to agricultural field trials.” Thesis Agricultural University Wageningen, 227 pp.

Crippen, R.E. 1987. "The regression intersection method of adjusting image data for band rationing." Int. Jour. Remote. Sens., 8:137 155.

Daubenmire, R. 1970. Steppe Vegetation of Washington. Washington Agricultural Experiment Station Technical Bulletin 62.

Fenneman, M.N. 1931. Physio-Graphy of the Western United States. McGraw-Hill Book Company, Inc., New York and London.

Freund, R.J. and R.C. Littell. 1992. SAS System for Regression. Second Edition.

Heady H.F. and R.D. Child. 1994. Rangeland Ecology and Management, Westview Press, Inc. Boulder, Colorado.

Hair, J.F. Jr., R.E. Anderson, R.L. Tatham, and W.C. Black. 1992. Multivariate data analysis with readings,. pp 193-208, Macmillan, New York.

Huete, A.R. 1988. "A soil adjusted vegetation index (SAVI)," Remote Sens. Environ. 25: 295-309.

Jackson, R.D. 1983. "Spectral indices in n-space," Remote Sens. Environ. 13: 409-421. 
Jackson, R.D., P.N. Slater, and P. Printer. 1983. "Discrimination of growth and water stress in wheat by various vegetation indices through clear and turbid atmospheres," Rem. Sens. of Environ. 13:187 208.

Jensen, John R. 1986. Introductory Digital Image Processing, Prentice Hall, Englewood Cliffs, New Jersey.

Kauth, R.J. and G.S. Thomas. 1976. "The Tasseled Cap -- A graphic description of the spectraltemporal development of agriculture crops as seen by Landsat." Proceedings Symposium Machine Processing of Remotely Sensed Data, LARS, Purdue University, West Lafayette, Indiana, pp 41-51.

Kawata,Y., S. Ueno, and T. Kusaka. 1988. "Radiometric correction for atmospheric and topographic effects on Landsat MSS images.” Int. J. Remote Sensing, vol (no. 4, 729-784).

Keller-Hatzell. 1992. Distinguishing Variability in Western Nevada Pinyon/Juniper Woodlands Using Remotely-Sensed and Ground-Based Data. Thesis University of Nevada at Reno.

Leonard, S.G., R.L. Miles, and P.T. Tueller. 1988. "Vegetation soil relationships on arid and semiarid rangelands," chapter 10 in Tueller, P.T.(ed). Vegetation science applications for rangeland analysis and management.

Manly, B.F. 1986. Multivariate Statistical Methods. pp 114-125, Chapman and Hall.

Mueller-Dombois, D. and H. Ellenberg. 1974. Aims and Methods of Vegetation Ecology. New York: Wiley.

Pearson, G.A. and L.D. Miller. 1972. "Remote mapping of standing crop biomass for estimation of the productivity of the short-grass Prairie," Proc 8th Int. Symposium on Remote Sensing of the Enviorn., Ann Arbor, MI, pp 1357-1381.

Richardson, A.J. and C.L. Wiegland. 1977. "Distinguishing vegetation from soil background information,” Photogramm. Eng. Remote Sens. 43: 1541-1552.

Rouse, J.W., R.H. Hass, J.A. Schell, D.W. Deering, and J.C. Harlan. 1974. Monitoring the vernal advancement of retrogradation of natural vegetation. NASA/GSFC, Type III, Final Report, Greenbelt, MD.

SAS Institute Inc. 1988. SAS/STAT Users Guide, Release 6.03, SAS Institute, Cary, NC.

Senseman, G.M., S.A. Tweddale, A.B. Anderson, and C.F. Bagley. 1996. Correlation of Land Condition Trend Analysis (LCTA) Rangeland Cover Measures to Satellite-ImageryDerived Vegetation Indices, USACERL Technical Report 97/07, ADA318517, October 1996.

Tazik, D.J., S.D. Warren, V.E. Diersing, R.B. Shaw, R.J. Brozka, C.F. Bailey, and W.R. Whitworth. 1992. U.S. Army Land Condition-Trend Analysis (LCTA) Plot Inventory Field Methods. USACERL Technical Report N-92/03, ADA247931, February 1992. 
Tueller, P.T. 1973. "Secondary succession, disclimax, and range condition standards in desert shrub vegetation," Arid Shrublands-Proceedings of the Third Workshop of the United States/Australia Rangelands Panel, Tucson, Arizona, pp 56-65.

Tueller, P.T. 1987. "Remote sensing science applications in arid environments." Rem. Sens. of Environ. 23:143 145.

Tueller, P.T. 1989. "Remote sensing technology for rangeland management applications.” Jour. of Remote Sens. 42(6):442-453.

Tueller, P.T. 1992. "Great basin annual vegetation patterns assessed by remote sensing." Paper presented at the symposium on Ecology, Management, and Restoration of Intermountain Annual Rangelands, Boise, Idaho, pp 145-150.

Tueller, P.T. and K.A. Platou. 1991. "A plant succession gradient in big sagebrush/grass ecosystem.” Vegetation 94: 5768.

Tueller, P.T. and A. C. Yuan. 1992. "Feature extraction from LANDSAT TM pixels: A preliminary example from shrub dominated rangelands." Proceedings of the American Society of Photogrammetry and Remote Sensing annual meeting Washington, D.C. Volume 4. Remote Sensing and Data Acquisition, pp 343-354.

Ustin, S.L., B.N. Rock, and R.A. Woodward. 1986. "Use of remote sensing techniques in the analysis of semi-arid shrub communities.” White Mountains Research Station UCLA, in press.

Warg, S.A. 1983. "Life History and Economic Studies on Bromus tectorum." Unpublished M.S Thesis, University of Montana, Missoula.

Young, J A. 1992. "History and use of semiarid plant communities-changes in vegetation." Proceedings-Ecology and Management of Annual Rangelands. Sept, 1994, pp 5:8. 


\section{Appendix: Scatter Plots}

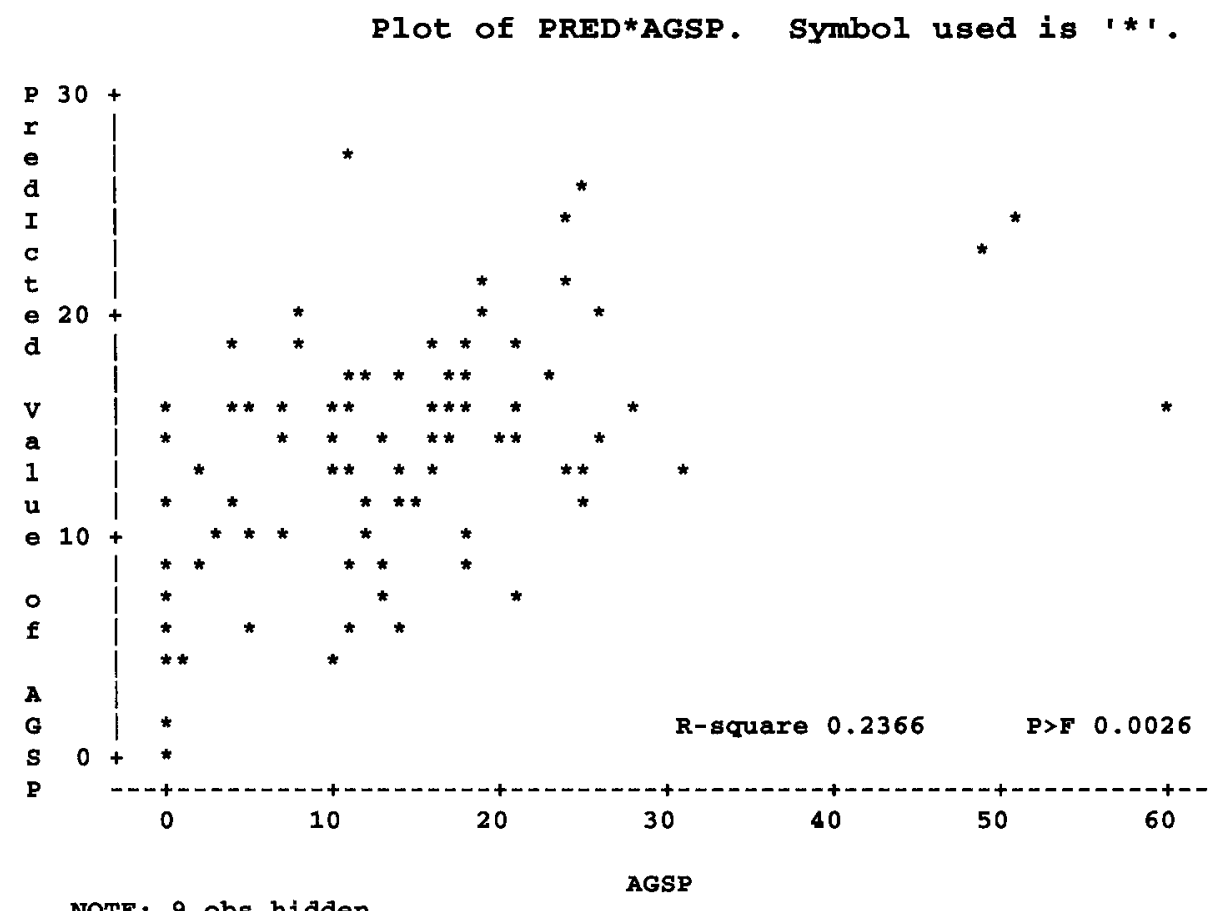

NOTE: 9 obs hidden.

Figure A-1. Scatter plot of actual versus predicted AGSP values from the May frequency data matrix. 
Plot of PRED*ARTR2, Symbol used is * *.

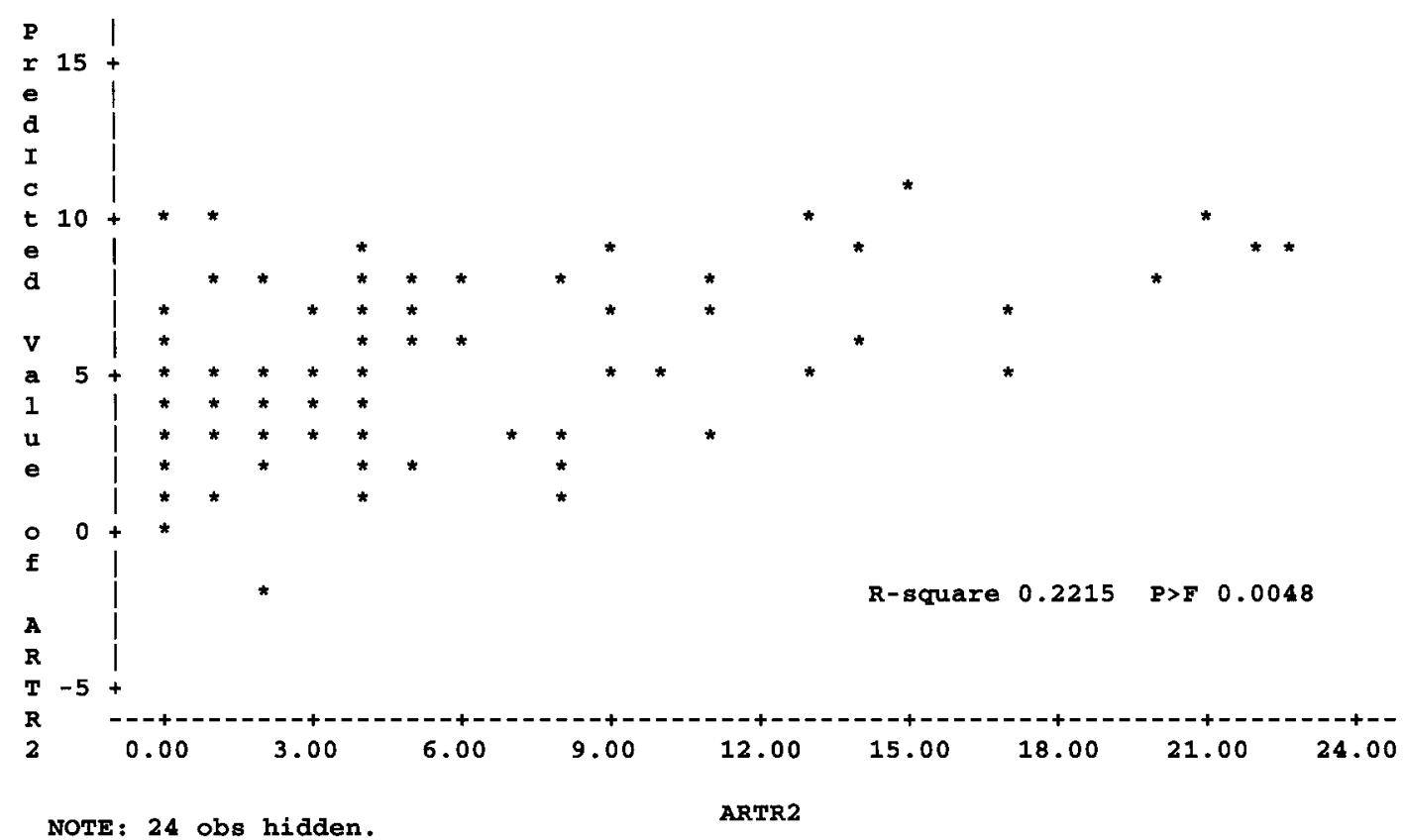

Figure A-2. Scatter plot of actual versus predicted ARTR values from the May frequency data matrix.

Plot of PRED*BRTE. Symbol used is $1 * 1$.

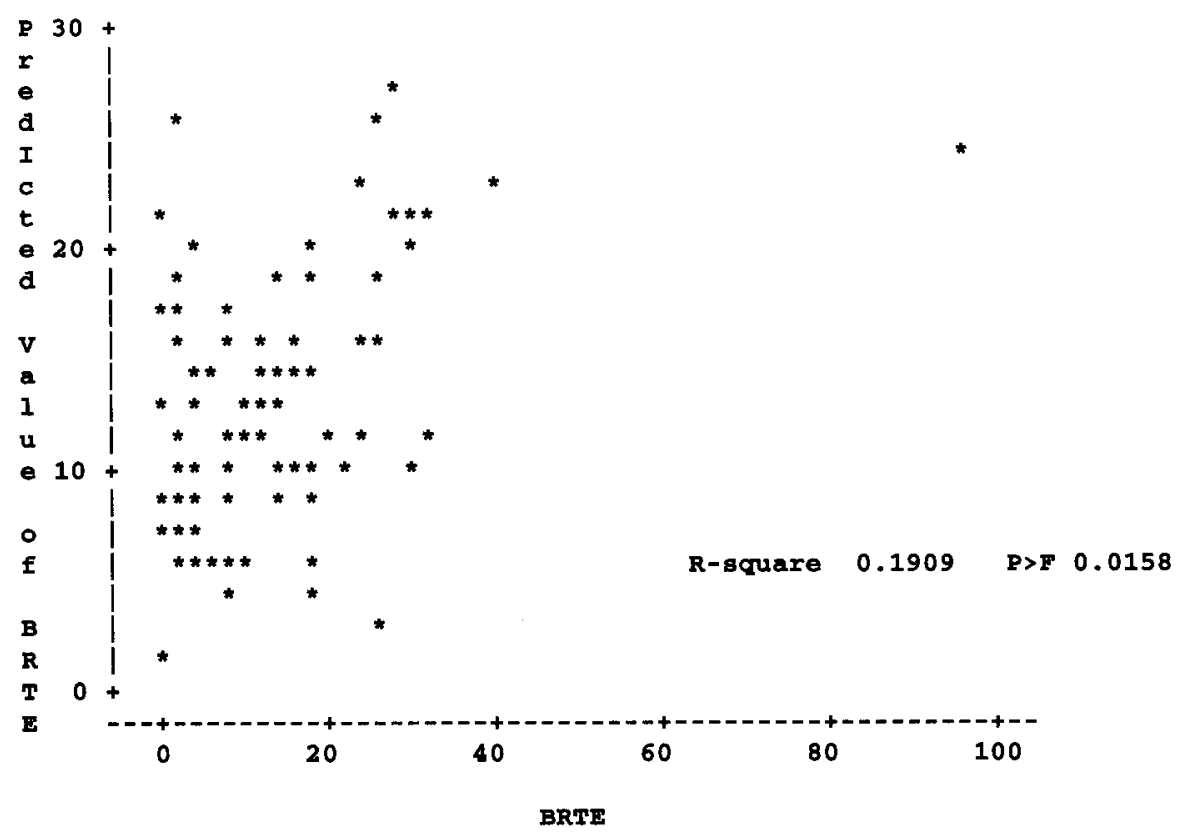

NOTE: 16 Obs hidden.

Figure A-3. Scatter plot of actual versus predicted BRTE values from the May frequency data matrix. 
Plot of PRED*TOTPER. SYmbol used is ' ' '.

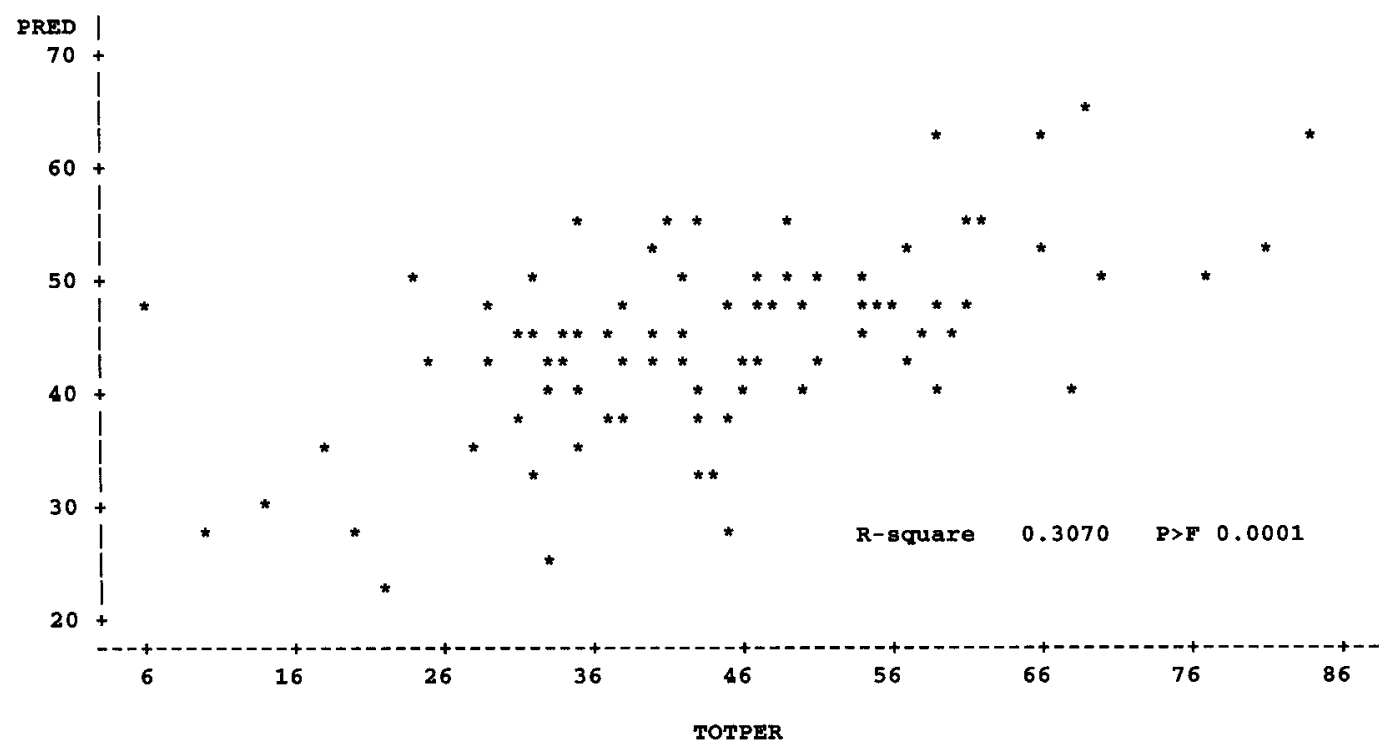

NoTe: 7 obs hidden.

Figure A-4. Scatter plot of actual versus predicted TOTPER values from the May frequency data matrix.

Plot of PRED*GCBARE. Symbol used is '*'

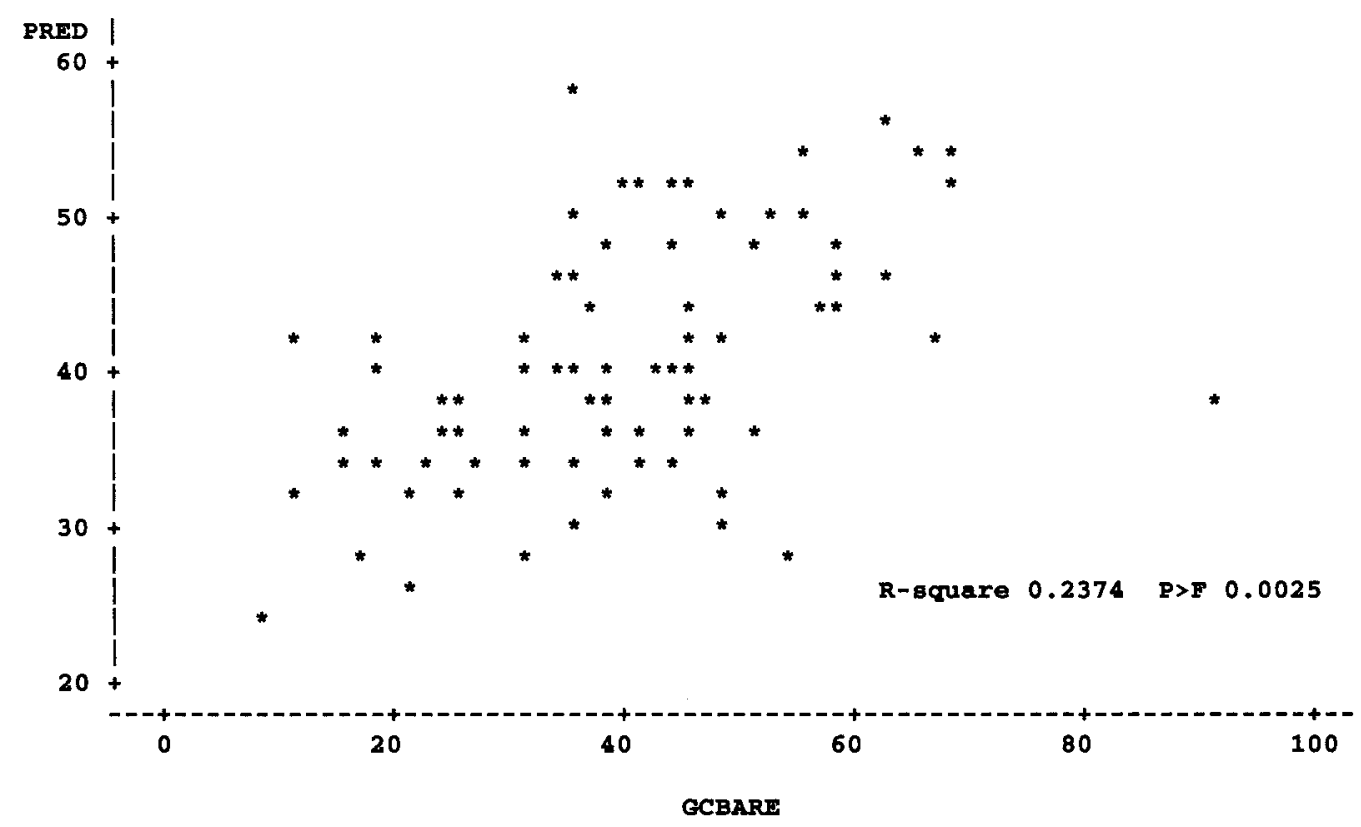

NOTE: 12 obs hidden.

Figure A-5. Scatter plot of actual versus predicted GCBARE values from the May frequency data matrix. 
Plot of PRED*GCLITTER. Symbol used is '*'.

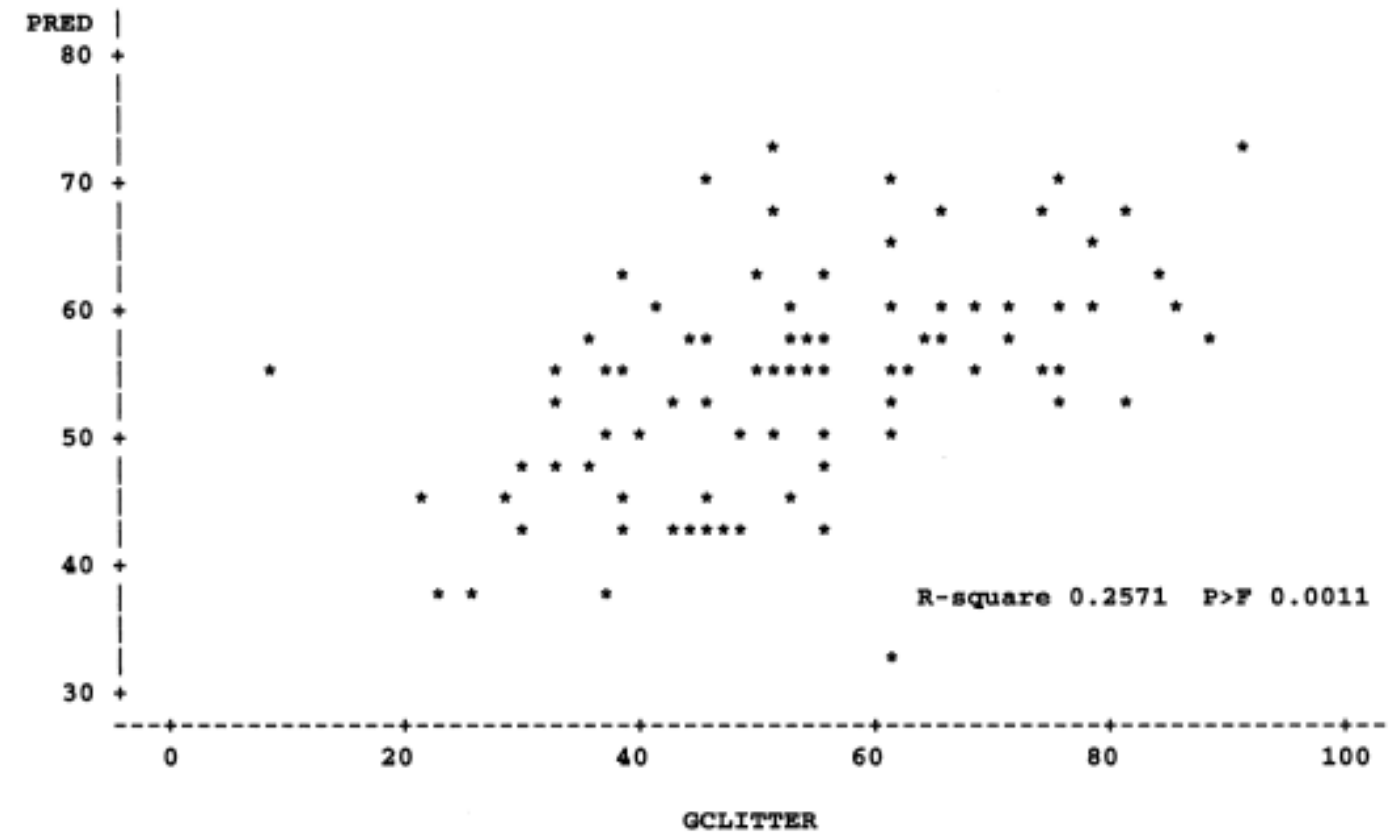

NOTE: 6 obs hidden.

Figure A-6. Scatter plot of actual versus predicted GCLITTER values from the May frequency data matrix.

Plot of PRED*ORGMATT. Symbol used is ' *'.

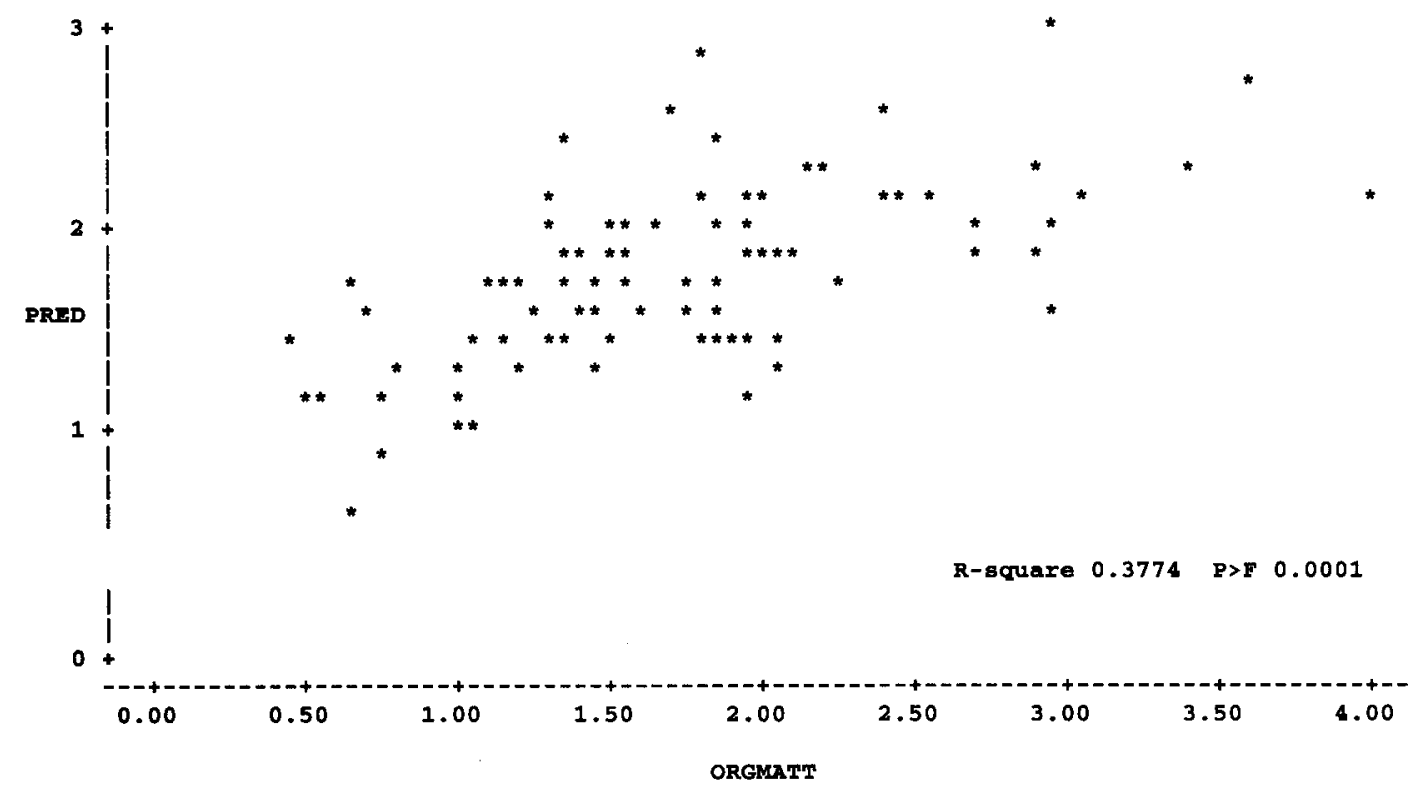

NOTE: 6 obs hidden.

Figure A-7. Scatter plot of actual versus predicted ORGMATT values from the May frequency data matrix. 
Plot of PRED*AGSP. Symbol used is ' * '.

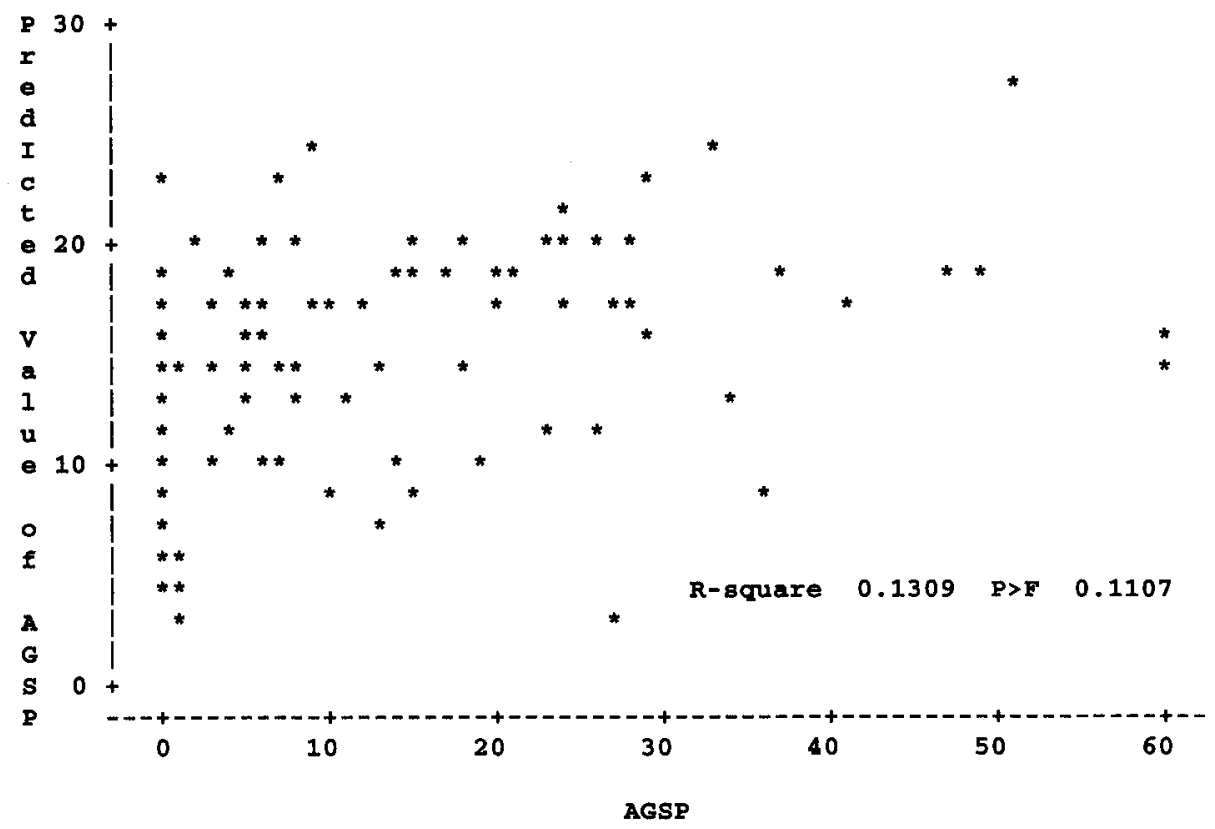

NOTE: 10 obs hidden.

Figure A-8. Scatter plot of actual versus predicted AGSP values from the May cover data matrix.

R1ot of PRED*ARTR2. Symbol used is '*'.

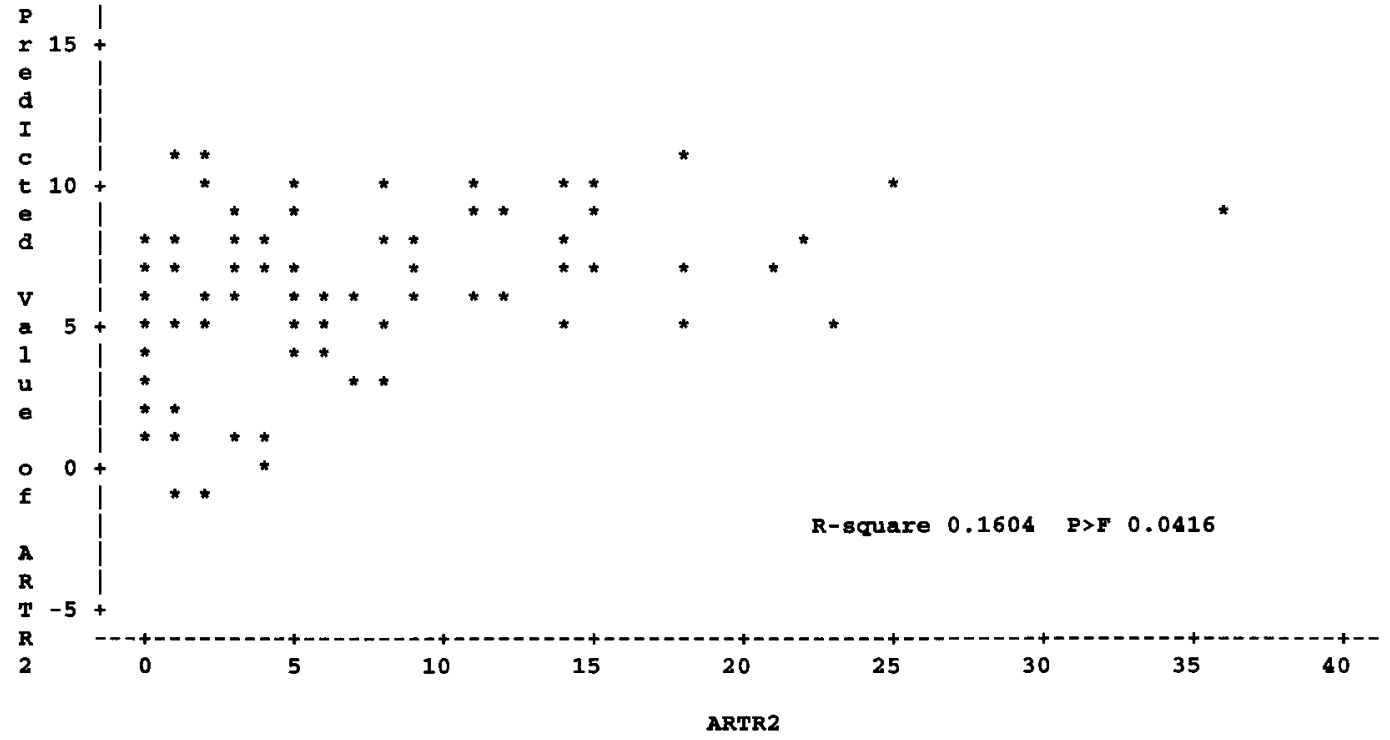

NOTE: 22 obs hidden.

Figure A-9. Scatter plot of actual versus predicted ARTR values from the May cover data matrix. 
Plot of PRED*BRTE. Symbol used is '*'.

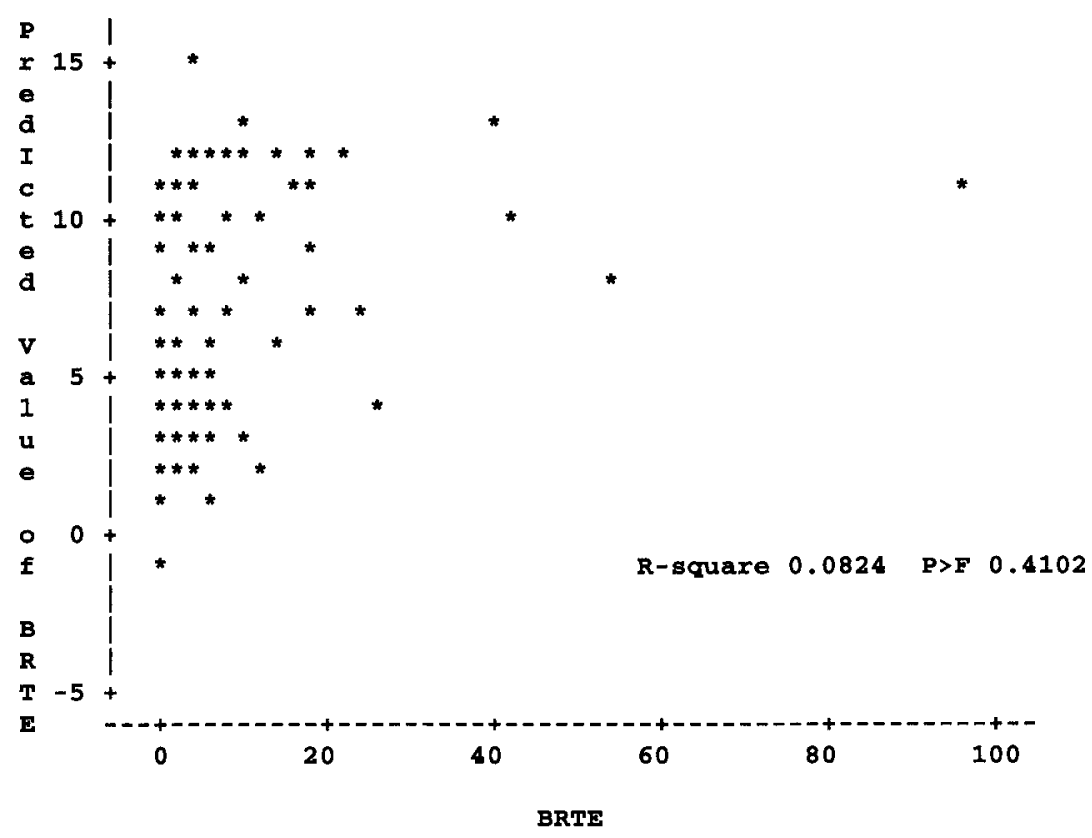

NOTE: 29 obs hidden.

Figure A-10. Scatter plot of actual versus predicted BRTE values from the May cover data matrix.

Plot of PRED*TOTPER. Symbol used is $' *$ '.

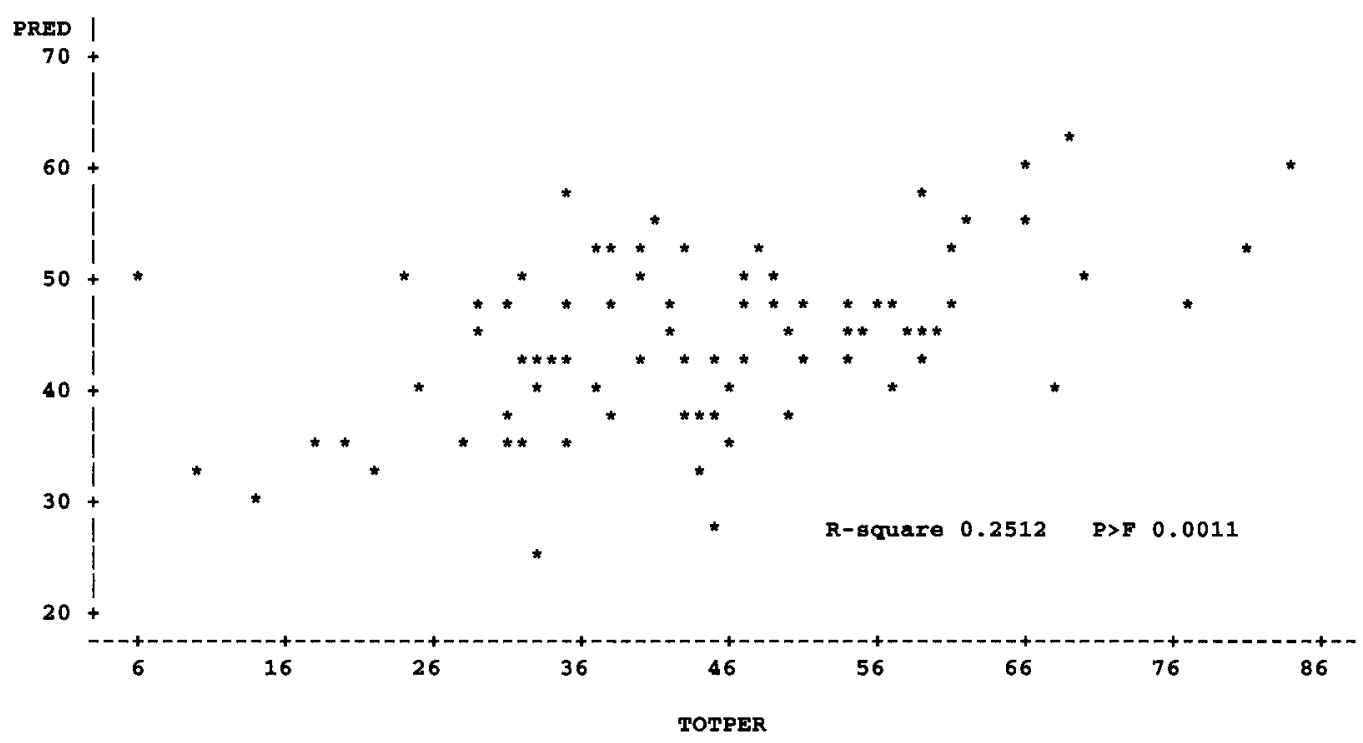

NOTE : 10 obs hidden.

Figure A-11. Scatter plot of actual versus predicted TOTPER values from the May cover data matrix. 
Plot of PRED*GCBARE. Symbol used is ' *'.

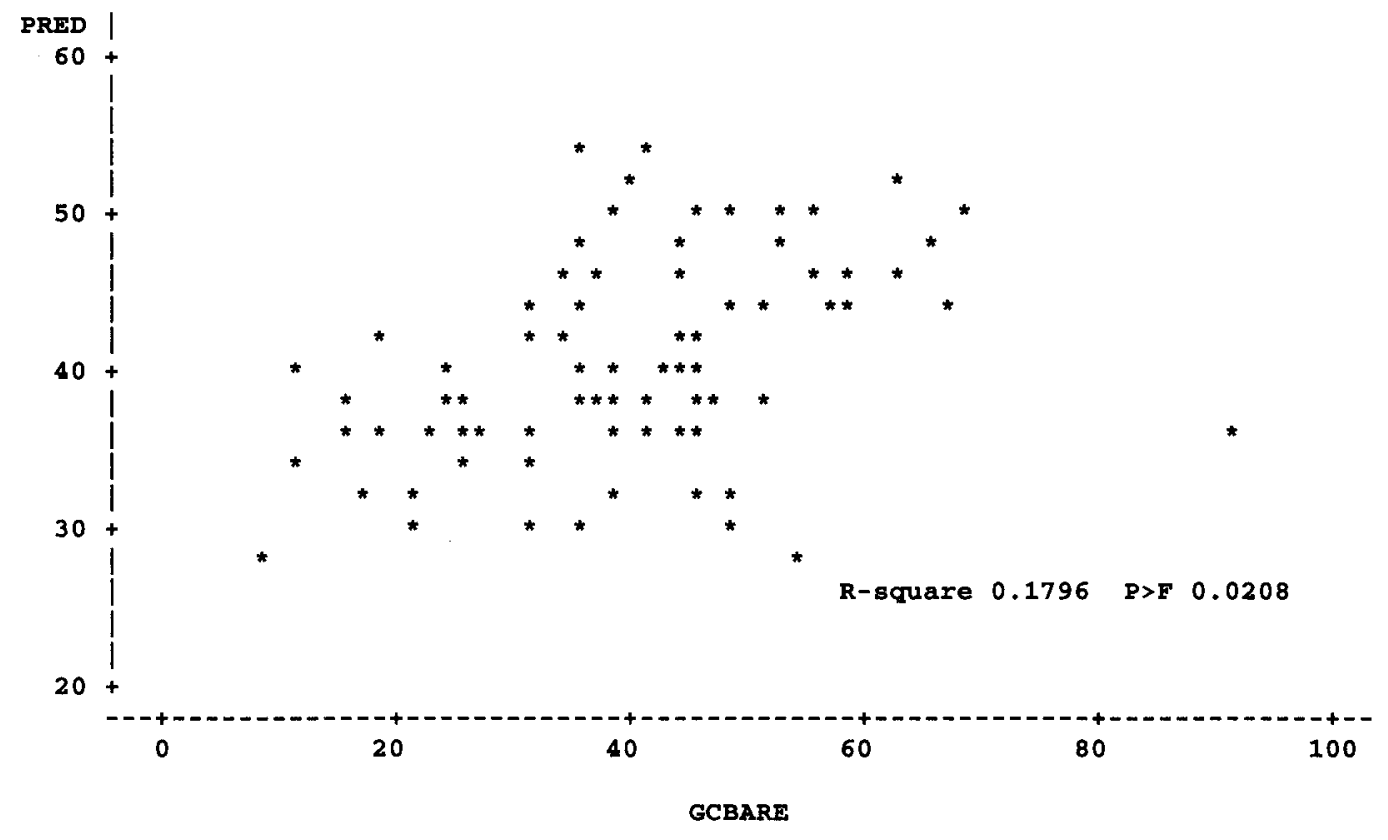

NOTE: 15 obs hidden.

Figure A-12. Scatter plot of actual versus predicted GCBARE values from the May cover data matrix.

Plot of PRED*GCLITTER. Symbol used is ' *'.

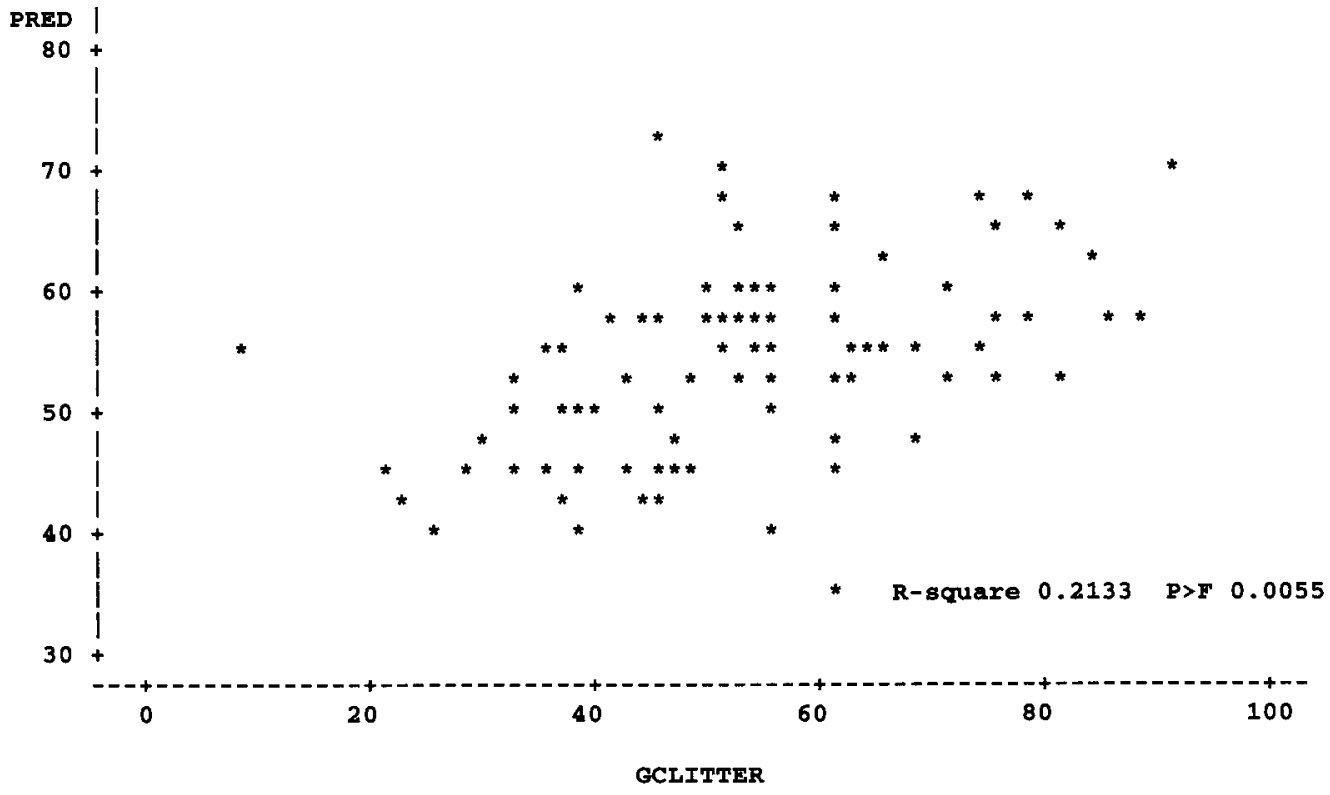

NOTr: 7 obs hidden.

Figure A-13. Scatter plot of actual versus predicted GCLITTER values from the May cover data matrix. 
Plot of PRED*ORGMATT. Symbol used is $1 *$ '.

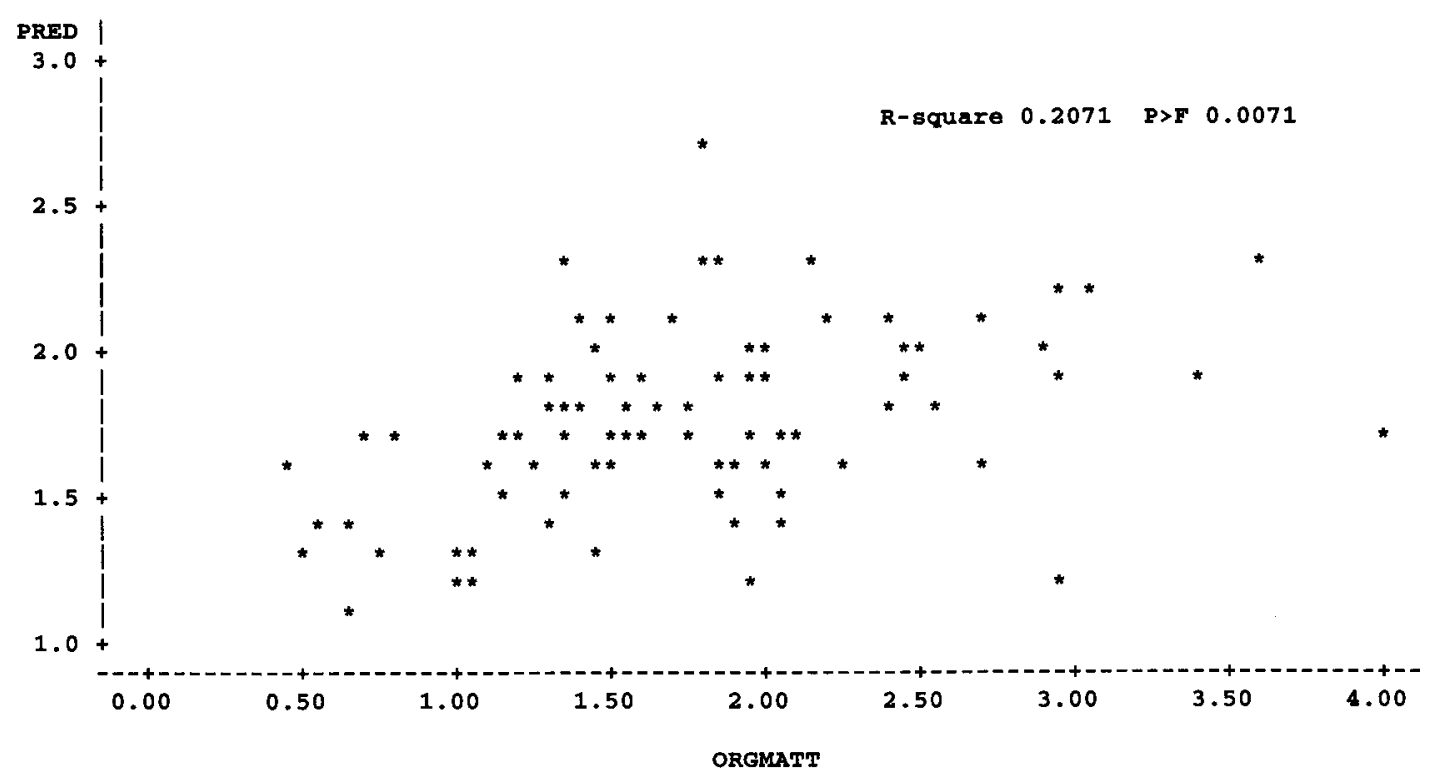

NOTE: 9 obs hidden.

Figure A-14. Scatter plot of actual versus predicted ORGMATT values from the May cover data matrix.

Plot of PRED*AGSP. Symbol used is ' *' .

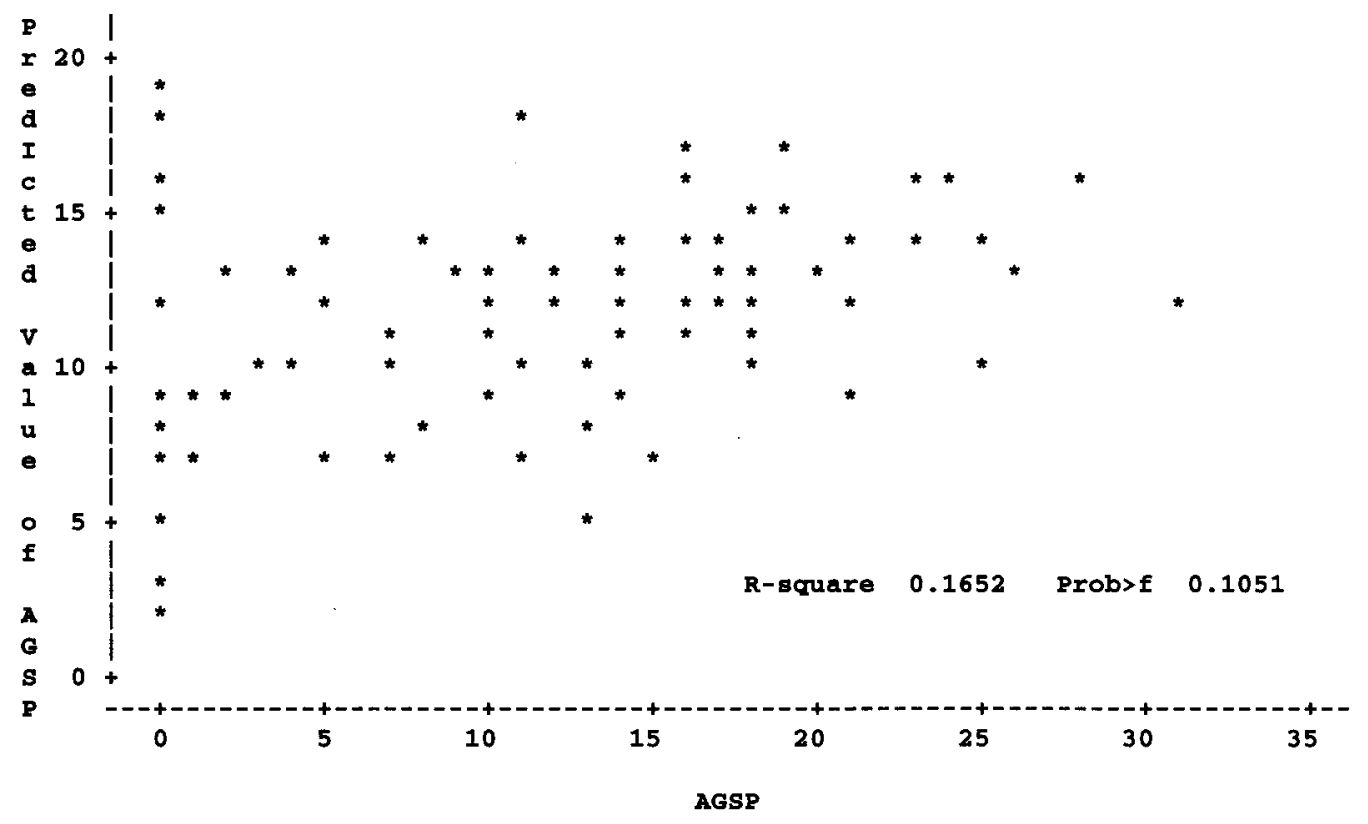

NOTE: 14 obs hidden.

Figure A-15. Scatter plot of actual versus predicted AGSP values from the August frequency data matrix. 
Plot of PRED*BRTE. Symbol used is '*'.

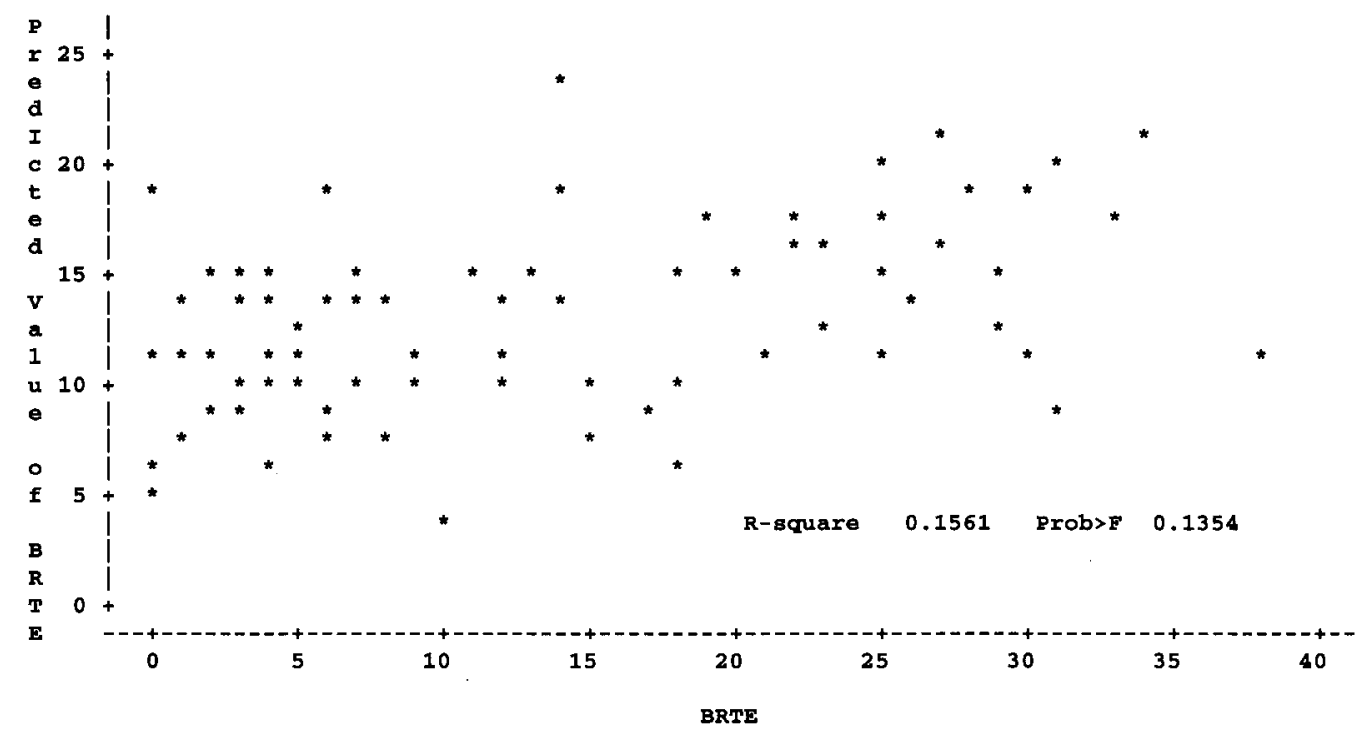

NOTE: 15 obs hidden.

Figure A- 16. Scatter plot of actual versus predicted BRTE values from the August frequency data matrix.

Plot of PRED*TOTPER. Symbol used is $r *$ '.

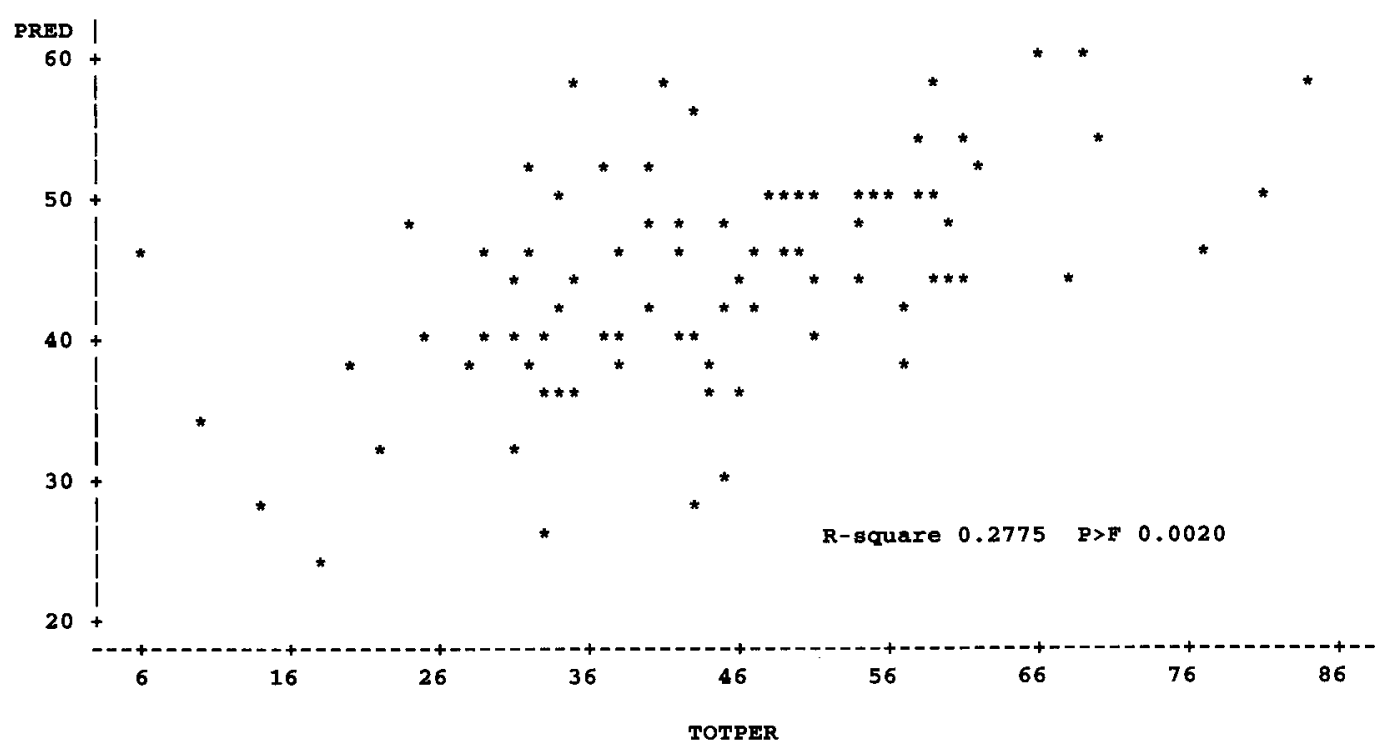

NOTE: 5 obs hidden.

Figure A-17. Scatter plot of actual versus predicted TOTPER values from the August frequency data matrix. 
Plot of PRED*GCBARE. Symbol used is ' *'.

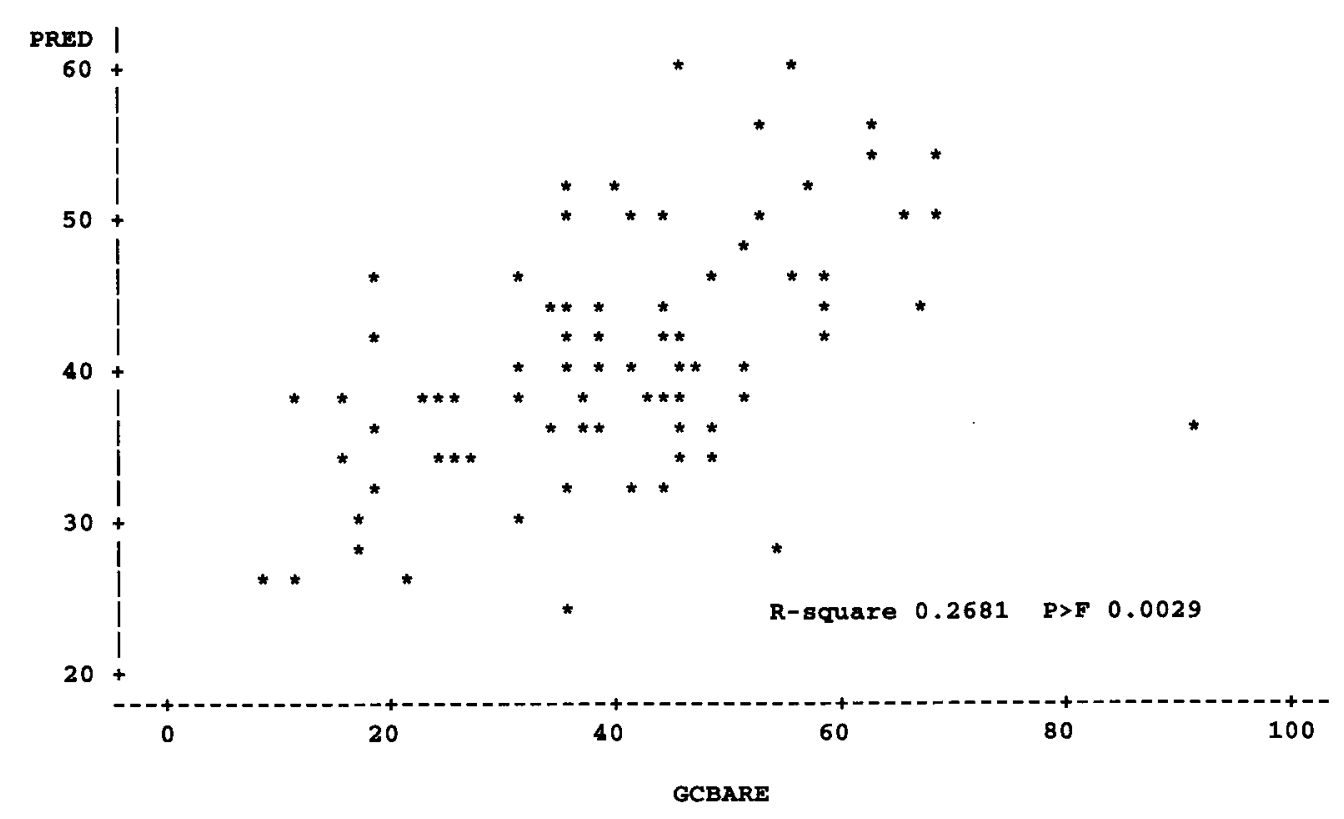

NOTE: 11 obs hidden.

Figure A-18. Scatter plot of actual versus predicted GCBARE values from the August frequency data matrix.

P1ot of PRED*GCLITTER. Symbol used is ' *'.

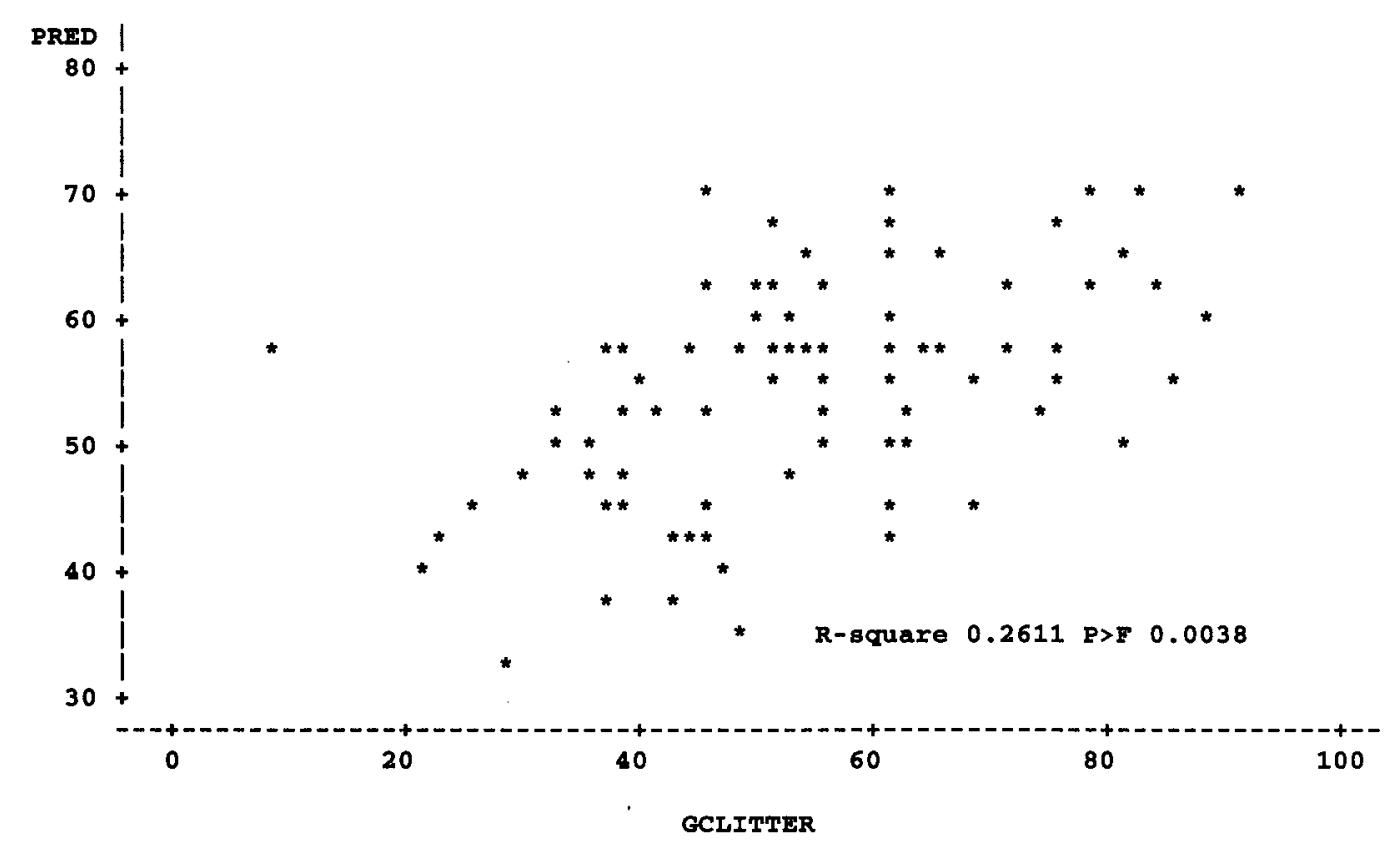

NOTE: 9 obs hidden.

Figure A-19. Scatter plot of actual versus predicted GCLITTER values from the August frequency data matrix. 


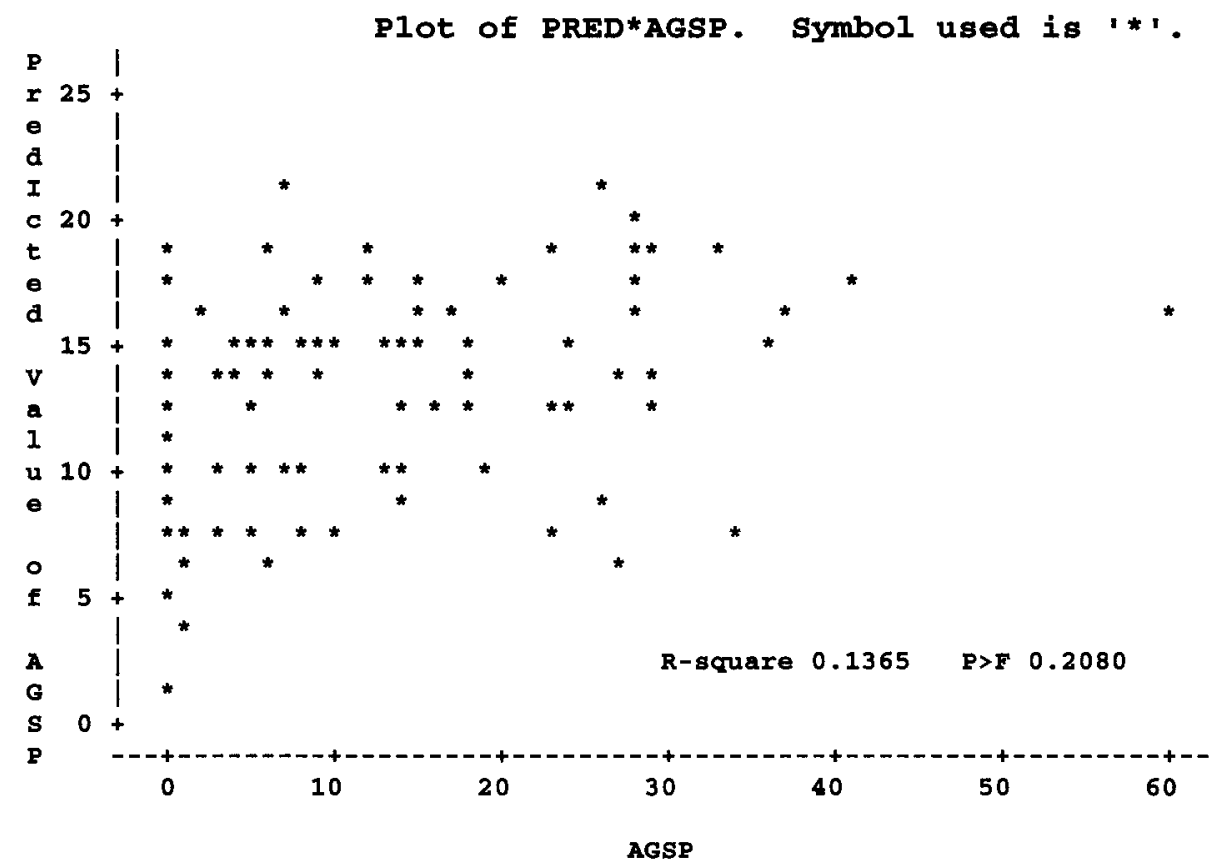

NOTE: 10 obs hidden.

Figure A-20. Scatter plot of actual versus predicted AGSP values from the August cover data matrix.

Plot of PRED*ARTR2. Symbol used is '*1.

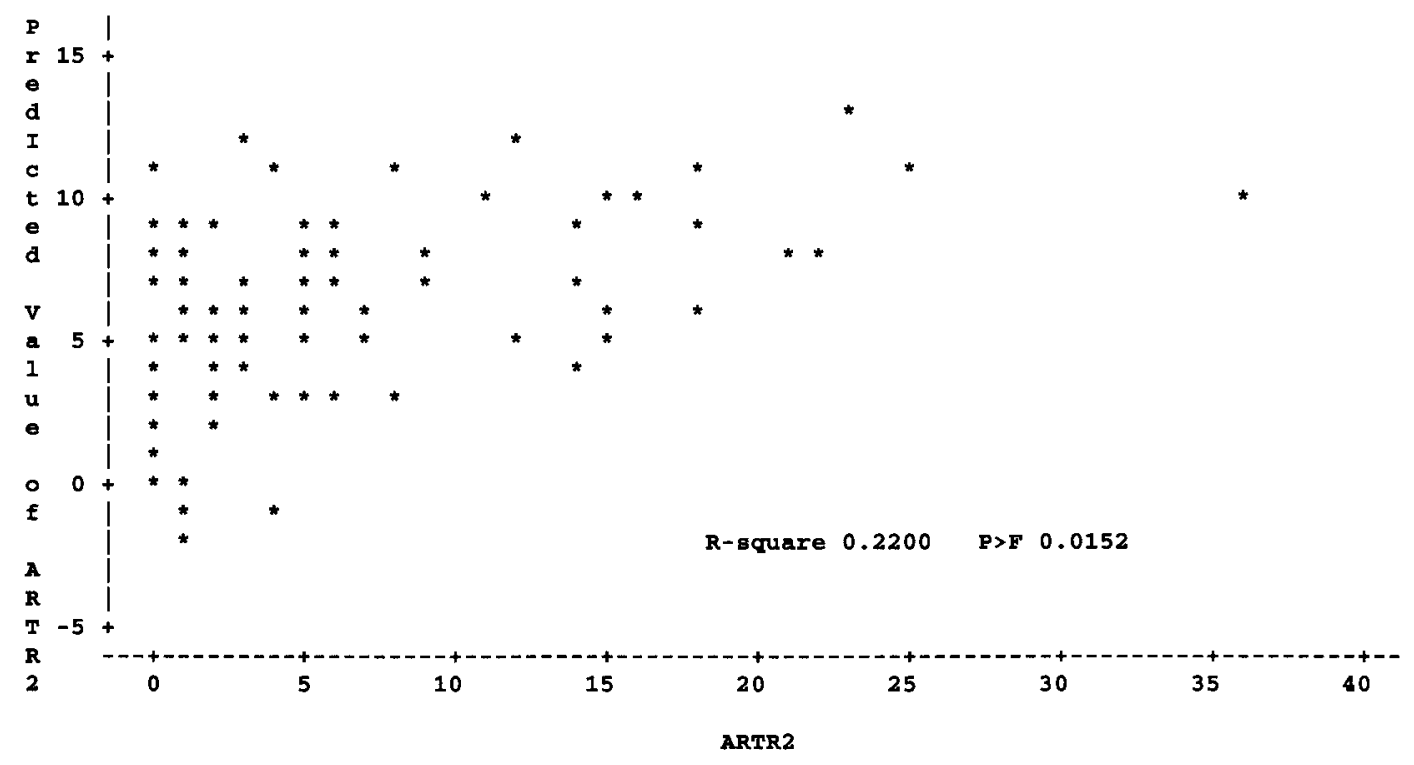

NOTE: 23 obs hidden.

Figure A- 21. Scatter plot of actual versus predicted ARTR values from the August cover data matrix. 
Plot of PRED*BRTE. Symbol used is ' *'.

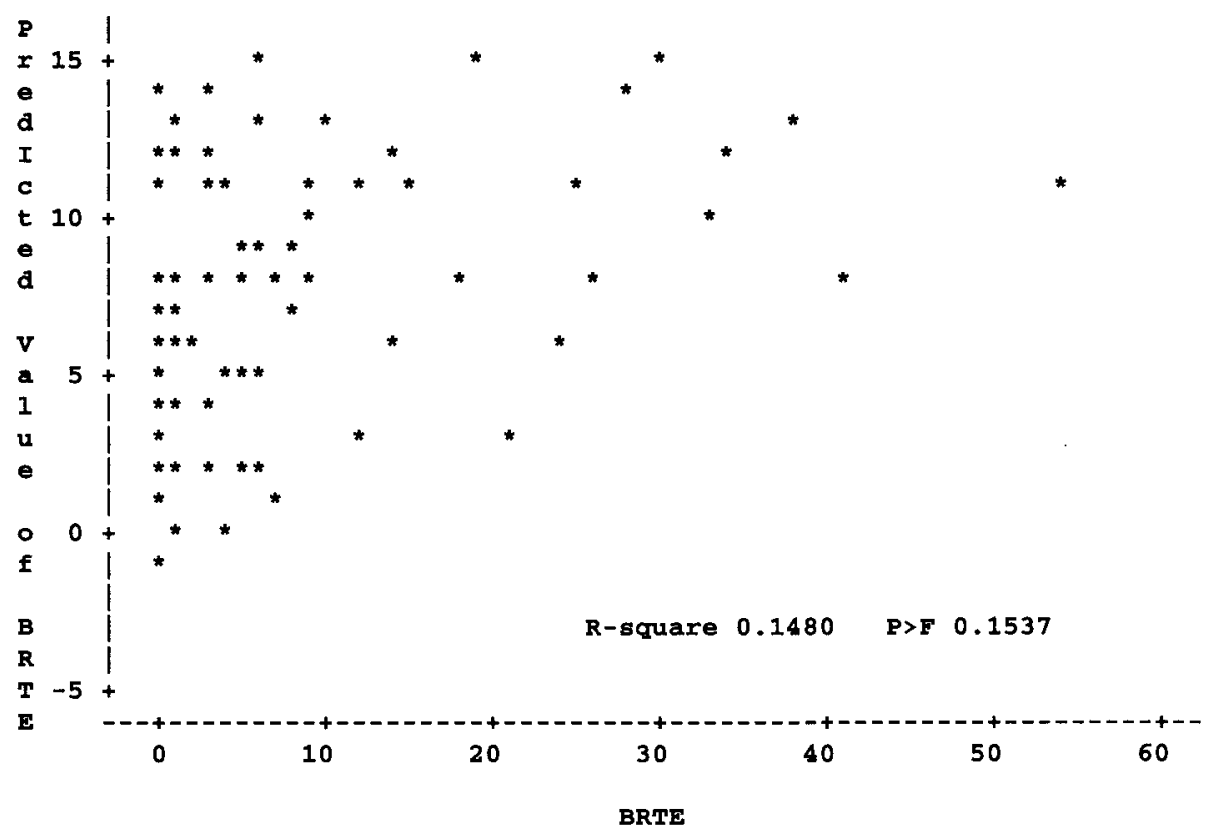

NoTr: 24 obs hidden.

Figure A-22. Scatter plot of actual versus predicted BRTE values from the August cover data matrix.

Plot of PRED*TOTPER. Symbol used is ' *'.

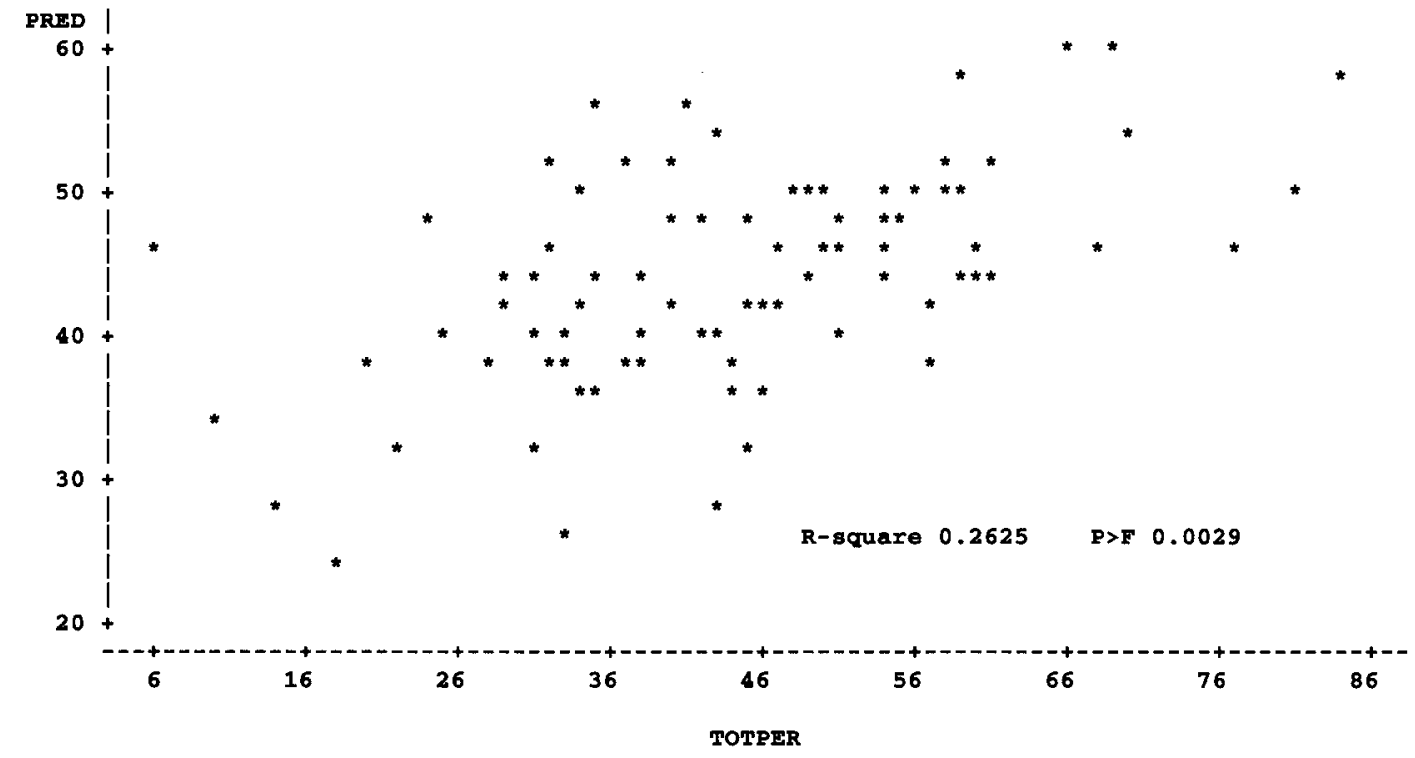

Figure A-23. Scatter plot of actual versus predicted TOTPER values from the August cover data matrix. 
Plot of PRED*GCBARE. Symbol used is '*'.

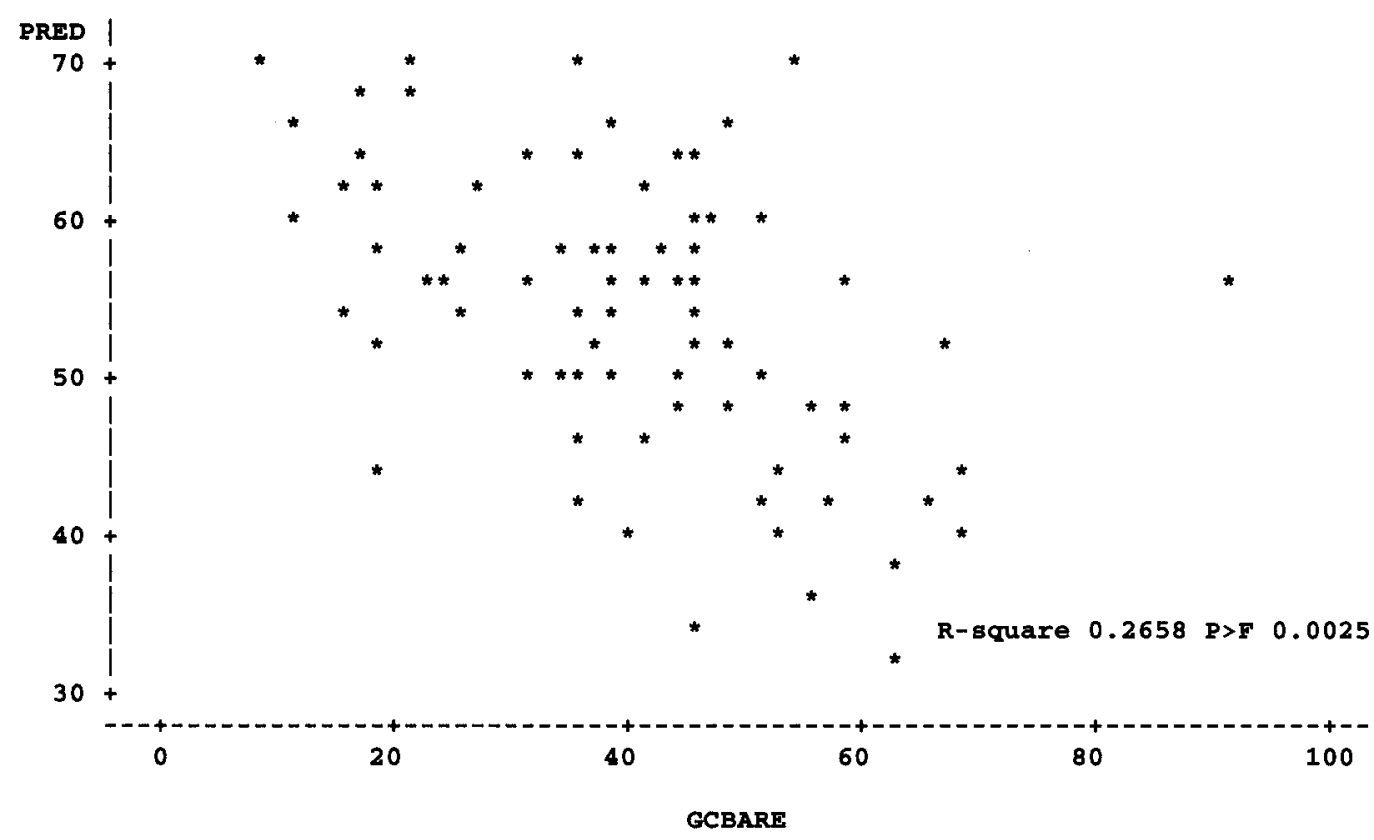

NOTE: 14 obs hidden.

Figure A-24. Scatter plot of actual versus predicted GCBARE values from the August cover data matrix.

Plot of PRED*GCLITTER. Symbol used is ' *'.

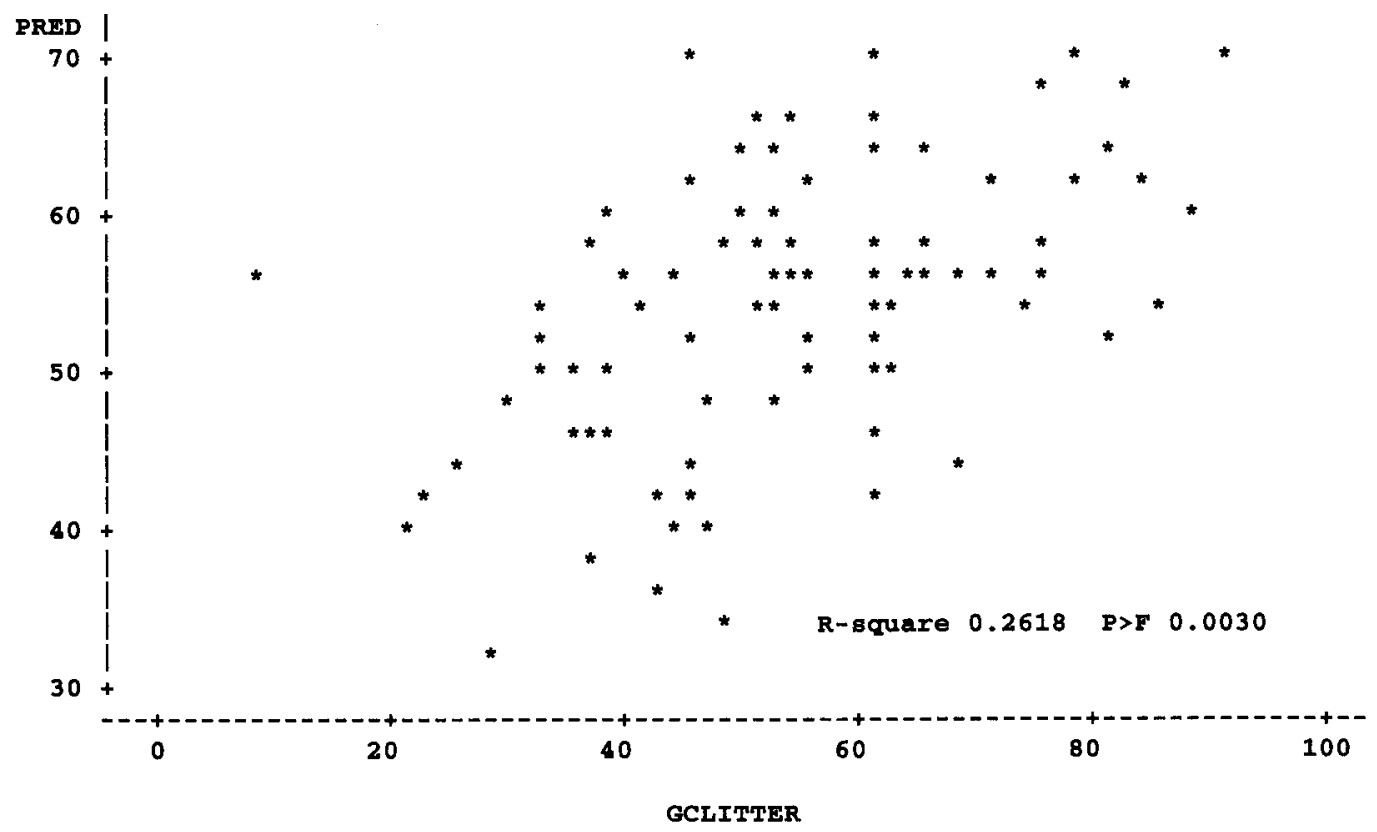

NOTE: 7 obs hidden.

Figure A-25. Scatter plot of actual versus predicted GCLITTER values from the August cover data matrix. 


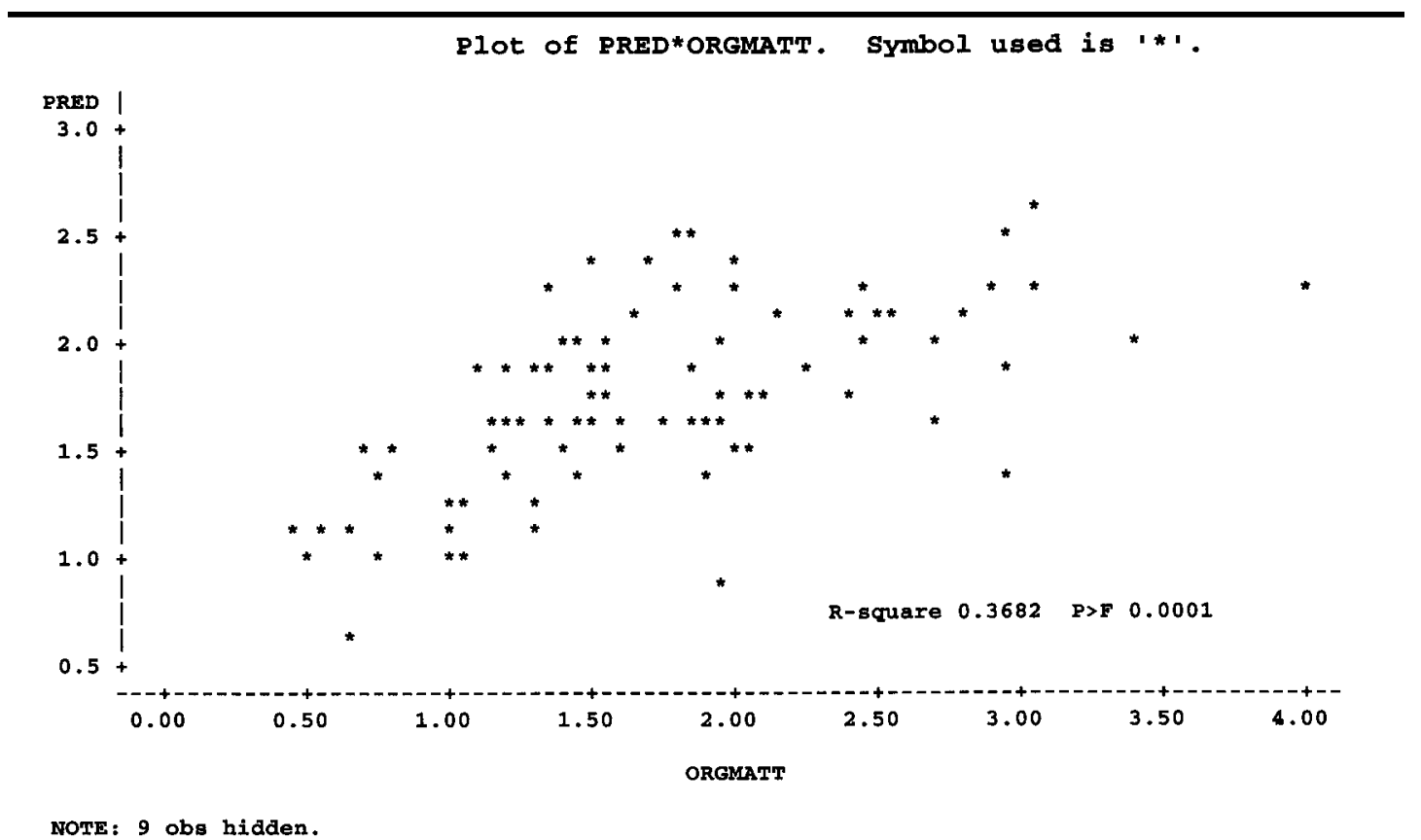

Figure A-26. Scatter plot of actual versus predicted ORGMATT values from the August cover data matrix. 


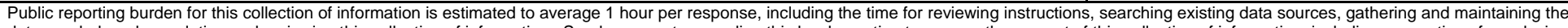

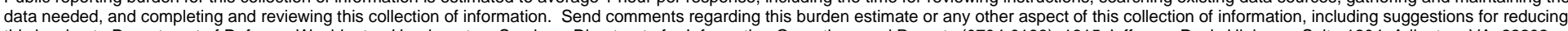

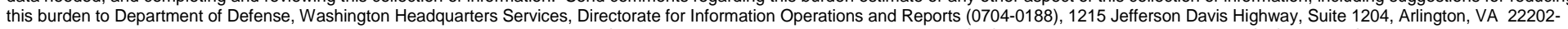

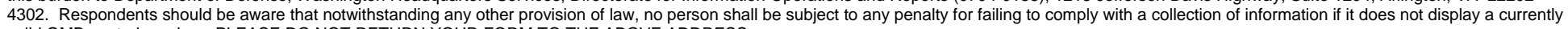
valid OMB control number. PLEASE DO NOT RETURN YOUR FORM TO THE ABOVE ADDRESS.
1. REPORT DATE (DD-MM-YYYY)
02-2004
2. REPORT TYPE
Final

4. TITLE AND SUBTITLE

Identification and Mapping of Sagebrush/Grass Successional Stages with Landsat Thematic

Mapper Data at Yakima Training Center, Washington
3. DATES COVERED (From - To)

5a. CONTRACT NUMBER

5b. GRANT NUMBER

5c. PROGRAM ELEMENT NUMBER

\section{5d. PROJECT NUMBER}

622720 A 896

5e. TASK NUMBER

EN-TS5

5f. WORK UNIT NUMBER

\section{PERFORMING ORGANIZATION NAME(S) AND ADDRESS(ES)}

U.S. Army Engineer Research and Development Center (ERDC)

Construction Engineering Research Laboratory (CERL)

PO Box 9005

Champaign, IL 61826-9005

\section{SPONSORING I MONITORING AGENCY NAME(S) AND ADDRESS(ES)}

Department of the Army

Office of the Director of Environmental

Programs

600 Army Pentagon

Washington, DC 20310-0600

\section{DISTRIBUTION I AVAILABILITY STATEMENT}

Approved for public release; distribution is unlimited.

\section{SUPPLEMENTARY NOTES}

Copies are available from the National Technical Information Service, 5285 Port Royal Road, Springfield, VA 22161.

\section{ABSTRACT}

In the future, remote sensing technologies will become an increasingly important and valuable tool for military land managers in semiarid regions. These technologies, when combined with field samples, have the potential to accurately monitor rangeland trends from year to year with smaller monetary investments compared to field sampling exclusively. This research attempted to identify and map successional changes on semiarid rangelands at Yakima Training Center, WA, using remote sensing techniques by developing a model derived from analysis of dependent and independent variables chosen from field surveys of vegetation and geomorphic data, along with the interpretation of Landsat TM data. Preliminary results based on small data sets separated by elevation and slope direction showed both low and some reasonable $\mathrm{R}^{2}$ values, including some $\mathrm{R}^{2}$ near 0.70 . The removal of elevation and slope direction and consideration of multicollinearity and outliers and influentials provided generally significant relationships among dependent and independent variables. Significant relationships between multiple dependent and independent variables were also identified using canonical correlation analysis. Variability among the releves, collection of field vegetation and soil data over the entire summer including many phenophases, and the correction of the raster radiance values for topography were assumed to be factors that may have reduced the predictive capabilities of the techniques investigated.

\section{SUBJECT TERMS}

land management, range lands, remote sensing, Yakima Training Center, WA

\begin{tabular}{|c|c|c|c|c|}
\hline \multicolumn{3}{|c|}{ 16. SECURITY CLASSIFICATION OF: } & \multirow{2}{*}{$\begin{array}{l}\text { 17. LIMITATION } \\
\text { OF ABSTRACT } \\
\text { SAR }\end{array}$} & \multirow{2}{*}{$\begin{array}{l}\text { 18. NUMBER } \\
\text { OF PAGES } \\
63\end{array}$} \\
\hline $\begin{array}{l}\text { a. REPORT } \\
\text { Unclassified }\end{array}$ & $\begin{array}{l}\text { b. ABSTRACT } \\
\text { Unclassified }\end{array}$ & $\begin{array}{l}\text { c. THIS PAGE } \\
\text { Unclassified }\end{array}$ & & \\
\hline
\end{tabular}

19a. NAME OF RESPONSIBLE PERSON Scott A. Tweddale

19b. TELEPHONE NUMBER (include area code) (217) 352-6511, ext 7409

Standard Form 298 (Rev. 8-98) Prescribed by ANSI Std. 239.18 